\title{
Renewable Energy and Sustainable Development
}

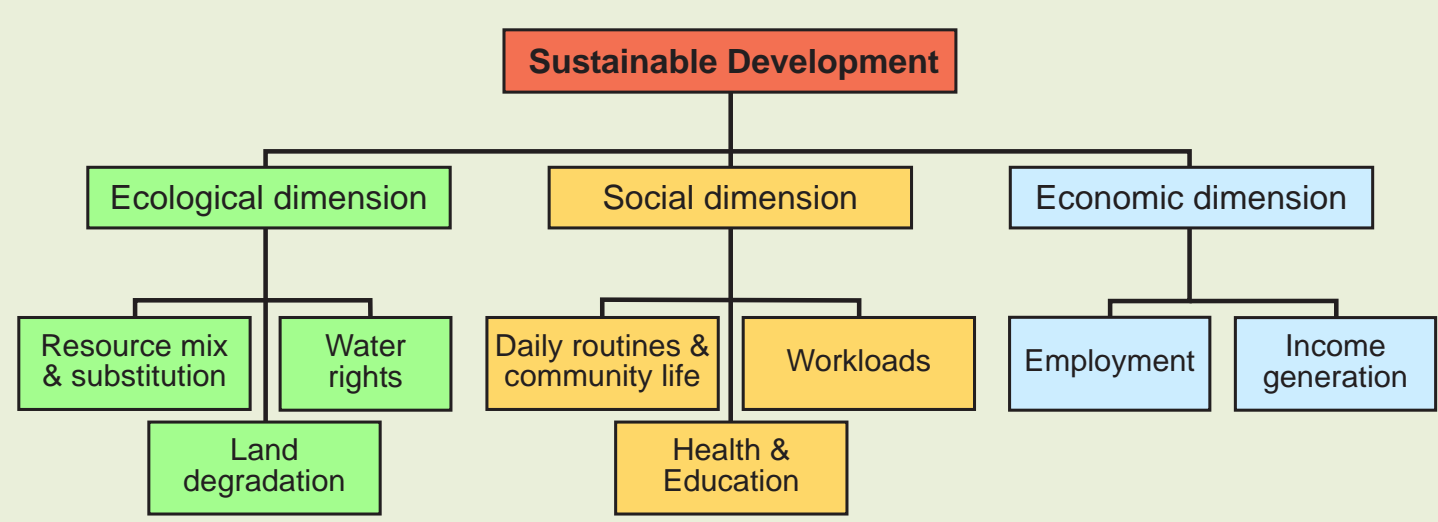

\section{An Impact Assessment of Micro and Mini Hydel Projects in Gilgit-Baltistan, Pakistan}

Max Vöhringer

Centre for Development Studies (ZELF) Institute of Geographical Sciences

Freie Universität Berlin 
Editor of Berlin Geographical Papers (formerly Occasional Papers Geographie) Prof. Dr. Hermann Kreutzmann

\section{Contact}

Centre for Development Studies (ZELF)

Institute of Geographical Sciences

Freie Universität Berlin

Malteserstr. 74-100

D-12249 Berlin

h. kreutzmann@fu-berlin.de

Tel: $\quad+49-30-83870223$

Fax: $\quad+49-30-83870757$

(c) 2010 Centre for Development Studies, Freie Universität Berlin

ISSN: $1869-3377$ 


\title{
BERLIN GEOGRAPHICAL PAPERS
}

\author{
Vol. 37
}

Renewable Energy and Sustainable Development

An Impact Assessment of Micro and Mini Hydel Projects in Gilgit-Baltistan, Pakistan

Max Vöhringer

Centre for Development Studies (ZELF)

Institute of Geographical Sciences

Freie Universität Berlin 



\section{Acknowledgements}

This paper is based on the author's Diploma thesis handed in at the Centre for Development Studies (ZELF) of the Freie Universität Berlin. There are many people to whom I would like to extend my thanks for their support, assistance, and contributions to it. Above all, I am greatly indebted to all my interview partners in Gilgit-Baltistan, as well as to the whole team of the Aga Khan Rural Support Programme (AKRSP), Pakistan, for their openness, cooperativeness, and great hospitality during my stay in northern Pakistan. This study would have not been possible without the collaboration with AKRSP. To the following members of AKRSP I would like to specifically express my gratitude for supporting me in multiple ways: Sher Khan, Ahman Ali Shah, Saima Shakoor, Manzoor Hussain and Hinan Aziz from the Community Physical Infrastructure section; Muzaffar Uddin, Regional Programme Manager, and Izhar Hunzai, General Manager; Ghulam Amin Baig and Muhammad Ibrahim, Policy Dialogue and Partnership section; Yasmin Qalandar, Naeema and Shahana, Gender And Development section; Zaib, Aftab and Kosar, Institutional Development section; Nazia, Monitoring \& Evaluation section; and Amjad Wali, Entreprise Development section. Special thank-yous further go to Sher Ghazi from MIES (Mountain Infrastructure and Engineering Services), as well as Nazir Abbas and Murad Shah, both working for the gems centre of Sumayar.

The successful completion of the field studies would have been unthinkable without the great collaboration with my translators Ali Nazir Abidy and Mohammad Baqir. I am also particularly grateful to the families of Abdul Karim from Bargo Bala, Mansoor Karim from Ahmedabad, and, again, Mohammad Baqir from Sumayar, for providing board and logding. They made me feel at home in their houses and made each of the visits to the case study villages very special and unforgettable.

A very special thanks furthermore goes to Prof. Dr. Hermann Kreutzmann, Director of the Centre for Development Studies (ZELF), Freie Universität Berlin, for getting the research internship with AKRSP into gear and encouraging and supporting me during the whole process of writing the thesis. I also want to thank Prof. Dr. Dörte Segebart, Junior Professor at the Institute of Geographical Sciences, Freie Universität Berlin, very much for her very valuable and detailed advice, especially in the beginning of the research.

A thank-you goes to the Geographical Society of Berlin (GfE), which supported my research financially. For supporting and advising me during the writing process in Germany, I finally express my gratitude to Andreas Benz, Christoph Hinske, René Herlitz, Holle Wlokas and Imogen Minton, as well as all others who discussed my results with me and offered their constructive criticism. And last but not least I would like to thank my parents for their irreplaceable support during all my years of study. 


\section{Table of Contents}

1 Global climate policy and the impact of local projects............................... 1

2 Analytical background and research concept .........................................

2. 1 The concept of Sustainable Development and its assessment ..................... 3

2.2 Rural electrification - High expectations and some critical issues.................. 4

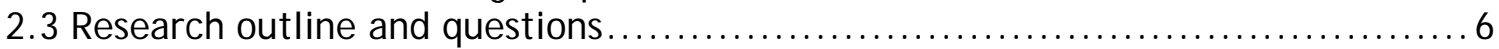

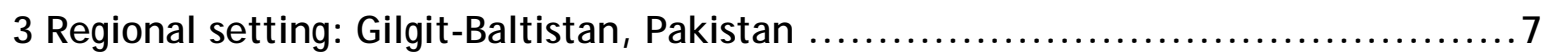

3.1 Overview, natural preconditions and mixed mountain agriculture $\ldots \ldots \ldots \ldots \ldots \ldots 7$

3. 2 Utilisation and management of water and forest resources $\ldots \ldots \ldots \ldots \ldots \ldots \ldots \ldots$



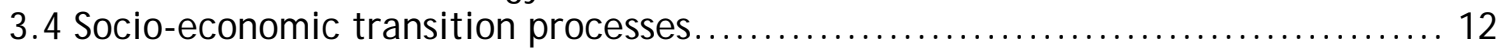

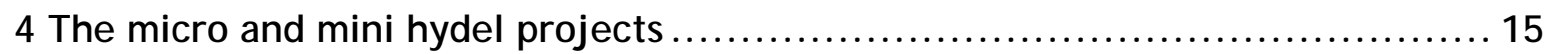

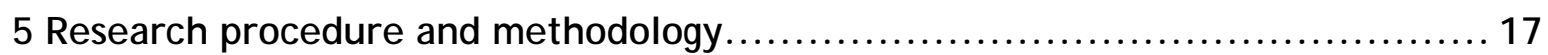

5.1 Collection, analysis and evaluation of the primary data $\ldots \ldots \ldots \ldots \ldots \ldots \ldots \ldots \ldots \ldots \ldots \ldots$

5. 2 Reflections on the representativeness of the data and the research procedure .. 18

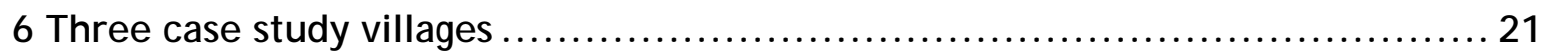

6. 1 Bargo Bala - A village with a large summer settlement and very deficient

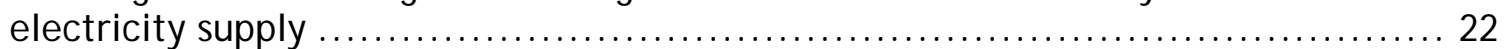

6.2 Ahmedabad - Close proximity to Central Hunza and limited but stable

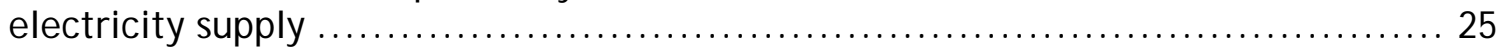

6. 3 Sumayar - Booming gemstone mining and trade and an extended electricity

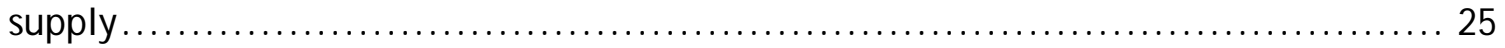

7 Ecological dimension ........................................................... 27

7.1 Impacts on the local environment and water utilisation practices $\ldots \ldots \ldots \ldots \ldots \ldots 27$

7.2 Complex parameters of energy resource choices................................. 31

7.2.1 Fuel wood as the primary energy basis with varying supplementary

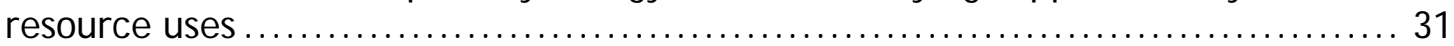

7.2.2 Household expenses for energy resources .............................. 37

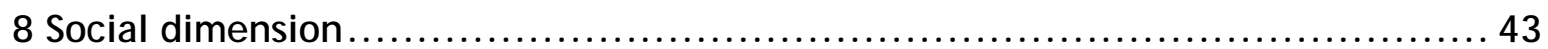

8.1 Improved illumination, varying use of appliances, and the everyday life .........43 43

8.2 Educational effects of electrical lighting and information technologies........... 48

8.3 Impacts on indoor health conditions and medical services ...................... 50

8. 4 Electricity and the complex causalities determining workloads of women ........ 52

9 Economic dimension ............................................................ 57

9.1 Off-farm employment and qualification opportunities in the hydel projects..... 57

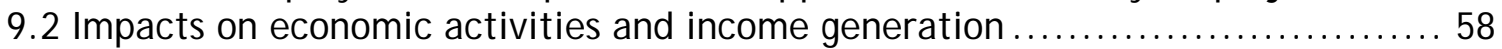

9.2.1 Cottage industries and their working conditions ........................ 59

9.2.2 Expansion of small businesses and industries, their premises, and related

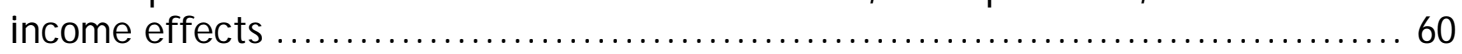

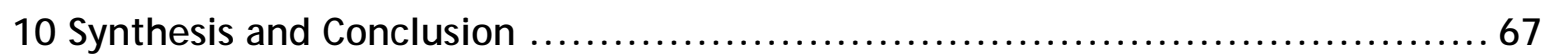



10.2 Recommendations for enhanced Sustainable Development impacts of rural electrification projects and conclusions for the global climate policy ............... 69

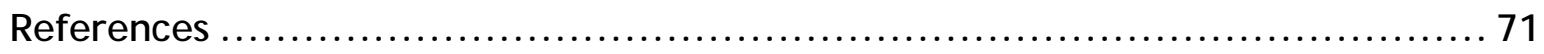




\section{List of Tables}

Table 1: Household energy mix in Gilgit-Baltistan (1996) ............................. 11

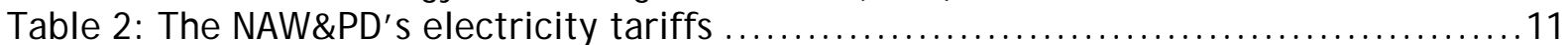

Table 3: Retail prices of energy resources in the case study villages and in Gilgit Town



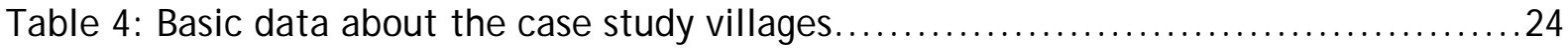



Table 6: Average annual household expenses for lighting resources...................... 38

Table 7: Most common infectious diseases reported in Sumayar's health centre for

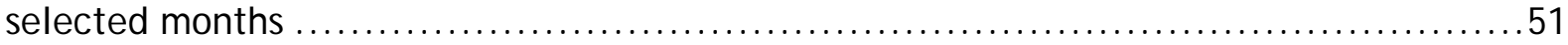

Table 8: Percentage of respiratory infections out of total health problems reported in

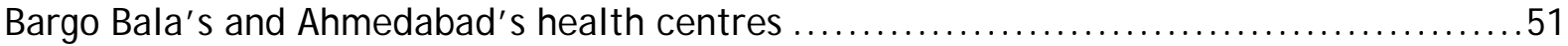

Table 9: Entreprises using electric or electronic devices................................ 61

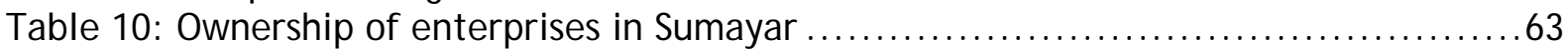

\section{List of Figures}

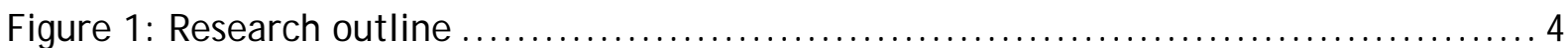

Figure 2: Basic elements of small-scale run-of-river hydro power stations................. 15

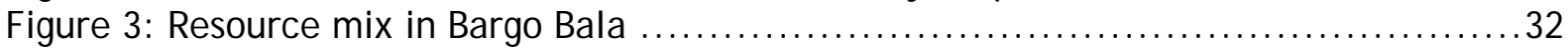

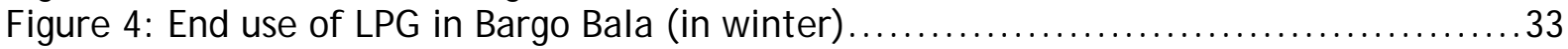

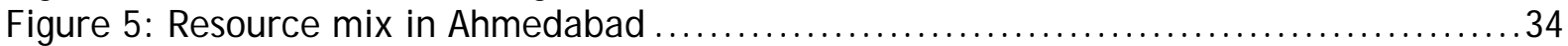

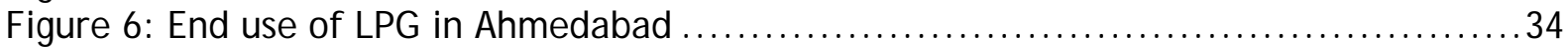

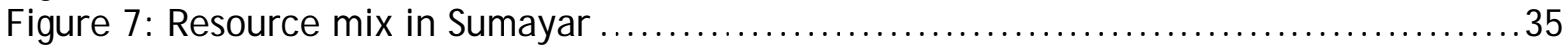

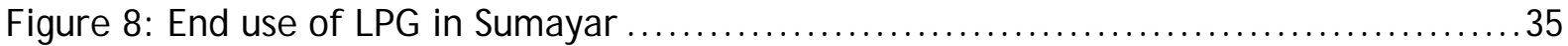

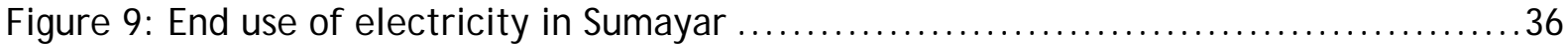

Figure 10: Average annual energy expenses by wealth groups................................. 40

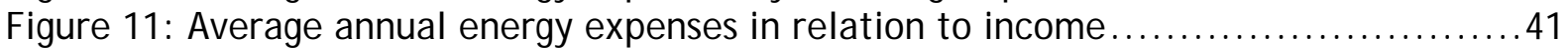

Figure 12: Ownership of appliances by wealth level (Bargo Bala) .......................... 45

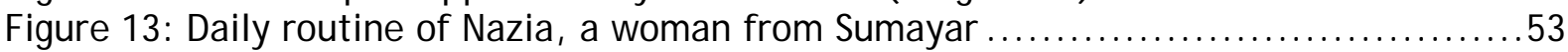

Figure 14: Daily routine of Perveen, a woman from Ahmedabad......................... 55

\section{List of Boxes}

Box 1: Environmental damages in Sumayar ............................................ 28

Box 2: Impact of the hydel project on the water management in Sumayar .................. 30

Box 3: Resource use of a shepherd from Bargo Bala ................................... 33

Box 4: Positive impacts of electric lighting on the daily routines and community life .....44

Box 5: Disparate opportunities of using electricity ..................................... 47

Box 6: Negative impacts of electricity on the social life and on individuals.............. 48



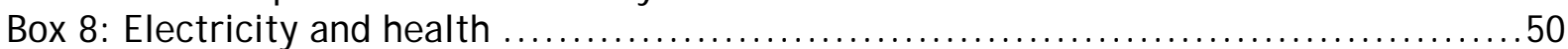

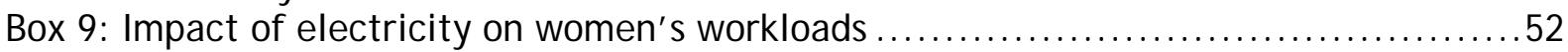

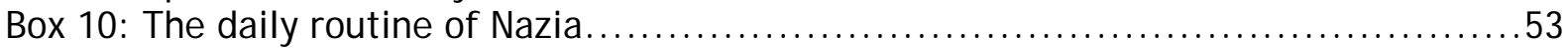

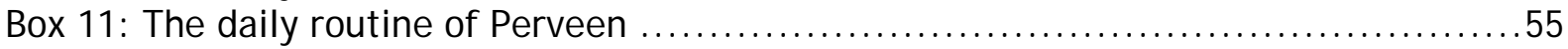

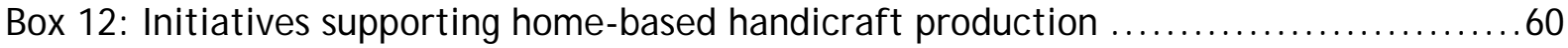

Box 13: A small industry in Sumayar: Hassan's sawmill .................................. 62

Box 14: A small business in Sumayar: Ali's ice-cream shop and flour mill ...................62

Box 15: Making economic benefits available for the poor and disadvantaged ...............64 


\section{List of Maps}

Map 1: Gilgit-Baltistan, Pakistan - Overview

Map 2: The location of the three case study villages in the Gilgit district....

\section{List of Abbreviations}

AKDN - Aga Khan Development Network

AKES - Aga Khan Education Services

AKRSP - Aga Khan Rural Support Programme

asl - above sea level

CDM - Clean Development Mechanism

CER - Certified Emission Reductions

GHG - Greenhouse gases

GoP - Government of Pakistan

GTZ - Deutsche Gesellschaft für Technische Zusammenarbeit

hh(s) - household(s)

IUCN - International Union for the Conservation of Nature

KADO - Karakoram Area Development Organisation

KKH - Karakoram Highway

kV - kilovolt $(=1,000$ Volt $)$

$\mathrm{kW}$ - kilowatt $(=1,000$ Watt)

LPG - Liquified Petroleum Gas

MW - Megawatt (1,000 kw or 1,000,000 Watt)

NAW\&PD - Northern Areas Water and Power Department

NGO - non-governmental organisation

Rs. - Pakistan Rupees (currency of Pakistan)

UNDP - United Nations Development Programme

UNFCCC - United Nations Framework Convention on Climate Change

UNSD - United Nations Statistics Division

VO - Village Organisation

WWF - World Wide Fund for Nature 


\section{Glossary}

nalla (Urdu) - side valley stream

\section{Measurement units}

$1 \mathrm{kanal}=505.86 \mathrm{~m}^{2}$

1 maund $=37.32 \mathrm{~kg}$

\section{Currency equivalents}

Minimum and maximum exchange rate of Pakistan Rupees (Rs.)

during the time of research (30.03. - 12.06.2008):

109. 25 Rs. $=1$ Euro $(21.05 .2008)$

97. 88 Rs. $=1$ Euro $(02.04 .2008)$

Source: FOREX 2009 


\section{Global climate policy and the impact of local projects}

Energy plays a major role in climate change as well as in development debates. About $60 \%$ of the global greenhouse gas (GHG) emissions derive from the energy sector as a whole, while power generation alone accounts for $40 \%$ of the world's $\mathrm{CO}_{2}$ emissions (UNDP 2007: 40ff.). The expansion of renewable energies is therefore one of the most important options to mitigate climate change by reducing GHG emissions. At the same time, 1.6 billion people lack access to electricity, most of them living in South Asia and Sub-Sahara Africa. In addition to the substitution of fossil or biomass fuels, the electrification of these regions by means of renewable energy is expected to lead to multiple social and economic benefits and contribute to poverty alleviation.

The Clean Development Mechanism (CDM) is a policy instrument that aims to take into account this climate development nexus. It is part of the global climate regime of the Kyoto protocol, in which most of the so-called developed countries ${ }^{1}$ of the world committed to reduce their GHG emissions by 5.2\% below the level of 1990 until 2012. The CDM includes the developing countries in the regime by allowing developed countries to comply with their reduction commitments through the support of renewable energy projects in developing countries ${ }^{2}$. The dual objective of the instrument - as laid down in article 12 of the Kyoto protocol - is to support developed countries in complying with their emission targets and to assist the developing countries in achieving Sustainable Development $^{3}$. There are no internationally standardized guidelines for the Sustainable Development objective but it is the host party's responsibility to define, assess, and monitor the respective criteria.

At its initiation in 1997, the CDM was widely welcomed with high expectations for its ability to stimulate developmental benefits (OLSEN 2005: 6). By 2010, the CDM has been a great success in terms of the high quantity of projects being implemented, but has been criticised for various qualitative reasons (see e.g. SUTTER and PARRENo 2007, SCHNEIDER 2007, WWF 2007). One of the areas of concern is that CDM projects often neglect the goal of fostering Sustainable Development on the project level and only rarely address the poorest segments of the population directly and appropriately (MICHAELOWA and MiCHAELOWA 2005: 16, SIROHI 2007: 98ff.). In order to test this hypothesis, processes on the local project level have to be analysed. What benefits are in fact created by the renewable energy projects initiated on the global climate policy level, and which of these actually impact the individual? It is the objective of this paper to investigate these questions through assessing the impact of three exemplary projects realized under the CDM.

The examples presented are small-scale hydro power plants implemented by the Aga Khan Rural Support Programme (AKRSP), a non-governmental development organisation, in

\footnotetext{
${ }^{1}$ The terms "developed" and "developing" countries are contested, not without justification. For instance, they imply that there is only one possible path of development, with the state of a "developed" country being the ultimate objective for all "developing" countries. However, due to the widespread use of these terms they are nevertheless employed in this thesis (UNSD 2009: footnote c).

2 This offset mechanism is implemented through the carbon market. For a more comprehensive explanation see e.g. BMU (2006): 10ff.

${ }^{3}$ The term "Sustainable Development" is capitalized in this paper as it describes a designated and specifically defined concept of development (see section 2.1).
} 
Gilgit-Baltistan ${ }^{4}$ in the north of Pakistan. Thus far, most of the local energy demand is met by the use of biomass and fossil fuels. By implementing so-called run-of-river hydro power plants that, in contrast to larger hydro power stations, have no storage reservoir, AKRSP aims to improve the deficient access of the region's rural population to electricity. The plants have capacities ranging between 35 and $600 \mathrm{~kW}$ and are also referred to micro and mini "hydels" 5 . Comparable projects have been implemented in the high mountain region for many years. Through their promotion by the CDM they are now gaining increased prominence on the global level.

To analyse what contributions to Sustainable Development are in fact made by the projects, and under which conditions, several subset research questions arise. It must be assessed which energy resources are used for what purposes, and what ecological, social and economic processes are related to these uses. What impact does the introduction of electricity through the implementation of the hydel projects have on these processes? And are benefits distributed equally, or do some groups profit more than others? In order to find answers to these questions, a $2 \frac{1}{2}$ month internship with AKRSP Pakistan was arranged, during which primary data for three case studies was collected. The evaluation of this data constitutes the basis for the empirical part of this research. The paper is outlined as follows: Following this introduction, chapter 2 summarizes the analytical context of the research and presents the detailed research questions. Chapters 3 and 4 provide the necessary background information about the regional setting, as well as about the technology applied and the projects' integration in rural development endeavours and the CDM. The research procedure and methodology are explained in chapter 5 . The following parts then contain the analysis and evaluation of the case studies: First, the three case study villages are introduced (chapter 6), after which the impacts of the hydel projects are assessed for each of the three dimensions of Sustainable Development (chapter 7-9). Finally, the results are summed up and conclusions drawn (chapter 10).

\footnotetext{
${ }^{4}$ The area of the administrative unit of "Gilgit-Baltistan" is congruent to that of the former "Northern Areas". The new name was given to the region under the "Gilgit-Baltistan Empowerment and Self Governance Order 2009" that was approved by Pakistan's government on $29^{\text {th }}$ August 2009 (DAWN 30. 08. 2009).

${ }^{5}$ There is no internationally standardized definition of the different sizes of hydro power plants. In this thesis the definition used by the government of Pakistan is followed. Accordingly, "micro" hydro power refers to plants with less than $150 \mathrm{~kW}$ installed capacity, "mini" refers to projects ranging from $150 \mathrm{~kW}$ to $5 \mathrm{MW}$ and "small" to those between 5 MW and 50 MW (AKRSP 2007d: 10). The sample projects examined in this thesis are of micro and mini level. In the following, the terms (micro and mini) hydels or (micro and mini) hydro power plants / stations / projects / schemes are used coequally.
} 


\section{Analytical background and research concept}

The starting point of this research is the debate about the objective of the CDM to promote Sustainable Development. Thus, an analysis of this concept of development provides the basis for the creation of the overall research design, that is furthermore adapted to the context of rural electrification.

\subsection{The concept of Sustainable Development and its assessment}

The concept of Sustainable Development has its origins in the forestry sector in the beginning of the $18^{\text {th }}$ century (GROBER 1999) and combines the idea of sustainability with a multi-dimensional approach to development. As it has been adopted and developed further in various contexts multiple definitions exist today. Probably the most often-cited one was published by the World Commission on Environment and Development in 1987 in its epoch making report "Our common future" - also known as the "Brundtland report". It defined Sustainable Development as a "development that meets the needs of the present without compromising the ability of future generations to meet their own needs" (quoted from UN DIVISION FOR Sustainable Development 2008).

There are two aspects of Sustainable Development about which most authors agree, and which shall form the basis of this study. Firstly, it is seen as a development towards the best possible quality of life that can be maintained permanently and that can be extended to all humankind. Secondly, Sustainable Development encompasses a three-dimensional approach integrating economic, ecological and social aspects, and aims to create a balance between growth, environmental impacts and social justice (STEURER 2001: 537, OLSEN 2005: 6). This definition still remains somewhat abstract. To solidify the concept, the suggestion of SUTTER (2003) shall be followed. Sustainable Development is seen as "a guiding principle. (...) To become meaningful at the project level, the term (...) needs a concrete context." (SUTTER 2003: 45). Thus, for the present study, the different aspects of examination were identified by applying the general definition of Sustainable Development to the context of rural electrification and the regional setting. Furthermore, existing assessment models were consulted to develop the outline of the research design. The approaches most appropriate for an in-depth analysis of Sustainable Development effects of small-scale renewable energy projects were found in the CDM-specific literature ${ }^{6}$. For a model developed on behalf of the British Department for International Development (DFID) with a specific focus on the evaluation of small-scale energy projects, 24 assessment criteria were established on the basis of the Sustainable Livelihoods approach, each associated to one of the three dimensions of Sustainable Development (BEGG et al. 2003). Similarly, OLSEN and FENHANN (2008), define a set of criteria in their draft of a general assessment taxonomy. Both approaches comprise several congruent aspects of which the following shall also be included in this study: In the environmental dimension, the question of resource mix and related emissions, possible land degradation processes and effects on water use are assessed. In the social sphere the projects' impacts on community life and workloads are

\footnotetext{
${ }^{6}$ Due to the non-existence of international standards for the assessment of the Sustainable Development objective of the CDM, various assessment procedures for different types of CDM projects have been developed by researchers and policy makers.
} 
evaluated, in addition to health and education aspects. The economic dimension includes the investigation of employment and income generation. The criteria sets are thematically structured as exemplified in Figure 1 and outline the research. The specified research questions were further derived from an analysis of the literature about rural electrification by means of renewable energy and about hydel projects in the region.

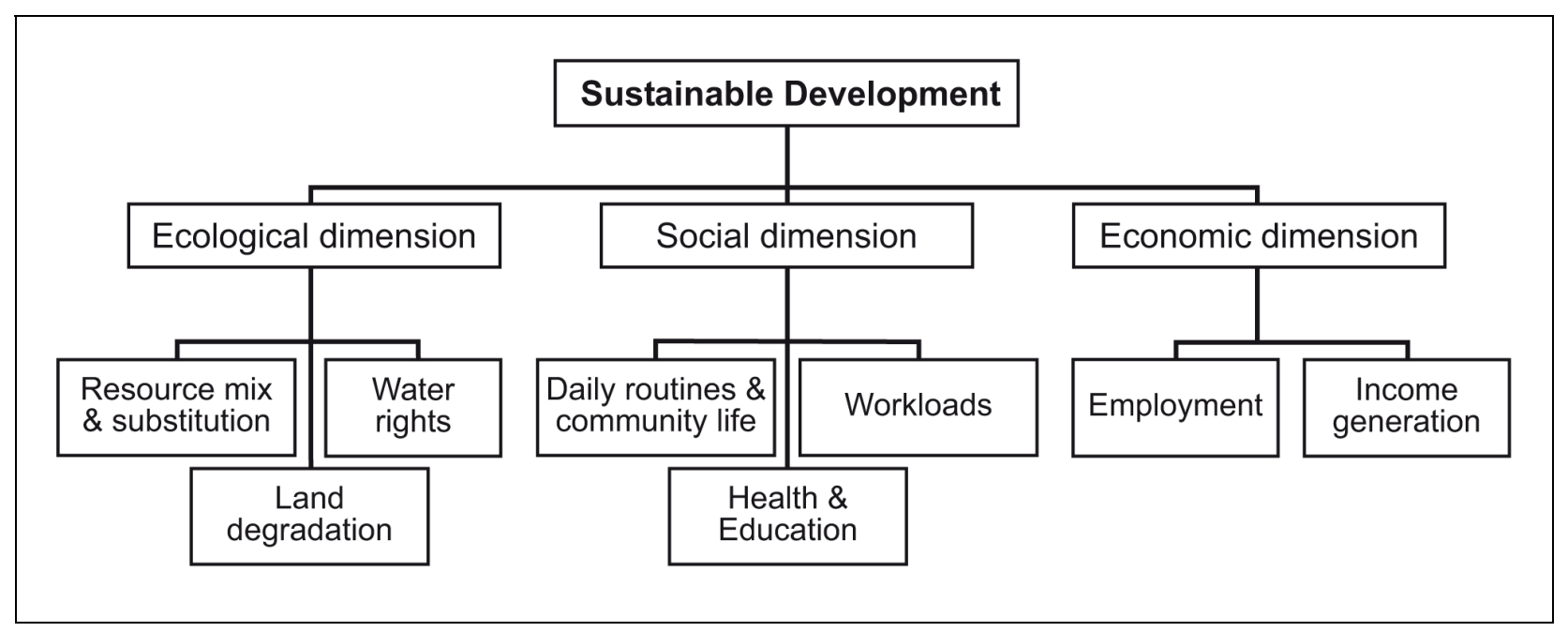

Figure 1: Research outline

Source: Own presentation

\subsection{Rural electrification - High expectations and some critical issues}

There is a broad bulk of publications especially from development institutions that review former experiences with rural electrification by means of renewable energy. Providing electricity that can be substituted for traditional fuels as a source of energy is anticipated to have substantial developmental effects in a variety of fields. It is expected to

- present a low-cost option of meeting basic needs by reducing expenses for energy resources otherwise used for lighting, cooking or heating purposes,

- reduce workloads by unburdening household members - often women - from the time-consuming task of collecting biomass fuels, and by allowing them to use household appliances,

- reduce indoor air pollution that is the main cause of acute respiratory tract infections and other dangerous health problems,

- foster the conservation of local biomass resources and protection of the global climate,

- facilitate infrastructural improvements in the health, as well as the water and sanitation, sectors,

- enhance education and information opportunities through access to modern communication technologies, 
- lead to increases in production and in household incomes by allowing an expansion of small-scale industries, further processing of agricultural products, the improvement of irrigation systems and the creation of new employment opportunities,

- improve security of energy supply and reduce the dependency on energy resource imports (cf. GTZ 2008a, GREENPEACE INTERNATIONAL and EUROPEAN RENEWABLE ENERGY COUNCIL 2007: 23).

In the face of such euphoric expectations there is certainly a danger to disregard critical issues. RICHTER and FRINGS (2005) point to some crucial aspects of the correlation between rural electrification and development: "A supply of electricity can only help reduce poverty if other framework conditions in rural areas are changed at the same time and if poor households receive direct support" (RICHTER and FRINGS 2005: 61). One of their arguments is that the use of electric appliances does benefit rural households, and especially women, but that these devices are mainly owned by middle-income and richer households. The productive use of electricity to gain additional sources of income is restricted to better-off households, too, as these are in a better position to apply for credits, or even independently repay investments, and to provide the necessary workforce. Poorer households on the contrary often don't have these capacities.

Specific publications about small-scale hydro power projects in the mountain ranges of the Hindukush, the Himalayas and the Karakoram reveal a similarly differentiated picture about the effects of providing electricity to rural households. The set of affiliated positive expectations is largely congruent with the general list given above (see e.g. ICIMOD 2001, SINCLAIR 2003) and impact studies conducted for AKRSP's hydel programme in northern Pakistan have also shown respective positive results (AKRSP 2000, AKRSP 2002b, AKRSP 2002c, UMMAR and SHER KHAN 2006) ${ }^{7}$ : All projects have led to substantial savings on household expenses for energy sources and the increased use of electric lighting instead of kerosene lanterns has reduced indoor air pollution and improved hygienic conditions. The bright light has furthermore immensely improved the studying environment for school children. Interestingly, the impact on women's workloads is assessed quite differently by these studies: On the one hand, household tasks become much easier through the use of electric lighting and household appliances. On the other hand, electric lighting may allow women to spend more time in the evenings for household tasks or productive activities such as handicraft production resulting in a total increase of women's daily workloads. This explains the hypothesis stated in one of the impact analyses that the respective hydel project had even "strengthened their [the women's, M.V.] traditional roles" (AKRSP 2002a: 27). There are a few other critical issues about small-scale hydro power projects in the high-mountain region that are brought forward. Both KREUTZMANN (2000b: 17) and CLEMENS (2001: 45) point to the possibly conflicting water requirements for irrigation versus electricity generation purposes. Furthermore, large-scale substitution of electric power for traditional biomass is not seen realistic for various reasons, such as the unreliability and seasonal irregularity of electricity supply, the autonomy of fuel wood cultivation and

\footnotetext{
${ }^{7}$ See section 4 for a detailed description of the AKRSP hydel programme. It has to be mentioned that the impact studies cited here often make statements on an aggregated level or on a very meagre empirical basis.
} 
collection free of charge, and the dislike of bearing additional costs for electric devices such as cookers and heaters (CLEMENS 2001: 36ff., SINCLAIR 2003: 12f.).

\subsection{Research outline and questions}

The crucial issues raised in the literature about rural electrification supplement and specifiy the criteria derived from the discussions about the CDM and Sustainable Development (cf. Figure 1). It is the aim of this study to assess these issues through a detailed study of three micro and mini hydel projects in Gilgit-Baltistan, Pakistan. The two major objectives of the research are:

- The use of the energy resources on the household level and interdependencies with ecologic, social, and economic processes are revealed.

- The impact of the introduction of electricity through implementation of the hydel projects on these processes is assessed to allow an evaluation of the projects with regard to the goal of Sustainable Development. A specific focus is placed on the question if and how processes differ between relatively better-off and poorer households, and the reasons for these developments.

To achieve these objectives, a set of questions is investigated. For the ecological dimension, assessing the impact on the domestic energy resource mix is of the highest relevance. How are resource consumption patterns influenced? Are biogenous and fossil fuels (i.e. firewood, kerosene, LPG) substituted with electric energy, and for which specific reasons? Furthermore, possible negative effects on the local environment, and the projects' influence on water utilisation practices and respective conflicts, are discussed.

In the social dimension, the impacts of various uses of electricity on daily routines and community life are first analysed. Whose daily life is influenced and in which manner? One aspect specifically studied in this context is the workload of women: Is it reduced through the use of appliances, or increased as more time is made available for work due to electric lighting? The third question in the social dimension concerns health and education: Are there improvements in these sectors through reduced indoor pollution and improved infrastructure (health), or through enhanced studying conditions and the access to modern communication technologies (education)?

In the economic dimension, the questions focus on employment and income generation: Do the hydel projects result in the emergence of new job opportunities? Does the access to electricity promote additional economic activities and enable households to generate extra income through new productive activities? For example, can value be added to agricultural or other products such as gemstones through advanced processing? Which framework conditions do these processes depend on, and who benefits from them? 


\section{Regional setting: Gilgit-Baltistan, Pakistan}

In the following chapter the concrete spatial context in which this assessment of Sustainable Development impacts of the hydel projects takes place is described. General introductions to the region, its agricultural basis and respective resource utitilisations are given, and the energy sector and current socio-economic transformation processes are depicted.

\subsection{Overview, natural preconditions and mixed mountain agriculture}

Gilgit-Baltistan is located in the utmost north of Pakistan. Its area is congruent to that of the former "Northern Areas" and was renamed under the "Gilgit-Baltistan Empowerment and Self Governance Order 2009" in August 2009 (DAWN 30.08.2009). The region is divided into six districts (Gilgit ${ }^{8}$, Ghizer, Astore, Diamir, Baltistan and Ghanche) which are further divided into subdivisions. The region is characterised by a high mountain environment and a decisive feature for its development are the access conditions from the lowlands of Pakistan. They dramatically improved with the construction of the Karakoram Highway (KKH, see Map 1) between 1968 and 1978. The completion of the road strongly influenced communication and exchange relations between the area and the rest of Pakistan, as well as the trade with China. It is therefore seen by many as the most important factor responsible for the tremendous social, economic, cultural and ecological changes that the region has undergone in the last three decades (KREUTZMANN 1995: 219ff.). According to the last population census of 1998 , just over 870,000 people live in Gilgit-Baltistan. $86 \%$ of the region can be characterised as rural (IUCN and GoP 2003b: 9, 40).

Gilgit-Baltistan is a subtropical steppic high mountain area with a hypsometrical zonation of vegetation. Due to the extreme verticality in the relief, precipitation also differs strongly according to altitude. In the settled valley floors, arid climatic conditions prevail, whereas in the highest altitudes of the nival zone maximum precipitation volumes locally exceed $2000 \mathrm{~mm}$ annually and serve as a precondition for the extensive glaciation of the area (KREUTZMANN 2000a: 93f., SCHICKHOFF 2006: 124f.). It is meltwater from snow and glaciers that mainly controls the hydrological regimes of the streams and rivers in the valley floors. Discharge patterns are characterised by a very strong seasonal fluctuation with peaks in summer and minima in the cold winter months.

The main settled and cultivated areas are situated close to the valley floors on flat river terraces and scree slopes / outwash fans of side valleys. As they are thus located in the arid or semi-arid altitudinal zone, crop-farming is only possible by means of irrigation. Irrigated crop cultivation constitutes one of the two foundations - the second being animal husbandry - of the mixed mountain agriculture that is traditionally practiced by the people of Gilgit-Baltistan. This strategy, well adapted to the prevalent natural conditions, is characterised by multiple linkages and interdependencies between the two sectors. The system of land use is structured vertically: Above the settlement nuclei and irrigated fields, seasonal settlements that are usually only inhabited by certain household members

\footnotetext{
${ }^{8}$ The Gilgit district is to be subdivided into two new districts along the former administrative border between two subdivions (Gilgit and Nager).
} 
during some periods of the year, with more private, irrigated fields, can be found at intermediate elevations. Natural pastures that are used as common property mostly lie at high altitudes (cf. EhLers and KReUtZMAnN 2000, KreUtZMANn 2006).



Map 1: Gilgit-Baltistan, Pakistan - Overview9

Source: Edited after Research Project "Culture Area Karakorum" (CAK) ${ }^{10}$

\subsection{Utilisation and management of water and forest resources}

To understand the local energy situation and analyse respective changes, it is at first necessary to know about the relevance of water and forest resources, as they represent sources of (hydro) power and heat energy respectively. Both resources, however, play crucial roles in the local agricultural system, too.

Water is an absolutely essential means of production for the irrigated agriculture. Meltwater from snow and glaciers at higher altitudes is conducted towards the cultivated areas and irrigated pastures via gravity-fed decentralized channel networks. For the water use and the operation and maintenance of the irrigation infrastructure, informal institutions have evolved over generations. They often include rotational cycles for the withdrawal times and volumes, rules about participation of members of each household in maintenance tasks, as well as respective control and sanction mechanisms, and detailed studies have shown, that have lead to a highly effective and sustainable use of the water resources (cf. KREUTZMANN 2000a, SCHMIDT 2004).

\footnotetext{
${ }^{9}$ The representation of locations, roads, international boundaries and the line of control should not be considered authoritative.

${ }^{10}$ I thank Dr. Matthias Schmidt from the CAK Research project for providing me with the map file for my own editing.
} 
Looking at the role of wood in the local agricultural system it is at first necessary to distinguish between the two origins of the resource present here: Cultivated trees on the one hand, and natural forests on the other. The cultivated trees are an integral component of the system of mixed mountain agriculture. They are planted on designated fields (orchards) as well as along irrigation channels, and include fruit trees (apricot, apple, etc.) as well as non-fruit-bearing trees (poplar, willow, etc.). The latter are sources of timber (mainly from poplars) and fuel wood, which are used to meet household needs, as well as for sale. Fruit-bearing trees are primarily cultivated to provide fruits as an additional nutritional base and a source of income, but also serve as minor fuel wood sources (SCHMIDT 2004: 81f.). The trees play a role in animal husbandry, too. Small lower branches are cut in order to improve the growth structure of the timber-producing species, and to prune the fruit trees. These branches are given to the livestock, which eat the leaves. Afterwards, they are dried and finally used as fuel wood, or in some case as construction material, e.g. to make baskets. Additionally, fallen leaves are collected at the start of winter and stored as fodder.

The maj or fuel wood collection from the cultivated trees usually takes place in the autumn months of October and November. Then, ideally, only mature or dead branches are cut, ill or mature trees are felled, and the wood is stored. Only a few households that don't own enough trees to take wood from, and who cannot afford to buy fuel wood, are occasionally forced to cut young branches or trees or even immature fruit trees to meet their needs (MUHAMMAD IBRAHIM, 24.05.2008).

All firewood taken from cultivated trees is named "on-farm firewood" in the following to distinguish it from wood gathered from "off-farm" sources, i.e. wild sources. Different types of natural forests exist in Gilgit-Baltistan. The majority of closed forests are found outside of the focus area of this research (Gilgit district). In the Gilgit district only few closed coniferous forests exist, however, there are numerous open forests or woodlands. These are dominated by different Juniper species and occur in higher altitudes of the montane and subalpine belts (SCHICKHOFF 2002: 44ff.). All of the forests of the Gilgit district are state property and officially designated as "Government Protected Forests". The management and regulation of their use is in the hands of the village communities, which usually comply with this assignment by imposing mostly informal rules and regulations. While the communities have open rights for grazing livestock and collecting fodder and fuel wood, the felling of trees from the closed forests is only allowed with special permission from the region's Forest Department. Nevertheless, as a result of excessive illicit logging and wood-cutting during the last decades, the majority of forests in the region have reached advanced degradation stages, or highly reduced stand areas, that lead to irreversible losses of forest habitats. One of the underlying factors causing this development is the regional supply and demand structure for fuel wood and timber: The main actors in this sector are influential clans, as well as staff members of the forestry administration, who together form the so-called "timber-mafia". But very poor households are often also forced to participate in the business, as timber represents a relatively easy source of income accessible to them. Thus it is mainly commercial and illegal logging, and not so much local households from the adjacent villages meeting their own fuel wood 
needs, that cause deforestation. Nevertheless, it has to be acknowledged that in Gilgit district, it is predominantly the regional demand for fuel wood stimulating deforestation ${ }^{11}$ (SCHICKHOFF 2006: 129ff., SCHICKHOFF 2002: 65ff.).

The question of whether the regional fuel wood demand is influenced by the electrification projects is discussed in section 7.2. To fully understand the project's impact on energy resource uses, it is also necessary to know what other resources are used for which purposes.

\subsection{Present state of the energy sector}

The area is characterized by an energy system that follows a pattern typical for remote highlands with the largest share of the energy demand deriving from household use (SCHWEIZER and PREISER 1997: 157). The most recent comprehensive data analysis on the energy mix of households of Gilgit-Baltistan is provided by KHAN and J OYIA (2003), who refer to data collected in the whole region from 1992 to 1996 from a survey implemented by GTZ and WAPDA (Water and Power Development Authority). They show that fuel wood - be it from on-farm or off-farm sources, or purchased from local traders - is used in nearly all households (Table 1) and serves as a cooking and heating ${ }^{12}$ resource. By far the largest proportion of the total energy demand is thus covered by fuel wood. Candles and especially kerosene are very important resources for lighting, the latter also being used as an additional cooking resource by almost half of all households. Liquefied Petroleum Gas (LPG) plays only a very minor role, which is attributed to the difficult access and costly transport conditions. Furthermore, the demand for batteries is increasing due to the growing use of electric and electronic devices.

For small industries (e.g. sawmills, flour mills, carpentries) and businesses (e.g. hotels) diesel represents another decisive energy resource, used to operate small generators to produce electricity (KHAN and JOYIA 2003: 13ff.). The area's supply of the commercial energy resources used in households, businesses and industries (kerosene, LPG, diesel) is supported by Pakistan's government with subsidies for their transport costs. These, however, only cover the transport to national depots. The subsequent distribution to the towns and villages is organised by private traders and retailers, so that local prices in peripheral locales may vary considerably (CLEMENS 2001: 34ff.).

\footnotetext{
${ }^{11}$ In the southern Diamir district, the larger-scale logging and marketing of timber from the extensive closed forest stands is predominantly driven by external political and economic influences, and strong demand from the lowlands of Pakistan.

${ }^{12}$ In this context the term "heating" necessitates some clarification: The common method of cooking and "heating" is to use a metal stove, placed in the common room of the house. The oven usually heats the room during the cooking processes through the extra heat emanating from it and is only rarely used exclusively for "heating".
} 
Table 1: Household energy mix in Gilgit-Baltistan (1996)

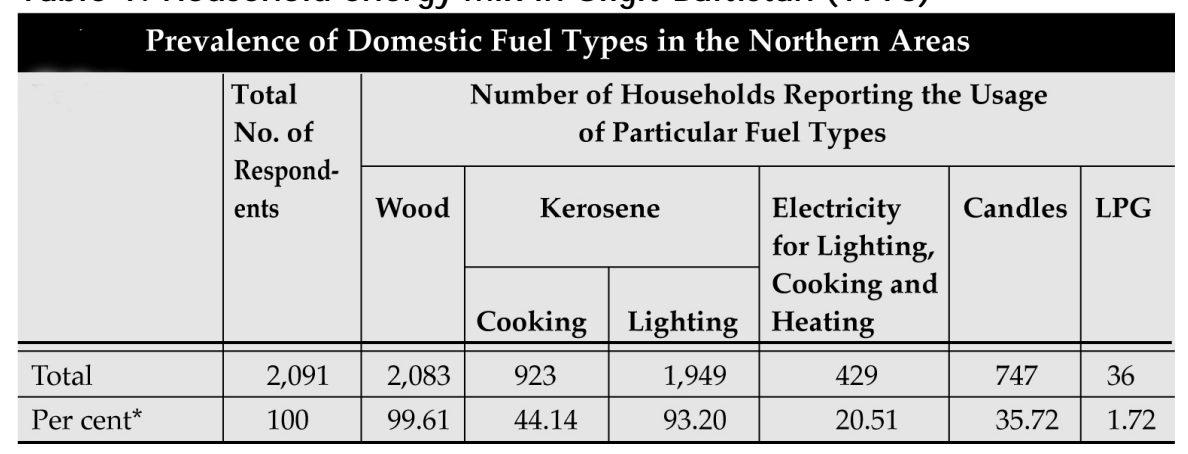

Source: Edited after KHAN and JOYIA (2003): 12

While electricity was available to only 29\% of all households in 1995 (CLEMENS 2001: 46), this figure had risen to an estimated $42 \%$ by 2001 . Most of the electricity is produced by small-scale hydro power plants, supplemented only by 15 diesel-based thermal power stations. The power stations' capacities range from below $50 \mathrm{~kW}$ to $6 \mathrm{MW}$ and they provide a total installed capacity of 64 MW (WORLD BANK 2007: 2). The small and most of the mini hydels, as well as the thermal stations, are managed, operated, and maintained by the Northern Areas Water and Power Department ${ }^{13}$ (NAW\&PD) of the regional governmental administration. They are supplemented by several micro and a few mini hydels installed by AKRSP and run by the communities. In those villages connected to power stations run by the NAW\&PD, the electricity is sold to the consumers at standardized tariffs (Table 2), while in villages with community-run stations it is their own responsibility to set the electricity prices.

Table 2: The NAW\&PD's electricity tariffs

\begin{tabular}{|l|r|r|}
\hline Consumer Category & \multicolumn{1}{l|}{$\begin{array}{l}\text { Units } \\
{[\mathrm{kWh}]}\end{array}$} & $\begin{array}{l}\text { Cost per unit } \\
{[\text { Rs. }]}\end{array}$ \\
\hline Domestic & $1-50$ & 1.82 \\
& $51-150$ & 2.72 \\
& $151-300$ & 3.64 \\
& Above 300 & 4.52 \\
\hline Commercial & $1-100$ & 4.86 \\
& Above 100 & 6.81 \\
\hline Industrial & All units & 3.04 \\
\hline
\end{tabular}

Source: KHAN and JOYIA (2003): 31
The power system of Gilgit-Baltistan is not connected to the national grid, and most of the power stations are not even interconnected among themselves, but only supply single villages or a few communities with an independent insular network. Only for the central area around Gilgit Town does a small subregional grid exist. This points to a regionally differentiated status of electrification efforts, which is further proved by a high variability of values of the installed specific capacity per capita. In 1999, the average value of nearly 43 Watt per capita was far below the national average of 91 Watt, but the Gilgit subdivision almost reached the latter value as it featured the regional maximum of 89 Watt. The minimum value, on the other hand, was 8 Watt in the Shigar subdivision (CLEMENS 2001: 43ff.). However, even the supply for those who are connected to power stations in areas of relatively high capacities (e.g. in the Gilgit

\footnotetext{
${ }^{13}$ As the government department was still carrying the former name of the region ("Northern Areas") as its official title at the time of research, this title is used in this thesis.
} 
subdivision) is deficient, and power outages occur frequently. A great problem of the electricity provision by hydro power stations in Gilgit-Baltistan is the seasonal discrepancy between electricity demand and supply: During winter the supply is significantly reduced due to the low volume of water in the rivers, while demand remains high or even increases as a result of the cold weather. Due to the insular network structure it is not possible to compensate these power shortages with electricity from other plants. Instead diesel generators are, if available, used to do so. In most areas, however, load shedding measures must be taken regularly, which means that certain groups of the households supplied by the network are disconnected for a designated time span. While in many parts of Gilgit-Baltistan load shedding has to be applied throughout the year due to the structural under supply, in other areas, such as the one connected to the subregional grid around Gilgit Town, unused surplus electricity is produced in the summer months ${ }^{14}$.

\subsection{Socio-economic transition processes}

All social and economic impacts of the hydel projects that are analysed here must be seen against the backdrop of the present situation and current trends, characterized by profound transitional processes. The formerly high share of agricultural revenues in households' income composition has decreased steadily in recent years as non-agrarian employment and income opportunities have grown substantially. This has brought with it positive, as well as negative, effects in the economic, social, cultural, and ecological sphere. On the one hand, growing monetary incomes and an increased agricultural productivity have - together with the steady supplies of publicly subsidized food contributed to an improvement of the formerly unstable food security situation. On the other hand, the integration in supra-regional markets has also amplified the area's dependency on the food imports. In order to purchase extra supplies, all households require cash, and apart from the somewhat limited income opportunities in the nonagrarian sectors of Gilgit-Baltistan, labour migration of young and middle-aged men is a livelihood strategy followed by more and more households to meet this need. Remittances of the migrants to the families they have left behind make up an increasingly important part of household incomes (KREUTZMAnN 1993: 28ff., KREUTZMANN 1995: 219ff.).

These developments are characteristic for an economy graduating from a subsistencebased to a cash-oriented one. Nevertheless, they neither apply to all districts and villages, nor to all households or individuals of each village in the same manner. In an analysis of distributional aspects of the economic growth in the region MALIK and PIRACHA (2006: 368) come to the following conclusion: "The traditional egalitarian but equally poor economy has been replaced by a modestly well-off but increasingly inequitable one. As a result, certain groups such as women and the very poor have not benefited proportionally from the overall gains credited to this transition."

Another implication of the transition process that shall be mentioned here is the changing gender roles that are examined in the studies of Herbers (1997, 2000), HalvorSON (2003)

\footnotetext{
${ }^{14}$ According to the NAW\&PD Executive Engineer for the Gilgit subdivision 4-5 MW excess power are produced during peak times in summer by the stations connected to the Gilgit grid (MOHAMMED ALI, 18.05.2008).
} 
and AZHAR-HEWITT (1999). One of their findings is that, as a result of the increase in offfarm employment and labour migration of male household members, women and elder men take over many of the agricultural tasks traditionally done only by young men. As all rural households continue agricultural production in spite of their off-farm incomes, this often leads to higher overall workloads for these household members. 


\section{The micro and mini hydel projects}

The regional setting depicted above must be seen as the starting point and context in which the micro and mini hydel projects focused on in this paper are based. Before presenting the methodological approach, and, finally, the results of the case studies, a little more clarification about the projects' technology, and their integration in rural development endeavours shall be given.

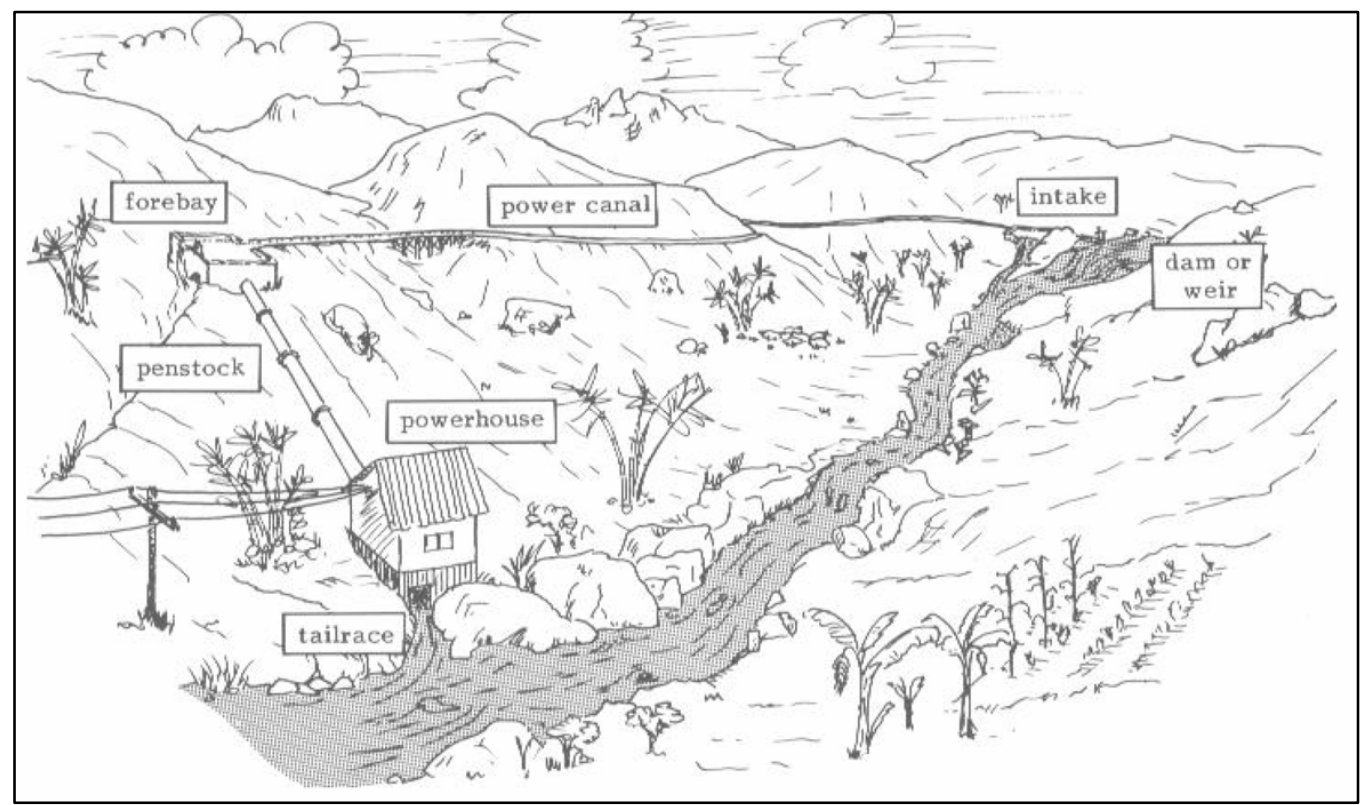

Figure 2: Basic elements of small-scale run-of-river hydro power stations

Source: SCHWEIZER and PREISER (1997): 162

The principle of harnessing the energy of flowing water is not new to the north of Pakistan, where flour mills driven by water wheels are traditionally used for milling grains and are still found in most villages. Hydro power projects expand on this principle. The typical small-scale installations are constructed as shown in Figure 2 and are referred to as micro, mini or small hydels. The basic idea is to use falling water to move a turbine, and to produce electricity with a generator connected to it. What significantly distinguishes the small-scale hydels from conventional large-scale hydro power stations is that they are designed as so-called "run-of-river" schemes. This means that no damming of water for storage is needed. The water is either taken directly from the stream, or through an intake structure, such as a small dam or weir, that directs it into the power canal. Often already existing irrigation channels are used as power canals in Gilgit-Baltistan. In this way only the naturally available discharge of the rivers is utilized. After passing the turbine, the water is returned to the stream through a tailrace channel. Like the power canals, the latter may simultaneously function as a lower-lying irrigation channel. Transmission and distribution lines finally transfer the power to the households (AKRSP 2007d: 18). Smallscale hydro power projects are only one of the many possible approaches to decentralised rural electrification by means of renewable energies. According to SCHWEIZER and PREISER (1997), however, they represent energy solutions very suitable for remote highland areas 
in developing countries, such as Gilgit-Baltistan. The technology is environmentally benign, relatively easy to manage, its operation is comparable to traditional water management tasks and the demand of dispersed settlements can be met with decentralized small units (SCHWEIZER and PREISER 1997: 161ff.).

The CDM-financed programme called "Community-Based Renewable Energy Development in the Northern Areas and Chitral, Pakistan" ${ }^{15}$ includes the installation of micro and mini hydel projects in various locations in northern Pakistan, and is implemented by AKRSP. AKRSP is a non-communal and not-for-profit NGO that "strives to contribute to promote inclusive human development, reduce extreme poverty and gender disparities" (AKRSP 2007b: 1f.). It has been working in the area since 1982 and has always followed a participatory development approach. For the integration of the communities in decisionmaking, project planning, and implementation processes, local Village Organisations (VOs) have to be established by the people. These VOs shall, on the one hand, evolve as selfsustaining institutions at village level dealing with local needs, and, on the other hand, are able to participate in AKRSP's program packages, such as physical infrastructure improvements. For the latter, AKRSP offers financial grants and technical assistance to the villages who, in turn, contribute their share in the projects in terms of subsidized labour, local construction material, and, in the case of hydro power projects, the land required for the construction. After the construction phase of the projects is managed cooperatively by AKRSP and the communities, the infrastructure schemes are owned, operated, and maintained by the VOs (AKRSP 2007d: 17f.).

Under the mentioned programme, AKRSP subsumes a total of 103 micro and mini hydel projects. The objectives of the projects include - as mandatory for the CDM - Sustainable Development, as well as GHG emission reduction impacts. While the former are more or less congruent with the expectations affiliated with rural electrification listed in section 2.2, the latter includes the objective to reduce emissions that would otherwise be produced from the use of fossil fuels and firewood (AKRSP 2007c: 4f., AKRSP 2007d: 7f.). This study originally intended to assess the impacts of three of the 103 projects. However, unexpectedly, at the time of research, many of the projects were still in the construction phase and none of the plants had started operating yet. Therefore, it was decided to select the case studies with running micro or mini hydels that feature the exact same constructional set-up as the CDM-financed projects and are thus optimally comparable to the CDM-financed plants. Specifications of each of the three selected schemes are included in the introduction of the case study villages (chapter 6).

\footnotetext{
${ }^{15}$ Due to the initiation of the programme before the renaming of the former "Northern Areas" into "GilgitBaltistan" (see section 3.1) the programme still includes the old name of the region.
} 


\section{Research procedure and methodology}

In order to do justice to the heterogeneity of the study area, and to capture the multiple impacts of interventions such as the hydel projects on the Sustainable Development of the region as comprehensively as possible, a comparative analysis of case studies in different locations, based on primary data, was conducted.

\subsection{Collection, analysis and evaluation of the primary data}

The primary data were collected between the $30^{\text {th }}$ March and $12^{\text {th }} \mathrm{J}$ une 2008 using a mix of empirical methods. Aiming at an in-depth and context-specific understanding of the processes induced by the projects on the village, inter- and even intra-household level, it was decided to base the assessment on a household survey and to supplement it with individual guided interviews. For the survey the goal was to select a sample of households which, in its composition, would reflect the socio-economic stratification of each village as much as possible. Due to the unavailability of village-specific socio-economic data, this selection was made on the basis of advice from village representatives and the translators. A total of 62 household interviews were conducted. In addition, 33 brief guided interviews were held with individuals from the villages, and 15 women were specifically interviewed about their their daily workloads. The stays in the case study villages furthermore offered an intensive opportunity for observations and, at times, participatory observations. In between the village stays discussions and interviews with AKRSP staff, as well as with representatives of the region's energy agency (NAW\&PD), provided further background information about the projects and the regional energy sector.

To start the evaluation process of the collected data, a relative wealth classification of the households was carried out. Against the background that the wealth assessment is not the primary focus of this study a relatively simple yet three-dimensional approach was chosen ${ }^{16}$. It is based on the factors of monetary income (measured in Pakistani Rupees = Rs. ), ownership of land (in kanal ${ }^{17}$ ), and ownership of livestock (in livestock units), and was applied separately to each village sample according to the following five-step procedure:

a) Per-capita values of the three factors were calculated for each household.

b) For each of the three factors, the households were ranked according to their percapita values. E.g. the household with the highest value of "per capita ownership of land" was assigned rank number 1 in the respective scale $R_{\text {land }}$. Thereby, three ordinal scales were obtained ( $\left.R_{\text {land }}, R_{\text {inc, }}, R_{\text {liv }}\right)$ that assign ranks ( $\left.r_{\text {land, }}, r_{\text {inc, }} r_{\text {liv }}\right)$ to each household for each factor: $r_{\text {land }}$ for the factor land ownership, $r_{\text {inc }}$ for the monetary income, and $r_{\text {liv }}$ for the number of livestock units owned.

\footnotetext{
${ }^{16}$ The wealth classification was done according to the example of Dipl.-Geogr. Andreas Benz, Centre for Development Studies (ZELF), Freie Universität Berlin. I thank him for explaining and sharing the method with me.

${ }^{17}$ Italics are used to highlight non-English words, as well units of measurement other than those of the metric system.
} 
c) By combining the three scales a wealth indicator (w) was computed for each household. It is equivalent to the average rank of a household over the three scales, the monetary income rank being double-weighted:

$\mathrm{w}=\left(2 r_{\text {inc }}+r_{\text {land }}+r_{\text {liv }}\right) / 4$

d) The households were then ranked according to their wealth indicator values and a new ordinal scale $\left(R_{w}\right)$ was attained.

e) Households with ranks 1 through 10 in this scale $\mathrm{R}_{\mathrm{w}}$ were classified as "better-off", those with ranks 11 through 20 or $21^{18}$ as "poor". Creating (nearly) equal class sizes of 10 resp. 11 cases was considered most meaningful for the relative classification undertaken. Furthermore, the data of the underlying three factors did not feature any threshold values nor cluster especially supporting a different classification.

In the following text and in all graphics, it is these two categories that are referred to when the terms "poor (households)" or "better-off (households)" are used.

For the qualitative data collected through the guided interviews another approach of evaluation was chosen according to the example of HERBERS (2006). The information from the written protocols was supplemented afterwards with (participatory) observations and selected remarks of other interviewees or persons present during the interviews. This allowed the reconstruction of some individual biographic anecdotes, historical processes, and developments specific to one household, one project site or one social initiative. Examples of these which illustrate succinct processes and enhance the understanding of backgrounds of developments, as well as individual statements and opinions, are presented in text boxes. Furthermore, the interviews conducted with AKRSP and NAW\&PD staff in Gilgit Town, as well as with community representatives in the case study villages, are cited as references directly in the text. The respective reference list is attached in Annex A.

\subsection{Reflections on the representativeness of the data and the research procedure}

For all quantitative information gathered in the interviews, e.g. monetary data about incomes and expenses, or land ownership figures, constraints regarding reliability and accuracy may not be disregarded. Firstly, for most of this information households do not keep exact accounts, so the interviewees made most statements based on estimates. A second and even more relevant reason for potential inaccuracies was the relationship between the respondents and me (the interviewer). In general, all interviewees showed enormous patience and at times enthusiasm while being questioned. However, they sometimes seemed to regard me as an employee of AKRSP, possibly disposing of financial funds that could be - if a need was identified - directed to their community, and their responses may have been influenced by strategic considerations. Also, information that would shed an unfavourable light on the interviewees was usually withheld. Additionally, in the case study village of Sumayar, respondents didn't specify their income from the

\footnotetext{
${ }^{18}$ One of the case studies (Bargo Bala) comprises 20, the other two (Ahmedabad, Sumayar) 21 households that were surveyed and classified.
} 
gemstone mining and trading business because of its great variability. However, according to a trader from Sumayar, the village's average income from this sector amounted to 45 million Rs. annually for the past three years (MOHAMmed SHAFA, 02.06.2008). This would mean an average additional earning per household of 73,000 Rs., implying an almost 30\% increase compared to the mean household income calculated on the basis of data excluding income from gemstones (see Table 4 in section 6.1).

A third constraint concerns the data about the volumes of on- and off-farm firewood use: Initially it was intended to include an inquiry of these volumes in the household survey. However, interviewees did not seem to know adequately precise figures, as preliminary respective results were scattering enormously around average values. CLEMENS (2001: 95f., 164) also points to the difficulties and inaccuracies of quantifications of biomass use, and establishes the need of very extensive surveys over a longer period of time if such a quantification is sought. Since such a long-term survey was beyond the scope of this study, the attempt to quantify the firewood use was entirely dismissed. These considerations about reliability and accuracy must be kept in mind when handling quantitative data presented in this study. They are of highest value when used comparatively, as done in the household wealth classification method. Absolute figures should be regarded as approximations.

A crucial issue regarding the research procedure is the lack of baseline data. No disaggregated data on the aspects analysed in this research are available for any of the three case studies, neither for the pre-project status, nor for an earlier date after the projects' implementation. Therefore, it could be argued that the Sustainable Development impacts assessed here are not necessarily actual effects causally linked to the projects, and that they might not represent long lasting changes. OLSEN and FENHANN (2008: 2822) note that for such assessments of the status quo, it might be more appropriate to just speak of "development impacts". This, however, would not reflect the explicit threedimensional nature of the Sustainable Development approach and would devalue many of the impacts that may indeed be long lasting. Furthermore, in the present research, the problem of missing baselines is encountered in a twofold manner: Firstly, current processes in three villages with contrasting conditions of electricity supply are analysed and compared to draw conclusions about project impacts. For all these processes their causal linkage with the electrification projects is established as explicitly as possible. Secondly, it is attempted to reconstruct the pre-project state and examine the changes that have accompanied the project's implementation by directly asking for information concerning both in the interviews. 


\section{Three case study villages}

The results of the empirical research work are summarized in the next four chapters. All information that is presented and that is not earmarked otherwise is derived from my own field data. After introducing the case study villages in this chapter, the impacts in the ecological, social and economic dimension of Sustainable Development are illustrated in the chapters 7, 8 and 9 respectively. The case studies were conducted in the villages of Bargo Bala, Ahmedabad and Sumayar (Map 2). Their selection was made according to two criteria: Firstly, and most importantly, villages with differing conditions of electricity supply were sought out. And secondly, the villages needed to be in different subdivisions of the Gilgit district, representing dissimilar socio-economic preconditions.

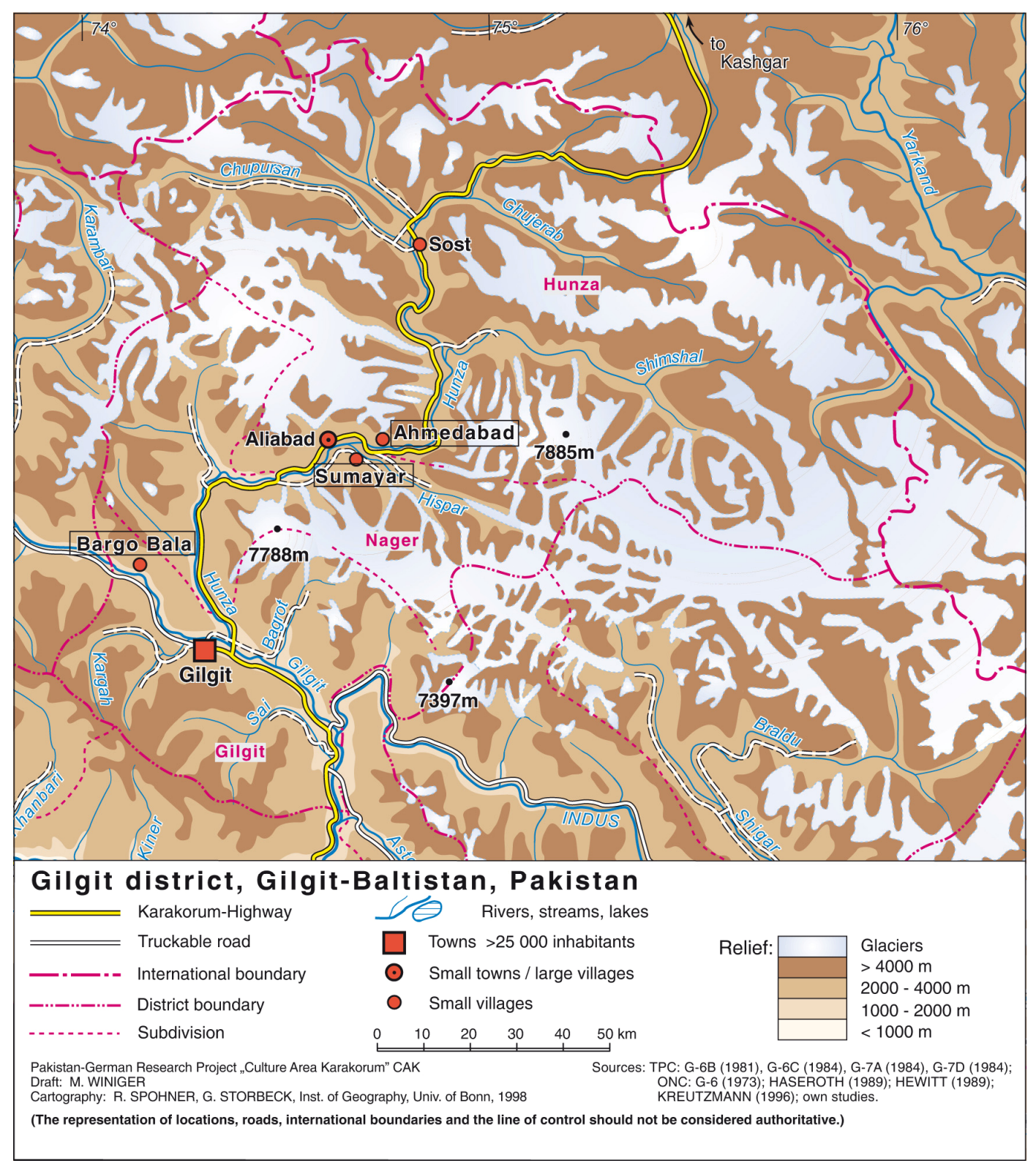

Map 2: The location of the three case study villages in the Gilgit district

Source: Edited after Research Project "Culture Area Karakorum" (CAK) 
Each of the following introductions of the case study villages comprises of general information about the villages as well as about their specific energy resource base. The presentation of the resource bases, however, focuses solely on the off-farm fuel wood resources, and especially on the hydro power projects, as the supply with other energy resources (traded fuel wood from outside, LPG, kerosene, candles and batteries) does not differ significantly between the three villages. These items were sold in all three villages at only slightly varying prices at the time of research (Table 3). Table 4 supplements the village introductions and presents relevant socio-economic data.

Table 3: Retail prices of energy resources in the case study villages and in Gilgit Town in April / May 2008

\begin{tabular}{|l|c|c|c|c|c|}
\hline & $\begin{array}{c}\text { LPG } \\
{[\text { Rs./kg }]}\end{array}$ & $\begin{array}{c}\text { Kerosene } \\
{[\text { Rs./l] }}\end{array}$ & $\begin{array}{c}\text { Candles } \\
{[\text { Rs./piece }]}\end{array}$ & $\begin{array}{c}\text { Batteries } \\
{[\text { Rs./piece }]}\end{array}$ & $\begin{array}{c}\text { Diesel } \\
{[\text { Rs./l }]}\end{array}$ \\
\hline Bargo Bala & 90 & 50 & $1-5$ & 5 & n.a. \\
\hline Ahmedabad & 95 & 50 & $2.5-5$ & n.a. & n.a. \\
\hline Sumayar & 90 & 65 & n.a. & n.a. & n.a. \\
\hline Gilgit Town & 85 & 43 & n.a. & n.a. & 50.13 \\
\hline
\end{tabular}

n.a. = no data available

Source: Own field data, gathered on 12.05.2008 (Bargo Bala), 20.04.2008 (Ahmedabad), 31.05.2008 (Sumayar) and 25.05.2008 (Gilgit Town).

\section{1 Bargo Bala - A village with a large summer settlement and very deficient electricity supply}

Bargo Bala was chosen as the case study village with the most deficient electricity supply. In addition to the settlement nucleus, it includes a relatively large seasonal (summer) settlement called Hopar Bargo. Population growth, as well as partition of land and its distribution among heirs and coheirs, has lead to a shortage of cultivable land in many villages in the area. To counteract this shortage, irrigation systems are often extended, and more land is being brought under cultivation wherever possible. On the land belonging to the community of Bargo Bala, new fields were opened up for agricultural use in 1971, when an irrigation channel was constructed for an area formerly only used as a pasture. During the following years, all households built housings in what became the relatively large seasonal settlement of Hopar Bargo. As the obligations for children to be present in Bargo Bala were very limited due to a lack of schools, many families moved with the majority of their household to Hopar Bargo during the summer months. This changed with the improvement of educational opportunities in Bargo Bala and the neighbouring villages in the 1990s. Until today there is no public infrastructure, such as schools, medical facilities, or piped water supply to buildings, in Hopar Bargo. Therefore girls and boys of school age stay in Bargo Bala for most of the year and only come up to Hopar Bargo during the two months of summer vacation. This period coincides with the harvest season and all family members are needed to work on the fields. Hence, the number of people living in 
Hopar Bargo is highest then. For the other agricultural tasks only some household members go up to the seasonal settlement, to stay for a few nights, or even just during the daytime, when it is their turn to water their fields. Since 2002 Hopar Bargo is accessible by car.

There are three spots on the common lands of the village where juniper tree stands ${ }^{19}$ provide the only off-farm sources of firewood, and wood may only be taken to Bargo Bala from the smallest of them. For the larger sources, a restriction limits the use of wood collected there to the summer settlement Hopar Bargo, and none of it may be brought to Bargo Bala.

The $200 \mathrm{~kW}$ mini hydel of Bargo Bala was installed by the NAW\&PD and started operating in 2004. The second-hand turbine that was used for the project is regularly subject to technical failures and thus provides only a very unreliable energy source. Furthermore, as it supplies the households of seven neighbouring villages ${ }^{20}$, the electricity produced is not sufficient to provide even basic daily supply continuously. During winter months, load shedding measures have to be taken, meaning that half of all the households are disconnected from the grid every other day. Ulterior load shedding measures are taken sometimes in the evening hours when not enough water is available and the storage tank has to be refilled. The hydel runs at a capacity of $60-65 \mathrm{~kW}$ from December to April and at $105-110 \mathrm{~kW}$ during the rest of the year. This shows that the figure of an installed specific capacity per capita of 37 Watt $^{21}$ reveals little about the electricity actually available for the households. At the time of this research, no electricity was available in Hopar Bargo.

\footnotetext{
${ }^{19}$ Only the species of J uniprus macropoda was observed here.

${ }^{20}$ In addition to Bargo Bala, where the power station is located, it supplies the villages of Sharote, Shikyote, Bargo Pain, Tholdass, Sharote Theney and Syedabad.

${ }^{21}$ The installed specific capacity of the power stations is calculated by dividing the installed capacity of the plants by the population covered. The population data were taken from GoP POPULATION CENSUS ORGANISATION (2000).
} 
Table 4: Basic data about the case study villages

\begin{tabular}{|c|c|c|c|}
\hline & Bargo Bala & Ahmedabad & Sumayar \\
\hline District & Gilgit & Gilgit & Gilgit \\
\hline Subdivision & Gilgit & Hunza & Nager \\
\hline \multicolumn{4}{|c|}{ Data from GOP POPULATION CENSUS ORGANISATION (2000): } \\
\hline Population & 1078 & 822 & 4372 \\
\hline Households & 108 & 125 & 614 \\
\hline Average household size & 10.0 & 6.6 & 7.1 \\
\hline Female / Male ratio & $49 \% / 51 \%$ & $49 \% / 51 \%$ & $46 \% / 54 \%$ \\
\hline Literacy ratio & $50 \%$ & $64 \%$ & $44 \%$ \\
\hline $\begin{array}{l}\text { Ratio of total population with } \\
\text { Matric }{ }^{a} \text { or higher education } \\
\text { level }(q / \hat{\jmath})\end{array}$ & $1.6 \% / 5.9 \%$ & $5.5 \% / 9.1 \%$ & $1.0 \% / 5.4 \%$ \\
\hline \multicolumn{4}{|c|}{ Data from own field study ${ }^{b}(2008)$ : } \\
\hline Distance to Gilgit (on road) & $42 \mathrm{~km}$ & $108 \mathrm{~km}$ & $120 \mathrm{~km}$ \\
\hline Altitude asl & $1850 \mathrm{~m}$ (approx.) & 2300 m (approx.) & $2300 \mathrm{~m}$ (approx.) \\
\hline Average household size ${ }^{c}$ & 9.4 & 7.6 & 11.3 \\
\hline $\begin{array}{l}\text { Ratio of adults }{ }^{d} \text { currently in } \\
\text { education above Matric level }\end{array}$ & $2.5 \%$ & $8.1 \%$ & $6.6 \%$ \\
\hline $\begin{array}{l}\text { Ratio of adults working / } \\
\text { studying outside of village }\end{array}$ & $7.6 \%$ & $16.2 \%$ & $9.3 \%$ \\
\hline $\begin{array}{l}\text { Ratio of adults with off-farm } \\
\text { employment }(Q / \overbrace{}^{\lambda})\end{array}$ & $1.9 \% / 47.7 \%$ & $13.2 \% / 59.0 \%$ & $4.6 \% / 41.9 \%$ \\
\hline $\begin{array}{l}\text { Average annual household } \\
\text { income }\end{array}$ & 125,925 Rs. & 156,702 Rs. & 250,701 Rs. \\
\hline $\begin{array}{l}\text { Average annual per capita } \\
\text { income }^{\mathrm{e}}\end{array}$ & 21,162 Rs. & 29,589 Rs. & 30,175 Rs. \\
\hline $\begin{array}{l}\text { Average land ownership per } \\
\text { household }\end{array}$ & 33 kanal & 41 kanal & 58 kanal \\
\hline
\end{tabular}

\footnotetext{
a The Matric level corresponds to the $10^{\text {th }}$ school grade.

${ }^{b}$ Includes data derived from the analysis of the household survey, individual interviews with village representatives and AKRSP data bases.

${ }^{c} \mathrm{n}=20$ households for Bargo Bala and $\mathrm{n}=21$ for Ahmedabad and Sumayar.

'All individuals aged 15 years or above were counted as 'adults'. The numbers of adults included here through analysis of the household survey were as follows: Bargo Bala: $n=118$, Ahmedabad: $n=99$, Sumayar: $\mathrm{n}=151$.

'According to MALIK and PIRACHA (2006: 360) annual per capita income averages out at 22,000 Rs. for all Gilgit district.
} 


\subsection{Ahmedabad - Close proximity to Central Hunza and limited but stable electricity supply}

Ahmedabad was chosen as the case study village with a power supply of medium capacity. An important feature for the village's development is its close proximity to what is locally called "Central Hunza". This neighbouring area includes the administrative and economic centre of the Hunza subdivision (Aliabad) and one of the most popular tourist destinations in all Gilgit-Baltistan (Karimabad). A lot of education and off-farm employment opportunities are sought there, and the regional market of Aliabad is also the place where the inhabitants of Ahmedabad mostly go to purchase goods of intermitent need. As opposed to Bargo Bala, the summer settlement of Ahmedabad is much smaller and household members only rarely stay overnight in one of the few small dwellings built there.

On the land belonging to the community, some very small remnants of once extensive juniper forests provide the only off-farm firewood sources. For the inhabitants of Ahmedabad and four of its neighbouring villages ${ }^{22}$, there are no restrictions on the extraction of wood or bushes. However, for outsiders from other villages the collection of any resources from this land is forbidden, and violations of this rule are penalized with a fine.. The scattered patches of juniper trees are found at high altitudes, and the hike up there is long and strenuous.

Ahmedabad was first electrified with the construction and opening of its 50kW-micro hydel in 1992. The project was initiated and supported by AKRSP and is still said to be one of the

Table 5: The Vo's electricity tariffs in Ahmedabad

\begin{tabular}{|l|l|}
\hline Service & Price \\
\hline $\begin{array}{l}\text { Price per unit (kWh) } \\
\text { - Domestic and Commercial } \\
\text { - Industrial }\end{array}$ & $\begin{array}{l}1.5 \mathrm{Rs.} \\
4.3 \mathrm{Rs.}\end{array}$ \\
\hline Registration / connection fee & $150 \mathrm{Rs.}$ \\
\hline Fine for burning of fuse and renewal & $100 \mathrm{Rs.}$ \\
\hline
\end{tabular}

Source: Own field data 2008 most successful ones, as the station has never been down for more than a day (AKRSP 2006: 1). Load shedding measures are not regularly taken. It supplies all households of the village with electricity, thus accounting for an installed specific capacity per capita of 61 Watt (whereas, in this case, the generated electricity actually comes up to the installed capacity). The Village Organisation (VO) of Ahmedabad operates and maintains the hydel project and also sets the tariff for the users (Table 5). At the time of research the VO was about to start running a second mini hydel in the village.

\subsection{Sumayar - Booming gemstone mining and trade and an extended electricity supply}

Sumayar was chosen as the case study with the largest and most recently extended electricity supply. About five to six hours walking distance from the village, at an altitude of about $4800 \mathrm{~m}$, a variety of semi-precious gemstones are mined. The mining and trade of the stones has had a substantial impact on the local livelihoods and brought significant

\footnotetext{
${ }^{22}$ Altit, Salmanabad, Atabad and Faizabad.
} 
wealth to some families. Almost every household sends at least one male member to the mines during the mining season, which usually lasts from late J uly to October. On the way to the mines lies the summer settlement of Sumayar, called Ter. Due to its close proximity just one hour walking distance away from the village's nucleus, only shepherds herding their animals on the lands lying above it usually stay here overnight.

A wooden gate at the upper border of Sumayar's summer settlement marks the beginning of the land commonly owned by the village. The relatively level area that connects here consists of grazing lands and areas once thickly forested. Quite a variety of plants are found, including different species of juniper, tamarix, and - at the highest sites - birches ${ }^{23}$. Since 2001 the cutting of branches or felling of juniper and birch trees is strictly prohibited. Only dry wood from the ground may be collected, and the cutting of tamarix is allowed. Any violators of the ban have to return the wood and pay a fine of 500Rs.

Sumayar is connected with three different sources of electricity: one micro hydel with an installed capacity of $100 \mathrm{~kW}$ constructed in 1987, a $250 \mathrm{~kW}$ mini hydel that started operating in 2007, and a $250 \mathrm{~kW}$ diesel generator that is located in the village of Askurdass. As the three neighbouring villages of Sumayar, Askurdass and Shayar are interconnected by a common grid, to which these three sources are feeding their electricity, they jointly manage their electricity supply. This is organised in a flexible manner, taking into account the seasonal and daily differences of the electricity demand and of the generation of each of the power stations. The new mini hydel station, for example, averages at a generated capacity of $160 \mathrm{~kW}$ in summer but only $25 \mathrm{~kW}$ in winter. Thus, while in summer the two hydels produce sufficient electricity to meet the demand, in winter sometimes the diesel generator has to be operated additionally to do so. All households in the area covered by the grid are connected. The installed specific capacity per capita amounts to 68 Watt. All the three power plants are owned, operated, and maintained by the NAW\&PD.

\footnotetext{
${ }^{23}$ Botanical names: J uniprus excelsa, juniprus macropoda, juniprus communis; tamarix tropii, tamarix dioca; betula utilis.
} 


\section{Ecological dimension}

In the previous chapter, the three case study villages were introduced individually. In the following three chapters, the results of the field studies in these villages are analysed to assess impacts of the hydel projects on Sustainable Development. Similarities and variations of ecological, social or economic processes are examined, and respective differences regarding the wealth levels of households are included in this analysis. For example, in the social dimension, new opportunities for the poor might open up, whereas in the economic sphere only better-off households share in certain developments. Hence, as suggested by the research concept and in order to allow a clear comparative presentation, the analysis is outlined according to the dimensions of Sustainable Development. When the dimension-specific processes are different for each village, each case studys' results are presented separately in the respective chapter, while in the case of very similar processes in all case studies, they are analysed in parallel and/or one very representative set of results from one of them is depicted in detail.

This chapter will focus on the ecological dimension. It will first discuss local environmental effects of the hydel projects, as well as their influence on water utilisation practices and respective conflicts. Then, in more detail, impacts on resource consumption patterns are examined.

\subsection{Impacts on the local environment and water utilisation practices}

Environmental reports and impact assessments are usually conducted for all rural infrastructure projects in the region. They assess possible local environmental problems related to the project location and design, as well as to their construction and their operational phases. For its programme "Community-Based Renewable Energy Development in the Northern Areas and Chitral (NAC), Pakistan", AKRSP (2007d: 29) states that no negative environmental impacts are likely to occur. In this research work, this predication cannot be tested by another complete environmental assessment for the three case studies due to time and resource constraints, but, notwithstanding, two aspects were included in the interviews and shall briefly be presented here.

First, the question of whether local environmental damages occurred during the construction or operation of the hydel stations is analysed. For the case studies of Bargo Bala and Ahmedabad none of the interviewees reported any negative effects on the environment. The situation in Sumayar appears differently, which is why this example is presented here in detail. Environmental problems occurred during the construction phase of the second, newer hydel station, and some are still not eliminated. The Rakaposhi Development Organisation (RDO), a cluster organisation, consisting of 12 Village and 17 Women Organisations from the three villages of Shayar, Askurdass and Sumayar, had decided to approach AKRSP in the end of the 1990s for support of a second power project, as their growing electricity needs could no longer be met by the old micro hydel (see also section 6.3). The construction of the new hydel, with a capacity of $250 \mathrm{~kW}$, had then started in 2000, but was confronted with many problems: An existing earthen channel had been selected as the power channel. Due to the extreme steepness of the slope on which it 
is located, there is an increased risk of natural hazards, i.e. gravitational mass movements. After the channel had been widened to meet the capacity demands of the plant, the slope had been destabilized by the interference and several small landslides and mudflows, as well as floods, repeatedly occurred and damaged the cultivated lands below. The construction of the hydel subsequently took much longer than expected. Only two months after it finally started running in 2006, the power channel was damaged once again and the operation had to be stopped. The NAW\&PD stepped in and funded the installation of metal pipes running underneath the surface and the cementation of the remaining parts of the channel. This prevented the seepage of water through the channel weirs and thus decreased the risk of landslides and mudflows. Since then, no environmental damages, except for occasional overflowing of the wasteway, have occurred (Box 1).

\section{Box 1: Environmental damages in Sumayar}

In the beginning of the construction there were a lot of problems, we had floods and landslides. We lost a lot of trees, and we still cannot cultivate parts of our lands there. The wasteway of the hydel runs right through our land and sometimes overflows when there is too much water in the channel and they don't manage to regulate it in time. That's why we can't use the land surrounding the project site. I am disappointed because compensations were promised to us but have not been made yet.

Sher Ali, 45 years, owner of the land of the hydel site 30.05.2008, Sumayar

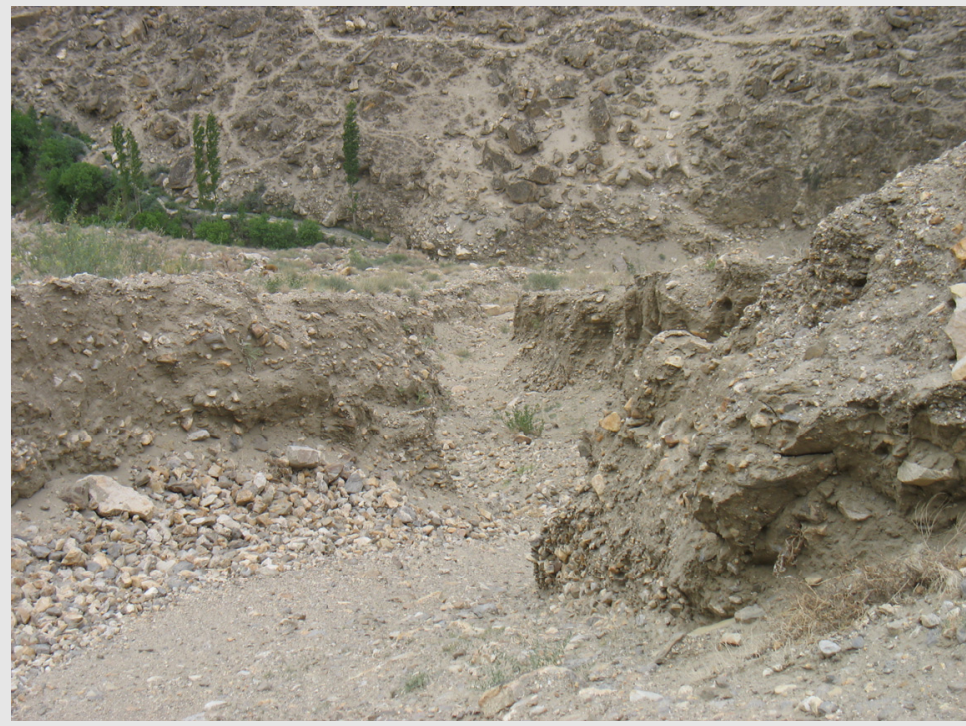

Environmental damages below the power channel Photo: Author, May 2008

Compared to the other two case studies, with 250kW, Sumayar's hydel project runs at the highest capacity. With increasing capacities of the hydels, the sizes of power channel, forebay tank, tailrace, and wasteway increase accordingly, due to the larger water 
discharge necessary ${ }^{24}$. As a consequence, the risk of local environmental damages increases, too, as the example of the hydel project in Sumayar demonstrates. It must be concluded that a very careful inspection and selection of construction sites, and adjusted civil engineering, is necessary in order to minimize this risk, above all for larger-sized hydels. And even then, some minor hazards such as overflowing cannot fully be precluded. The experiences described in Bargo Bala (plant running at a capacity below 150kW) and Ahmedabad $(50 \mathrm{~kW})$ suggest, however, that for hydels of micro capacity, negative impacts on the local environment are rather improbable.

The second impact on the local environment that shall be briefly discussed here is that on local water utilisation practices. The hydro power projects constitute interferences, as they use the same water resources as the irrigation systems, and redirect them at some points of the channel network. To examine if this affects the water management institutions, and if it leads to conflicts over the water utilisation, it is helpful to look at the periods of scarcity (e.g. in spring time), when rules are potentially challenged and users are potentially discriminated against. Again, similar observations were made in Bargo Bala and Ahmedabad, while the case of Sumayar presented the only example of some conflicts over the utilisation of water resources.

In Bargo Bala, the hydel station is situated above almost all of the village's irrigated lands. Hence, the only compromise that had to be made was that in Spring time the plant is turned off from early morning to 3pm to allow those few farmers who own one of the small irrigated fields upstream from it the watering of their land. Apart from that, there are neither fixed limitations nor a distribution key for the irrigation in Bargo Bala, and thus nothing had to be changed after the installation of the power station. In Ahmedabad, a similar compromise that prioritizes irrigation needs is followed. In spring time, when there is scarce water supply and a high need for irrigation, the plant doesn't run during daytime until early afternoon, as the water of the power channel is needed then on the fields. During rest of the year, however, there is enough water to meet the needs both of the farmers and of the hydro power station. The water management of Ahmedabad is based on a rotational cycle system assigning graduated priorities to different agricultural production zones (cropland, orchards, irrigated meadows). According to the manager of the Village Organisation (VO) operating the hydel, this system was not altered as a result of the implementation of the station (INAYAT ULLAH BAIG, 20.4.2008).

In Sumayar the situation is a little more complex: Here, opposing views about the effect of the new hydel's installation on the distribution of water were expressed. As the village is located on two sides of the nalla, some of those living on the side opposite of the power station (the "Khai-side") complain about having less water available in the Spring, and claim that more water is directed into the channel leading to the hydel than before its construction. This, however, is contested by the water guard of Sumayar, who states that the main channel on the hydel's side of the nalla is used at full discharge capacity in any case from Spring onwards, thus ruling out the possibility of illicitly increasing the amount of water being directed to this side and decreasing the amount available elsewhere (Box

\footnotetext{
${ }^{24}$ While in Sumayar the maximum discharge amounts to 26 cusecs (cubic feet per second), in Ahmedabad the designed discharge maximizes at 15 cusecs.
} 
2). To obtain a certain answer about the water quantities in the different channels, a more in-depth analysis with discharge measurement would be necessary. However, and more importantly, despite these contradictory views, no open conflict has been created, and disputes about irrigation water that were brought to the local informal conflict arbitration body have - according to a member of the latter (MOHAMMED HUSSEIN, 27.05.2008) - not increased.

\section{Box 2: Impact of the hydel project on the water management in Sumayar}

We have not changed the distribution key after the new hydel was built. But there is less water available for us now in Spring. During this time we face some problems. They had made plans to install extra pipes behind the powerhouse to direct water to the Khai-side, but didn't carry them out.

Shahid, 42 years, farmer from the quarter of Khai 29.05.2008, Sumayar

The system of rules for the irrigation system of Sumayar is very old. There are two water guards on the main side and one on the Khai-side overseeing it. For some parts like the lower channels on the Khai-side and the upper quarters on the main side there is a free irrigation system. For the other parts there are rotational terms.

Neither the quantities of water assigned to each side of the nalla nor the rules for the terms and the number of guards had to be altered after the construction of the new hydel.

Mohammad, 61 years, water guard of Sumayar 02.06.2008, Sumayar

The water distribution key for the multiple secondary channels of Sumayar's irrigation system is somewhat complex, too: For some part of the channel system there is a rotational cycle system in effect, for others there is not. However, the institutions governing the water management were not altered as a consequence of the construction of the hydel (cf. Box 2).

Regarding the impact of the micro and mini hydel projects on the local water management, the following conclusions can be drawn: The projects are designed in a way that they can be integrated in the channel structure and no water is lost. The sites of the hydels and their position in the system of channels seem to have been selected carefully, as no major changes to rules governing the water management were made in all three villages. Where minor changes did become necessary because of upstream water needs, the water requirements for irrigation purposes was prioritized. The only case study where the hydel project led to conflicting opinions about the water distribution was Sumayar, where the station with the highest capacity and the largest water need is located. This shows that not only the direct impacts of the hydel construction but also indirect consequences for the irrigation practices have to be pre-examined with great care, especially when building stations of higher capacity. But if the placement and design of the power plants is adjusted accordingly, alterations of institutions governing the use of water resources and conflicts can be prevented. 


\subsection{Complex parameters of energy resource choices}

The aspects of the ecological dimension that are analysed in more detail concern the impact of the electrification projects on the energy resource consumption patterns: How are domestic resource mixes influenced? Are biomass and fossil fuels (i.e. firewood, kerosene, LPG) substituted with electric energy and respective emissions reduced? And are there differences between better-off and poor households in these respects? In addition, the impact of the projects on household expenses for energy resources is examined, even though it could be argued that this falls under the category of economic impacts. However, for clarity reasons this aspect is included in the ecological dimension. To answer these questions, the current consumption patterns, respective dynamics, and impacts of the hydel projects have to be understood thoroughly. A broad, integrative perspective of the local energy system must be taken, which not only looks at the electricity supply, but includes all other energy resources, too. As the biggest share of energy consumption derives from domestic cooking and heating activities (see section 3.3), a specific focus in the following analysis is placed on these end $u^{2} \mathrm{~s}^{25}$.

\subsubsection{Fuel wood as the primary energy basis with varying supplementary resource uses}

A hypothesis that is often brought forward concerning the energy resource mix of households in developing countries is that of the so-called energy ladder: It states that with increasing wealth levels, households are switching from traditional (i.e. mostly biomass) to commercial energy fuels, and subsequently from lower-value to higher-value resources (e.g. from kerosene to LPG) (CLEMENS 2001: 29, also cf. WORLD BANK 1996). For the present study this would mean that - once a household is sufficiently supplied with electricity - the question of substituting electricity for biomass or fossil fuels is only one of the respective wealth level. The results of the survey of household energy consumption patterns challenge this assumption. Moreover, they show that there are multiple other factors, besides the wealth level, and besides the mere availability of the high-value resource of electricity, that determine peoples' decisions about which resources to use for what purposes. This will be elaborated upon below.

One result of the survey is common to all three villages and shall be anticipated at this point before analysing the significantly varying details about resource mixes and end uses from each case study, one by one: In all villages, firewood is used as the primary fuel for cooking and heating by all households (100\%), and all alternative resources are used supplementarily. Firewood has thus remained by far the most important source of energy for these purposes. The graphics about the end use of wood are therefore omitted in the following analyses as they all show the same result.

\footnotetext{
${ }^{25}$ The energy resource uses of small businesses and industries, and respective substitutions, are examined under the economic dimension (chapter 9) in connection with the analysis of their income-generating potential.
} 


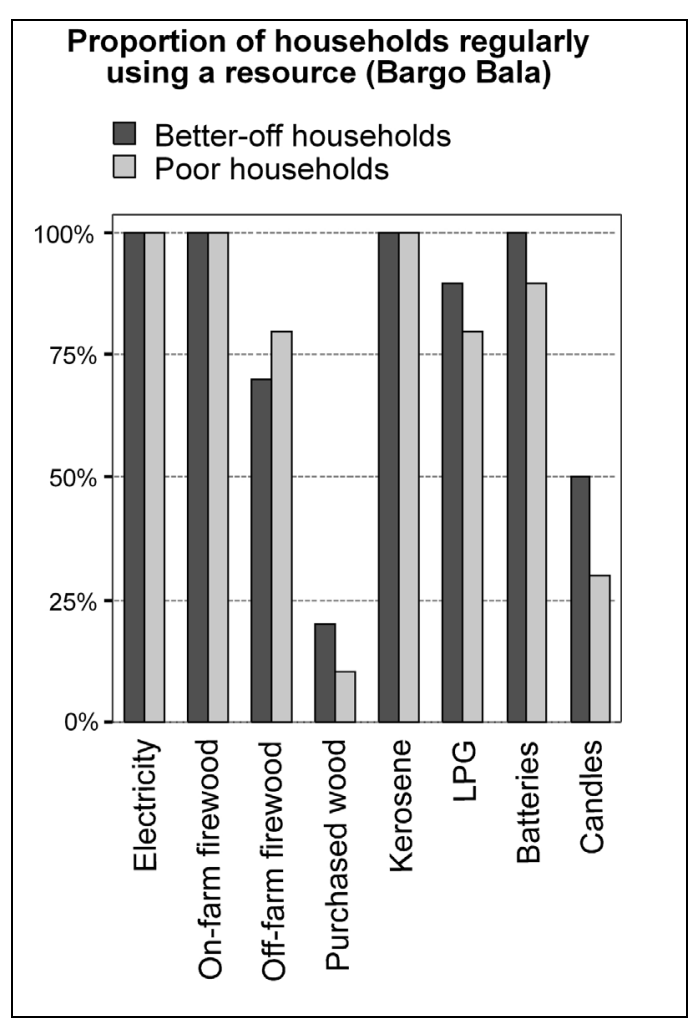

Figure 3: Resource mix in Bargo Bala

Source: Own field data 2008, $n=20$

To start with, this assessment holds true for the surveyed households - the poor as well as the better-off - of Bargo Bala (Figure 3). All use wood from their own land (on-farm), both for heating and cooking. The majority supplements this with off-farm firewood sources. This high share of offfarm firewood use is due, especially, to the respective use in the summer settlement (Hopar Bargo), as in Bargo Bala itself the use of off-farm sources is largely prohibited (see section 6.1). Interestingly, the use of off-farm wood does not show a strong correlation with the poverty level, as one might expect knowing that poorer households mostly don't own as much land with on-farm wood resources as better-off households, and as the hypothesis of the energy ladder would suggest, too. The reasons for this provide one example of the strong associations of resource use with the agricultural system: All households own lands in Hopar Bargo, and many interviewees argued that, while they are staying in the summer settlement, they have time to collect off-farm wood between their terms of watering their fields. This would also allow them to save greater amounts of on-farm wood in Hopar Bargo to bring to Bargo Bala for the winter. Box 3 exemplifies another, special relation between resource consumption patterns and agricultural activities: The shepherds' task of bringing livestock to the high pastures can be combined with the gathering of firewood, even enabling some to sell excess amounts collected. Furthermore, the collection of on-farm wood is done according to the prevalent practice in the region by all households of Bargo Bala (and of the other case study villages) and thus serves various functions in the agricultural system, too, e.g. to provide animal fodder, improve growth structure of timber species, prune fruit trees, remove mature branches etc. (also see section 3.2).

Only few households of Bargo Bala have to purchase additional wood, and, if so, they buy it mostly from other farmers of Bargo Bala. The village is thus largely independent of wood supplies from other locations.

Electricity - if not unavailable due to the frequent load shedding - is used by all households of Bargo Bala for lighting purposes and appliances. Due to the missing electricity supply in Hopar Bargo, high shares of the households surveyed regularly use alternative lighting resources: 95\% reported the frequent use of battery-powered torches ${ }^{26}$, and all households keep kerosene lamps in Hopar Bargo, which are the most important source of lighting in the summer village. $80 \%$ use kerosene lamps in Bargo Bala, too, usually for lighting in times of failing electricity supply. Furthermore, candles represent an important backup resource.

\footnotetext{
${ }^{26}$ These torches are often replaced with Chinese-made one-way lighters with an integrated light.
} 


\section{Box 3: Resource use of a shepherd from Bargo Bala}

Ali is a 50year-old shepherd from Bargo Bala. For 8 months of the year he spends most of his time in the summer settlement Hopar Bargo together with his 17year-old son as they daily bring their herd of 130 goats up to the high pastures. When they cook meals or heat their small house in Hopar Bargo they use only wood from juniper trees that they collect during their daily trips to the pastures. The wood from the trees growing on their own land in Hopar Bargo is saved and transported to Bargo Bala where the other 8 members of their household live. Even during the winter months Ali goes up to some lower-lying pastures and collects wood on the way. By doing so Ali and his son enable his household to not only cover their own need for firewood but to earn an extra income of 1500 Rs. each winter by selling wood.

Ali, 50 years, shepherd 11. 05.2008, Bargo Bala

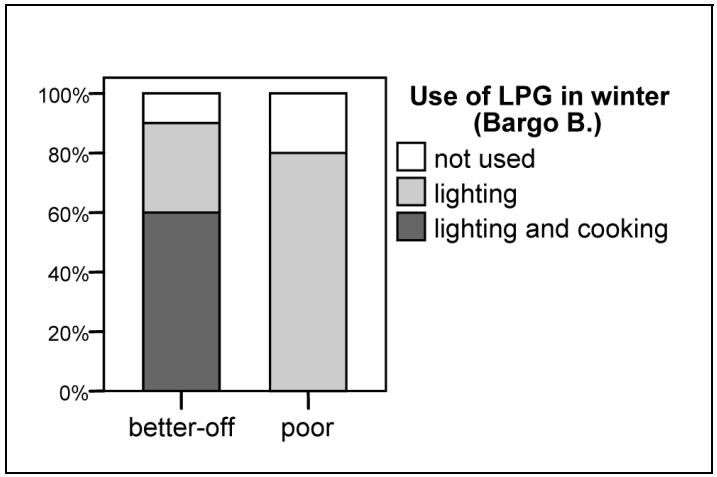

Figure 4: End use of LPG in Bargo Bala (in winter)

Source: Own field data 2008, $n=20$

LPG, that did not play a major role in the resource mixes of households from the region until recently (see section 3.3) has gained importance: $85 \%$ of the poor and the better-off households are using it for lighting during the winter months that they spend in Bargo Bala (Figure 4). It seems to be replacing kerosene as an attractive fossil fuel, used especially for lighting even though it is more expensive. The reasons for this are the higher energy efficiency of $\mathrm{LPG}^{27}$, its enhanced distribution infrastructure, and the fact that it's clean and more convenient to use. It was easily available in all three case study villages; however, only one out of twenty households transported LPG to Hopar Bargo to use gas lamps there. The fact that $60 \%$ of the better-off also use LPG for cooking purposes, as opposed to none of the poor households, seems to conform at first glance to the argument of the energy ladder: The better-off use the commercial cooking fuel LPG as a supplementary resource to replace biomass fuels. However, the question of whether this changing resource use pattern does indeed implicate an automatic substitution of any type of low-value resource, i.e. firewood of any origin, for the high-value resource LPG with an increased wealth level, is not clarified at this point. It will be discussed at the end of this section.

\footnotetext{
${ }^{27}$ LPG's energy efficiency is high both in terms of its energy content as well as in terms of the efficiency with which it is typically burned (CLEMENS 2001: 37, WORLD BANK 1996: 27).
} 




Figure 5: Resource mix in Ahmedabad

Source: Own field data 2008, $n=20$
The resource mix of the surveyed households of Ahmedabad, the village with a slightly larger but much more stable electricity supply, is similar in some basic characteristics but also features significant differences (Figure 5): J ust like in Bargo Bala, electricity is used regularly in all households for lighting and running appliances. For almost all households, on-farm firewood is the most important resource for heating and cooking. The only exceptions are the two poorest households who use off-farm wood, i.e. especially bushes from the common lands. For most others their own onfarm resources suffice. In total, buying wood is only an option for one quarter of the households. They purchase to supplement their own stocks. As opposed to Bargo Bala, only very few use kerosene, candles, and batteries on a regular basis for lighting in Ahmedabad. This is similar in Sumayar (Figure 7, below), the village with the most extended electricity supply, and demonstrates how decisive not only the capacity but also the reliability of the electricity supply is, especially for reducing the use of these resources. Even though their substitution for electricity as a source of lighting only has a limited effect on the GHG emissions - compared those caused by cooking and heating activities - it does appreciably influence the households' energy related expenses (see next section) and the indoor air quality (see section 8.3).

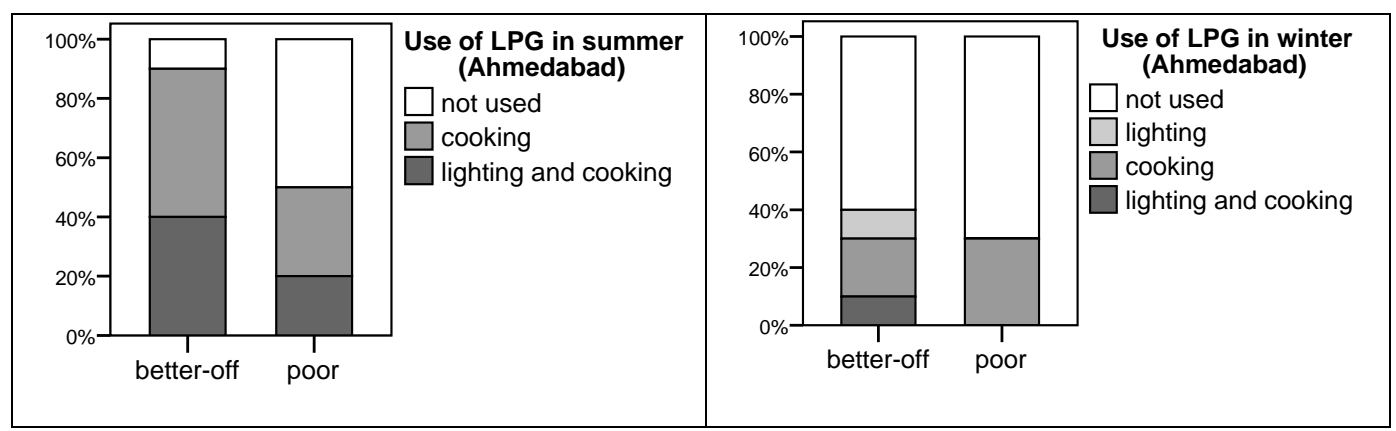

Figure 6: End use of LPG in Ahmedabad

Source: Own field data $2008, n=20$

Similarly to Bargo Bala, LPG is used by a more than half of all households, and again more of the better-off are flexible in meeting their energy need by applying it for cooking purposes as well (Figure 6). Interestingly, many of those using LPG refrain from doing so in winter. Interviewees explained this by pointing out the fact that cooking with LPG does not 
heat the room at the same time, as is the case with fuel wood. Thus cooking with wood is preferred in winter.

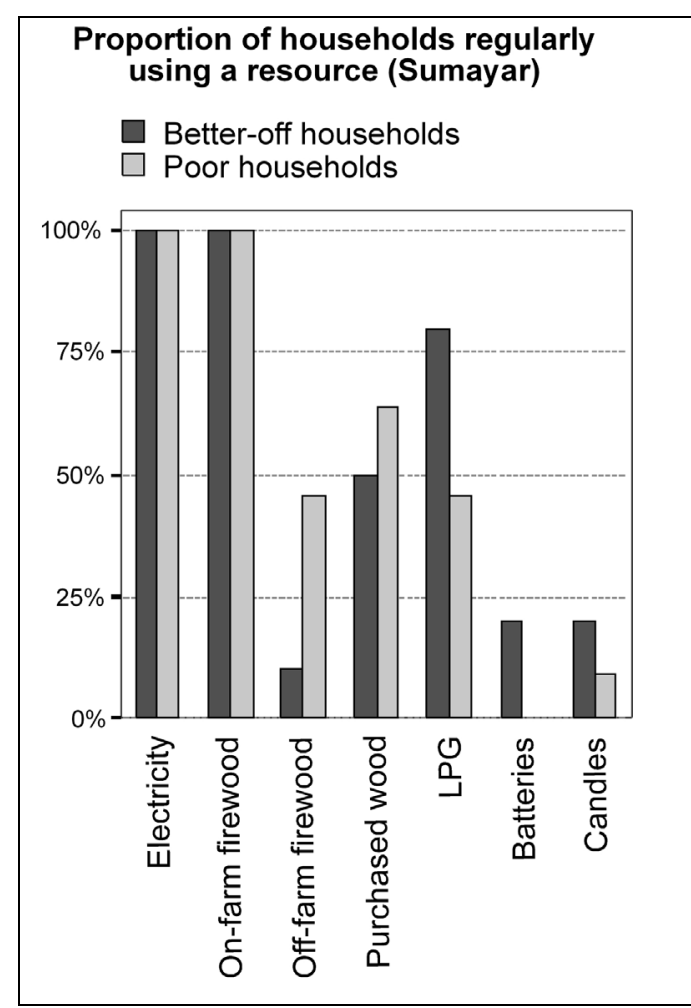

Figure 7: Resource mix in Sumayar

Source: Own field data 2008, $n=21$

Finally, comparing the resource mix surveyed in Sumayar's households (Figure 7) with the results from Bargo Bala and Ahmedabad, one difference especially stands out: There is a higher proportion of households resorting to off-farm or purchased wood. This is especially true for the poor, almost half of whom collect wood from off-farm sources, while $63.6 \%$ of them must purchase additional wood. These purchases are mainly made from traders from other parts of Gilgit-Baltistan. All this points to a shortage of wood from Sumayar's own lands. In contrast to the other two case studies, almost one third of the households surveyed in Sumayar - 83\% of them being "poor"- even regularly resort to biogenous resources other than wood, e.g. dung cake, plant roots, or Artemisia shrubs. All the biomass resources are used for cooking and heating and represent the most relevant resource for these purposes. However, LPG is additionally used to fill these needs by a relatively high proportion of households, especially the better-off (Figure 8): In Winter, 50\% of the better-off and 18\% of the poorer households use LPG as a supplementary heating resource, and even more cook with it. Heating with gas is either done in addition to firewood heating on especially cold nights or in extra rooms aside from the common room where the stove is located.

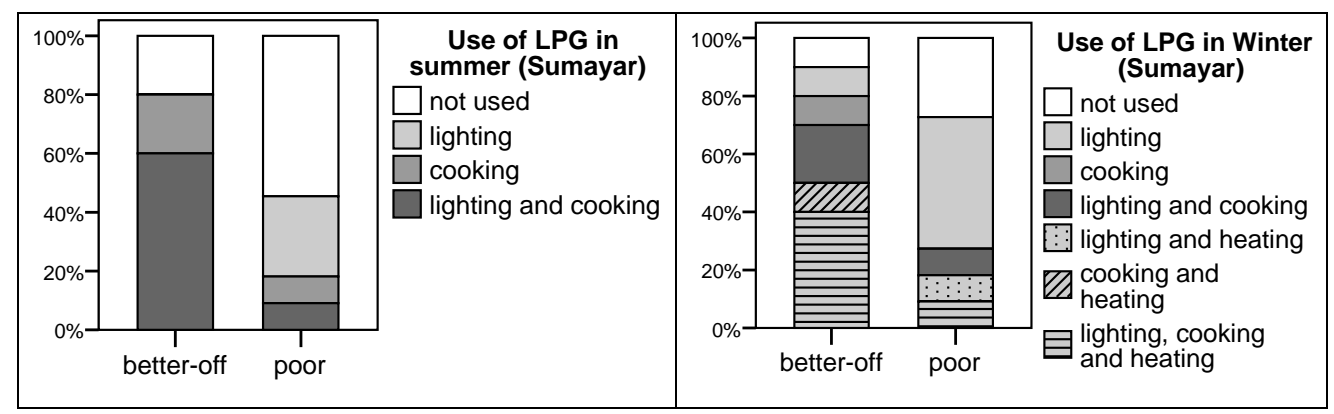

Figure 8: End use of LPG in Sumayar

Source: Own field data 2008, $n=21$

In this case study, it is not only LPG that partially substitutes fuel wood for cooking and heating, but electricity, too: J ust as in the two other villages, all surveyed households use electricity for lighting as well as for household appliances (which are listed and analysed in 
section 8.1). In addition, however, many households of Sumayar also regularly use electricity for cooking (Figure 9). This applies especially to the better-off, of which one fifth even use electricity for heating rooms ${ }^{28}$. Thus, in this case, the extended electrification of the village indeed allows at least the partial substitution of biomass fuel use, especially by better-off households.

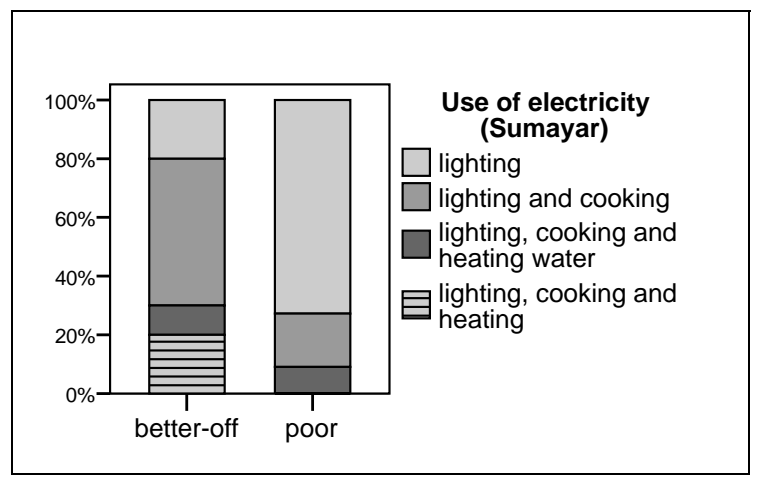

Figure 9: End use of electricity in Sumayar

Source: Own field data $2008, n=21$
As shown, Sumayar is the case study with the highest share of cooking and heating uses of LPG, and the only one where a partial substitution of biomass use for electric cooking and heating takes place. One important reason for this development is, presumably, the fact that every extra amount of fuel wood used in Sumayar's households causes extra monetary costs for its purchase. Alternatively, off-farm firewood, or even other low-value biomass fuels (dung cake, shrubs, etc.), must be collected.

The collection at off-farm sites is a very strenuous task in Sumayar, since the relatively easier collection in the nearby forest has been largely prohibited (see section 6.3). This ban has thus increased the costs of biomass use in terms of workloads, for which labour force is needed in the household. Especially better-off households seem to balance these costs against the costs of LPG and electricity when making the choices about which resources to use. For the regular collection of wood from on-farm sources, on the contrary, such a valuation is not considered, as it plays such an integral role in the system of agricultural activities (as shown above), and on-farm wood is therefore seen as an energy resource free of extra financial costs.

Most of the poor, who continue to use off-farm wood and non-wood biomass, seem not to be in a position to ascribe a monetary value to the workload and time needed for its collection, and balance it against the costs for the alternative energy resources. A factor influencing resource choices, aside from the wealth level, and further explaining these different valuations of resources is introduced by LEACH and MEARNS (1988). They state that in this context the availability of labour gains significance: "If spare labour is abundant it may not matter if woodfuel collecting trips are long or getting longer. If labour is very scarce, even the collection of abundant woodfuel supplies may be perceived as a serious problem." (cited in CLEMENS 2001: 31). The higher share of off-farm employment or labour migration in better-off households, that reduces the availability of labourers for agricultural tasks in the household, suggests that this holds true for the case study of

\footnotetext{
${ }^{28}$ The locally most common electric cookers emanate extra heat to the rooms in which they are used and are characteristicly called "heaters" by the people. Nevertheless, as this heating capacity on its own is not at all sufficient to heat a room in winter, the category "heating" was only assigned to those households using electric devices specifically designed for heating rooms. Furthermore, the category "heating water" applies only to households owning and regularly using a hot water tank, not to those occasionally heating water with rods.
} 
Sumayar: While $42 \%$ of the adults belonging to better-off households have off-farm employment, work, or study outside of the village, for the poor this ratio only amounts to $27 \% 29$. Hence, it can be stated that the factors influencing energy resource choices include processes outside the local context, such as the employment of migrants outside the region, and are thus partially decoupled from it.

The case study of Sumayar differs from the other two, not only in terms of relatively high costs for fuel wood due to a scarcity of resources, but also in terms of the quality of the electrification. The village's electricity supply is of the highest capacity and enough stability, whereas instability or insufficient capacity largely impede the use of electricity for cooking and heating in Bargo Bala and Ahmedabad. Hence, the following conclusion can be drawn from the findings about the differentiated valuation of energy resources: If the costs of using firewood (monetary costs for the purchase or extra workloads for the collection of off-farm sources) are relatively high, and a sufficient and stable electricity supply is available, better-off households do start to partially substitute electricity for biomass as a cooking and heating resource. This makes them more flexible in their response to energy needs than the poor who rather use off-farm firewood. It is, however, not only the wealth level determining the resource choices, but also the availability of labour. The hypothesis of the energy ladder does not clarify these complex relationships: Resource substitutions according to wealth levels only occur for specific resources (offfarm but not on-farm wood), under specific circumstances (scarcity, high costs), and factors influencing it, such as labour or the role of resources in the agricultural system, are not included.

The commencing substitution of electricity for fuel wood can be seen as a step in the right direction in order to reduce the consumption of biomass energy resources. Due to the merely supplementary use of electricity for cooking and heating purposes, however, it can be assumed that this partial substitution does not have substantial impact on the overall demand for fuel wood in the region. Therefore, the electrification projects' impact on deforestation reductions in the region is negligible.

\subsubsection{Household expenses for energy resources}

The following analysis of the energy-related expenses serves two purposes. Firstly, it reveals insights about the positive effects of electricity provision on the total expenses of poor and of better-off households from the three villages. And secondly, some of the conclusions drawn from the previous analyses of resource mixes are further affirmed. Moreover, the examination of expenses could possibly be used as a basis to analyse the quantities of consumptions of the different commercial resources in more detail, as these can easily be converted from the respective expenses. However, the monetary expenses provide a more suitable basis for the main objective of this part of the research, which is to draw comparisons between the resource consumption patterns observed in the three

\footnotetext{
${ }^{29} \mathrm{~N}=78$ for adults from better-off and $\mathrm{N}=74$ for those from poor households.
} 
case studies as well as between better-off and poor households $s^{30}$. The additional presentation of consumption quantities was therefore largely left out.

Table 6: Average annual household expenses for lighting resources

\begin{tabular}{|l|r|r|r|r|}
\hline & $\begin{array}{c}\text { Expenses for } \\
\text { candles [Rs.] }\end{array}$ & \multicolumn{1}{c|}{$\begin{array}{c}\text { Expenses for } \\
\text { batteries [Rs.] }\end{array}$} & $\begin{array}{c}\text { Expenses for } \\
\text { kerosene [Rs.] }\end{array}$ & $\begin{array}{c}\text { Share of total energy } \\
\text { expenses [\%] }\end{array}$ \\
\hline Bargo Bala & 480 & 448 & 2455 & $31.5 \%$ \\
\hline Ahmedabad & 157 & 62 & 122 & $7.2 \%$ \\
\hline Sumayar & 143 & 23 & 1052 & $7.7 \%$ \\
\hline
\end{tabular}

Source: Own field data 2008

One of the expected effects of the electrification of villages in the study region is the substitution of electricity for formerly used alternative lighting resources, i.e. candles, batteries and kerosene, and the saving of respective disbursements. By comparing the proportions of household expenses from the three case studies it can be estimated that households indeed use much less of these resources, and save considerable amounts, as a consequence of using electricity for lighting instead. In Bargo Bala, where the electricity supply for the main village is of lowest capacity and reliability, and where quite some time is spent in the non-electrified summer settlement of Hopar Bargo, the use of these three resources is most common (see section 7.2.1) and the mean expenses are highest. On average a household spends 480 Rs. per year on candles, 448 Rs. on batteries, and 2455 Rs. on Kerosene. In Ahmedabad and Sumayar, where kerosene in nearly all households only presents an emergency resource for occasional power outages, and where only very few households reported a regular use of candles and batteries for lighting purposes, the expenses are accordingly much smaller (Table 6). Thus the effect of electrification on the substitution of lighting resources and respective expenses is valuable and measurable. This significant reduction of the proportion of expenses, especially for kerosene, but also for candles and batteries, applies for better-off as well as for poorer households, as both substitute electricity as a lighting resource. This indicates that in terms of monetary savings for energy resources used for lighting, the benefits of the hydel projects are distributed quite equally between different wealth levels.

The expenses for these resources represent only a limited share of the total energy resource expenses. In all three villages a very large share is further spent on LPG (Figures 10 and 11). In addition to being used as an alternative backup resource for lighting, LPG is - as shown above - used for cooking, and in some cases for heating. There are significant

\footnotetext{
${ }^{30}$ The mere quantities of consumption, measured in litres, kilograms or watt hours respectively, would not reveal any insights that cannot be derived from the examination of the expenses, and are furthermore less clearly comparable. For in-depth quantitative analyses seeking to assess substitution potentials of energy resources, the so-called effective price per energy unit (measured in J oules), is an adequate unit of measurement. Its calculation includes the calorific value of the resources and the (average) energetic efficiency of the appliances commonly used. The latter values were unavailable for the appliances used in the area and their inquiry would have outgrown the scope of this research.
} 
differences between better-off and poor households regarding not only these end uses, but also the quantities of consumption. In all case studies, the better-off spend much more on LPG than the poor. This reaffirms the argument raised above, that the better-off are more flexible in their response to energy needs.

The fact that in Ahmedabad, households spend by far the least on energy resources in total can be explained by two decisive advantages of the village's energy resource base. Firstly, the electricity supply is reliable and sufficient at least for lighting purposes throughout the year. The energy consumption for lighting, and thus respective costs, are comparably low, all the more as the use of energy-efficient bulbs and tube lights is widely spread. In Bargo Bala, on the contrary, the people spent larger shares of their income on kerosene and LPG, as the main source of lighting or as a backup resource for power outages respectively. And secondly, as opposed to the case study of Sumayar, the majority of households from Ahmedabad rely on their own firewood sources, and don't have to purchase additional fuel, resulting in much smaller mean expenses. This points once more to the importance of a reliable minimum electricity supply, but also to the relevance of the integration of biomass resources in household energy-oriented projects if they aim at keeping household expenses low. 


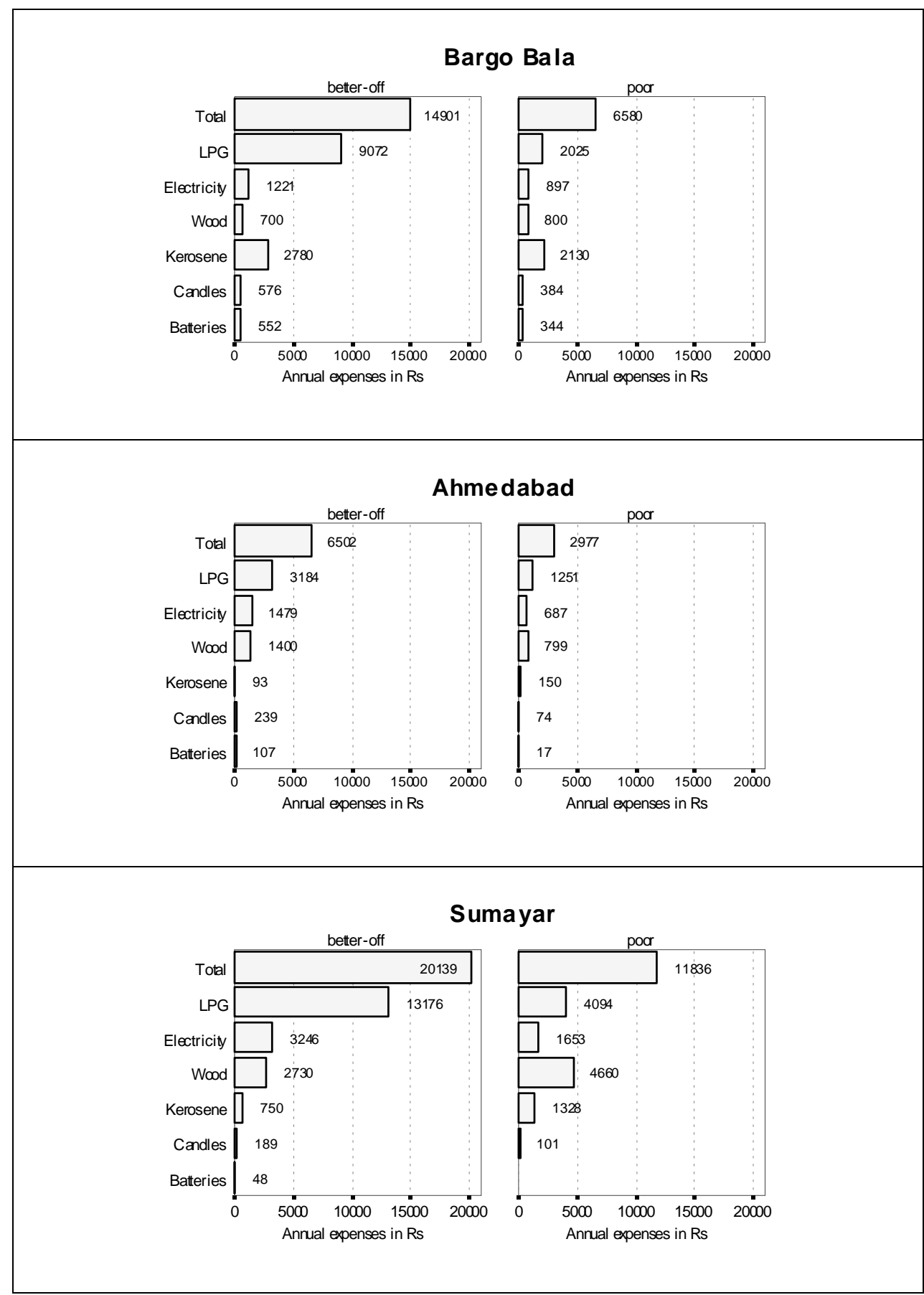

Figure 10: Average annual energy expenses by wealth groups ${ }^{31}$

Source: Own field data 2008, $n=20$ for Ahmedabad and Bargo Bala, $n=21$ for Sumayar

${ }^{31}$ The following mean annual quantities of electricity consumption per capita can be converted from the these expenses:

\begin{tabular}{|c|c|c|c|c|c|c|}
\hline & \multicolumn{2}{|c|}{ Bargo Bala } & \multicolumn{2}{c|}{ Ahmedabad } & \multicolumn{2}{c|}{ Sumayar } \\
\cline { 2 - 7 } & Better-off & Poor & Better-off & Poor & Better-off & Poor \\
\hline $\begin{array}{c}\text { Electricity consumption } \\
\text { [kWh] }\end{array}$ & 68 & 54 & 107 & 79 & 118 & 73 \\
\hline
\end{tabular}

For comparison: The mean per capita consumption in all Pakistan was 172 kWh in 2004 (KoJ IMA 2006: 12). 


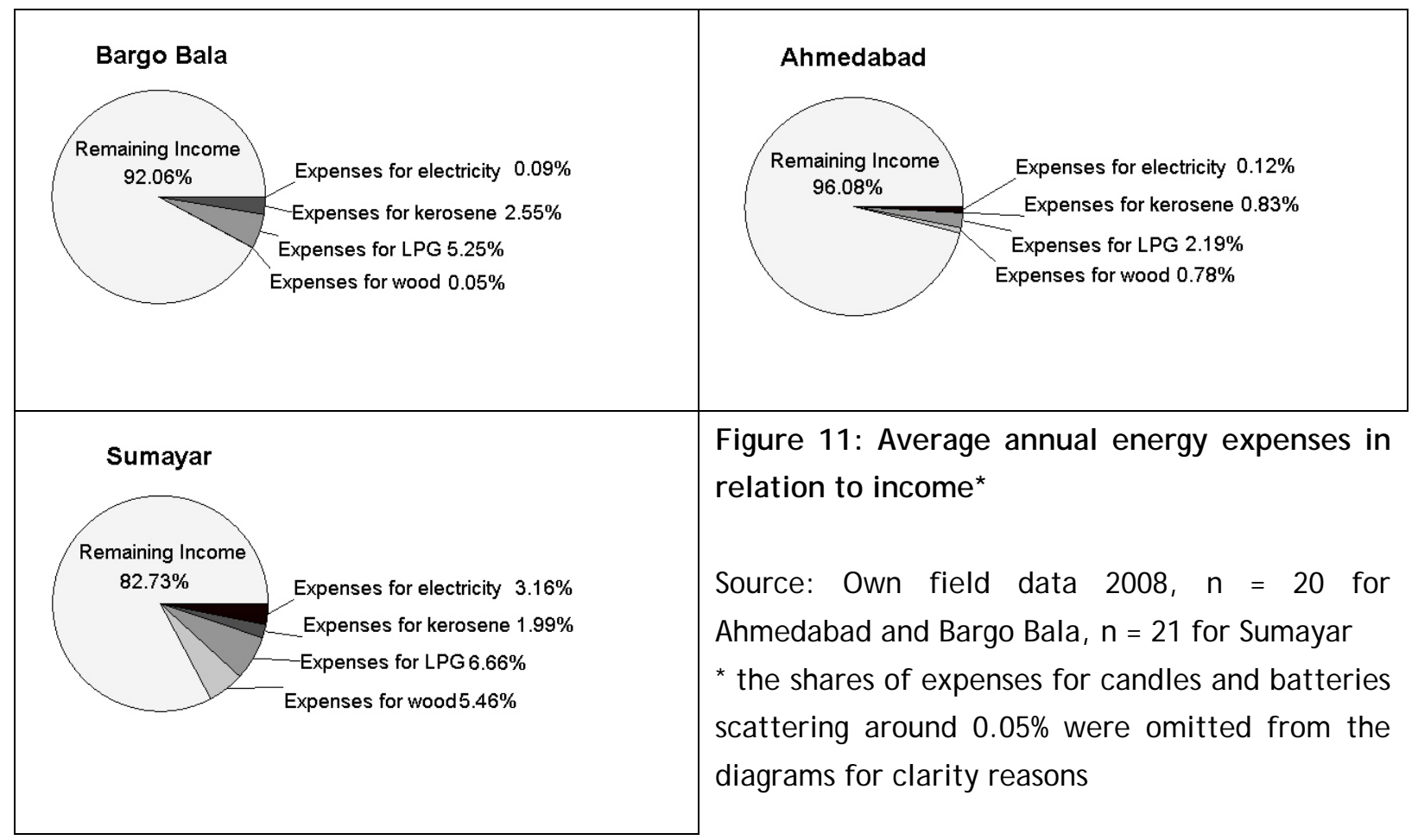

Last but not least, the examination of the average shares of the energy expenses in relation to the total households' income (cf. Figure 11) points to another aspect somewhat limiting the substitution potential of electricity. In Sumayar, the only case study where households are starting to use electricity as a supplementary resource for cooking and heating, the respective expenses are by far the highest compared with the other villages (3.16\% versus $0.09 \%$ and $0.12 \%$ ). This shows that due to the fact that electric cooking and heating are rather energy-intensive end uses, the costs arising therefrom represent very considerable financial burdens for Sumayar's households, even though they only supplement firewood use. This holds especially true for the poor, for whom the relative share of all energy expenses is naturally much higher than for the better-off, due to their lower income. In Sumayar, on average, they spend $4.15 \%$ of their income for electricity, compared to a share of $2.09 \%$ of the better-off ${ }^{32}$. In this context it is very questionable whether large-scale substitution of electricity for cooking and heating will occur when biomass resources are not valued in monetary terms (see discussion above).

${ }^{32} \mathrm{~N}=11$ for poor households of Sumayar and $\mathrm{N}=10$ for the better-off. 


\section{Social dimension}

The analysis of the ecological dimension has shown - aside from a great complexity of relationships - that there are some processes induced by the hydel projects that benefit all households, while others only affect the better-off. The question of wealth-related impact differences will also be central for all processes examined in the social dimension. These include, in the first section, changes to daily routines, workloads, and community life. Then, processes in the realm of education and health are assessed, before finally looking at impacts on workloads, i.e. especially those of women.

\subsection{Improved illumination, varying use of appliances, and the everyday life}

To assess the impact of the hydel projects on daily routines and the community life it is necessary to examine the different end uses of the generated electricity in greater detail. Interestingly, often the first thing coming to the interviewees' minds when asked about the impact of electrification was the availability of light. Electric lighting is used in all surveyed households, and similar statements were given in all three case study villages concerning the effects of it. Box 4 shows some examples and demonstrates that there are several more positive effects of the availability of electricity for lighting aside from reducing expenses for alternative resources (see section 7.2.2). This is due to the fact that electricity is not only a cheaper lighting resource than kerosene and LPG, the two most widely spread alternatives, but is also brighter and therefore more convenient. While kerosene or LPG lamps only light the spot surrounding them, with electric bulbs or tube lights a full room, or a larger area in front of a building, can be illuminated. As a consequence, daily life outside and inside the buildings changes as more activities are pursued during hours after dusk or before dawn. This is seen positively, as it increases each person's freedom to do what he or she wants to do, especially during the evenings, e.g. meeting neighbours or doing different things individually at home. The latter also allows an improved studying environment for school children, as with LPG or kerosene lamps they are often distracted by the many people gathering around the light together with them. Especially when guests are present, there is little privacy to work (see also section 8.2 on education impacts).

Group activities, such as religious or other festive events, benefit from electric lighting, too. For early morning meetings to read the Quran, for instance, expenses for lighting resources are saved, and the meetings become more convenient and attractive due to the better quality of the illumination. For wedding ceremonies, festive lighting can be installed, and sometimes loudspeakers are used. Without the electricity supply this was, if at all done, only possible by renting diesel generators and therefore connected with much higher costs. As all households in the three sample villages use electricity for lighting purposes, it can be concluded that the respective positive impacts depicted for the realm of daily routines and community life benefit all - the poor as well as the better-off. 
(1) In the past there was one specific place to meet in the house that was lighted by a lantern. Mostly we didn't do much at night, just have dinner and go to bed. Now, as there is electric lighting, we can go and do anything.

Yusuf Ali, 62 years, farmer 13.05. 2008, Bargo Bala

(2) Electricity brought big changes for gatherings at night. We visit neighbours during evening hours more often now.

Abdul Rahim, 45 years, farmer 22.04.2008, Ahmedabad

(3) Electricity has upgraded our lives. We can easily gather during the dark hours early in the morning to read and recite the quran and discuss religious issues with the light from bulbs or tube lights. Also, formerly weddings were only held in one room, now we have tents, colourful lights for decoration and many people can gather. The use of loudspeakers is cheaper, too.

Hassan, 43 years, employee in the local administration 03.06.2008, Sumayar

However, there are further end uses of electricity. As shown in section 7.2 the use of electricity for cooking and room heating is only supplementary and is only prevalent in Sumayar. So what else are the households using the electricity for apart from lighting, and how does that influence their lives? This question shall be discussed by examining the range of appliances owned by the surveyed households. Comparing the results from all three villages, similar patterns can be observed (Figure $12 \mathrm{a}-\mathrm{c}$ ). There are three appliances, apart from tube lights and bulbs, that almost all households of the three case studies own: Electric butter churners, irons, and ovens. The butter churners enable the households to churn the milk of their goats and sheep much faster and with less manual effort. Milk is churned to produce the various dairy products, fresh as well as preservable ones, which form an important part of the local diet. Traditionally, the churning is done by hand with a device made of goat skin (tharingi in Shina language), a strenuous task that takes up to four hours. At the time of research in 2008, however, this device was hardly found in any of the villages anymore, as most households owned a wooden device instead (zahú), which makes the churning task less strenuous and time-consuming. With this, nevertheless, it still takes up to two hours. Thus, household save a lot of time formerly reserved for this rather strenuous task by using electrical churners. The frequency of its use depends on the season and on the number of livestock owned, but averages out at least once a week, usually more often.

Similarly, the irons and ovens make other regular household tasks more comfortable and less time-consuming. Without electricity supply, simple irons that are heated with wood charcoal are used, which make the task less comfortable and more time-consuming. The same applies to the ovens that are used exclusively for the daily baking of bread (and not for the preparation of any other meals). It stands out that, in all case studies, some poor households do not own one or more of these three household appliances, but all of those 
stated that they could borrow them from neighbours or relatives whenever they wanted. This was not reported for other appliances, owned by only some of the sampled households.

Thus, the use of butter churners, irons and ovens positively impacts the workloads in households, as depicted, and benefits the better-off as well as the poor. The consequence for the intra-household distribution of workloads, i.e. the question whose workload is reduced, is further analysed in section 8.4.

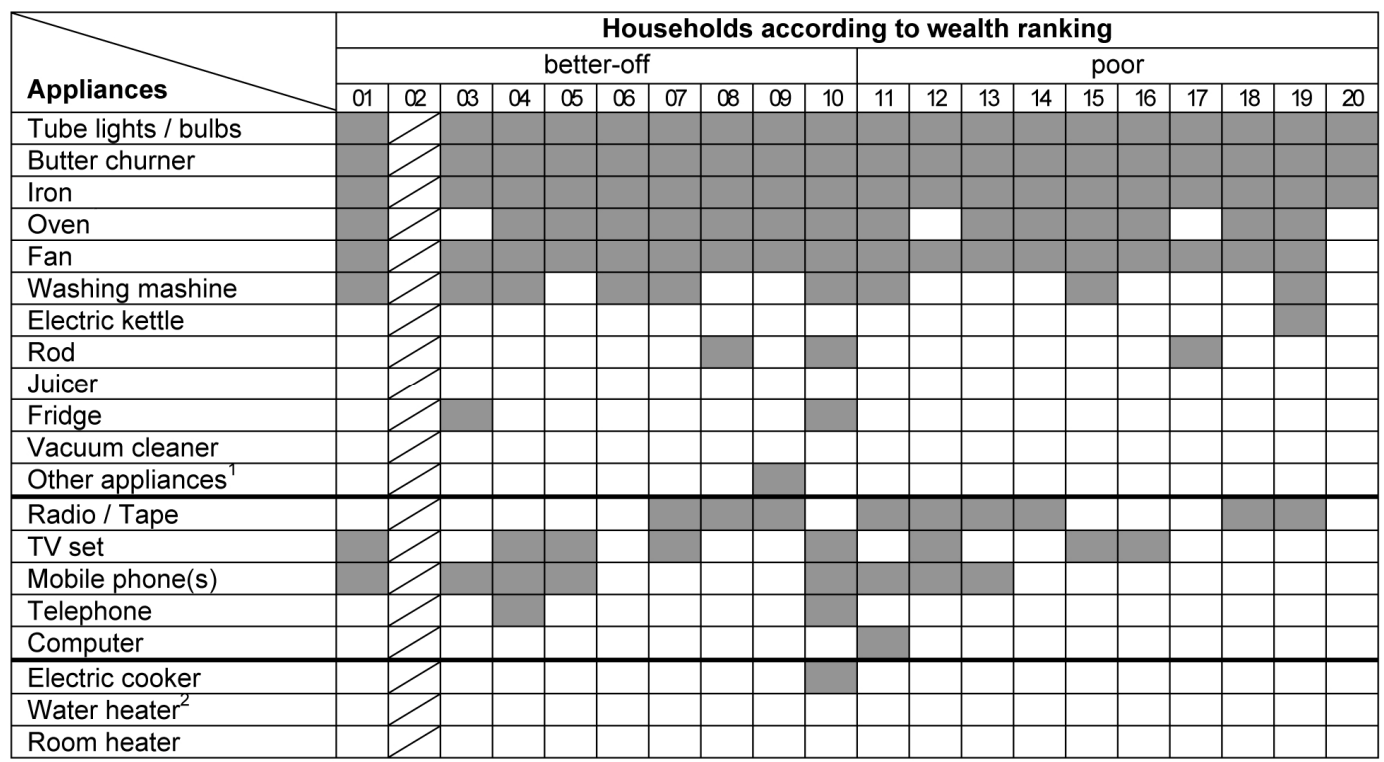

Figure 12 a: Ownership of appliances by wealth level (Bargo Bala)

Source: Own field data 2008

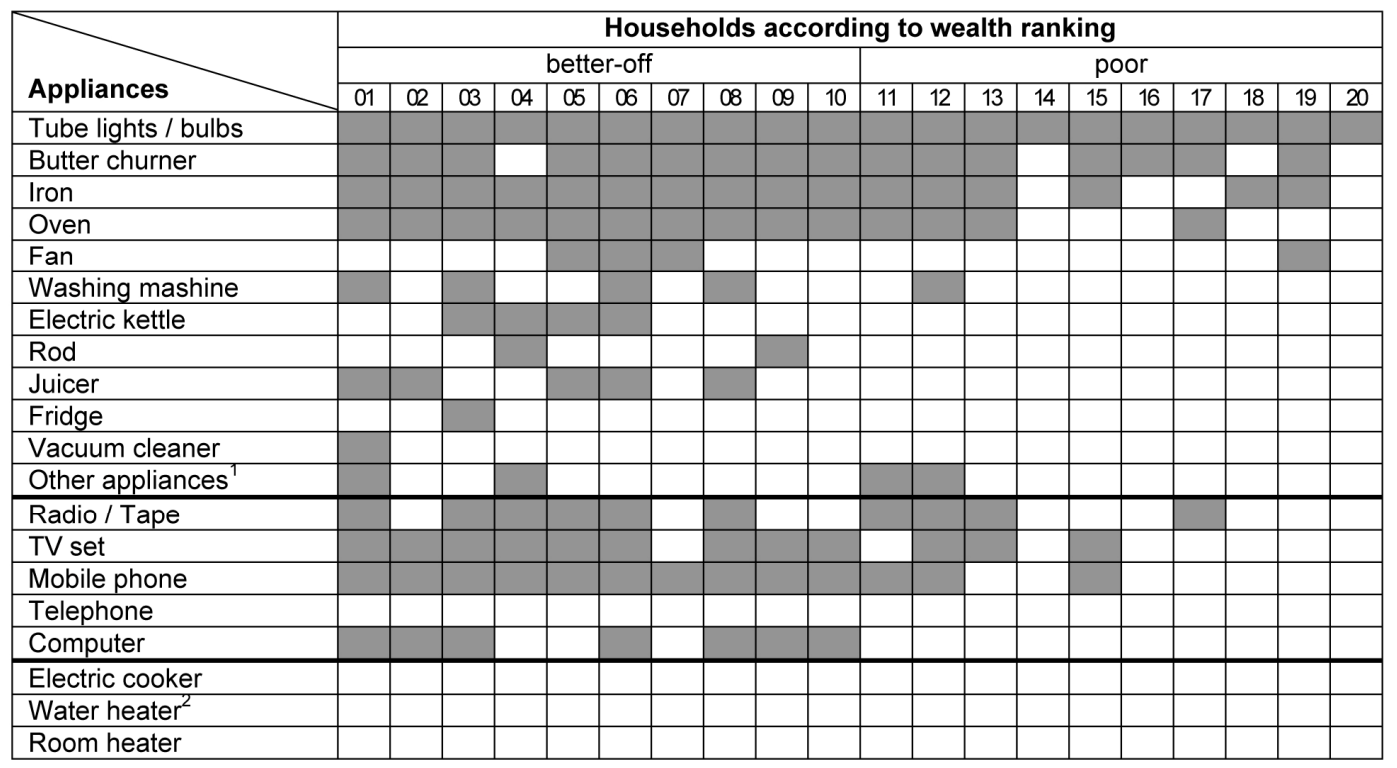

Figure 12 b: Ownership of appliances by wealth level (Ahmedabad)

Source: Own field data 2008 


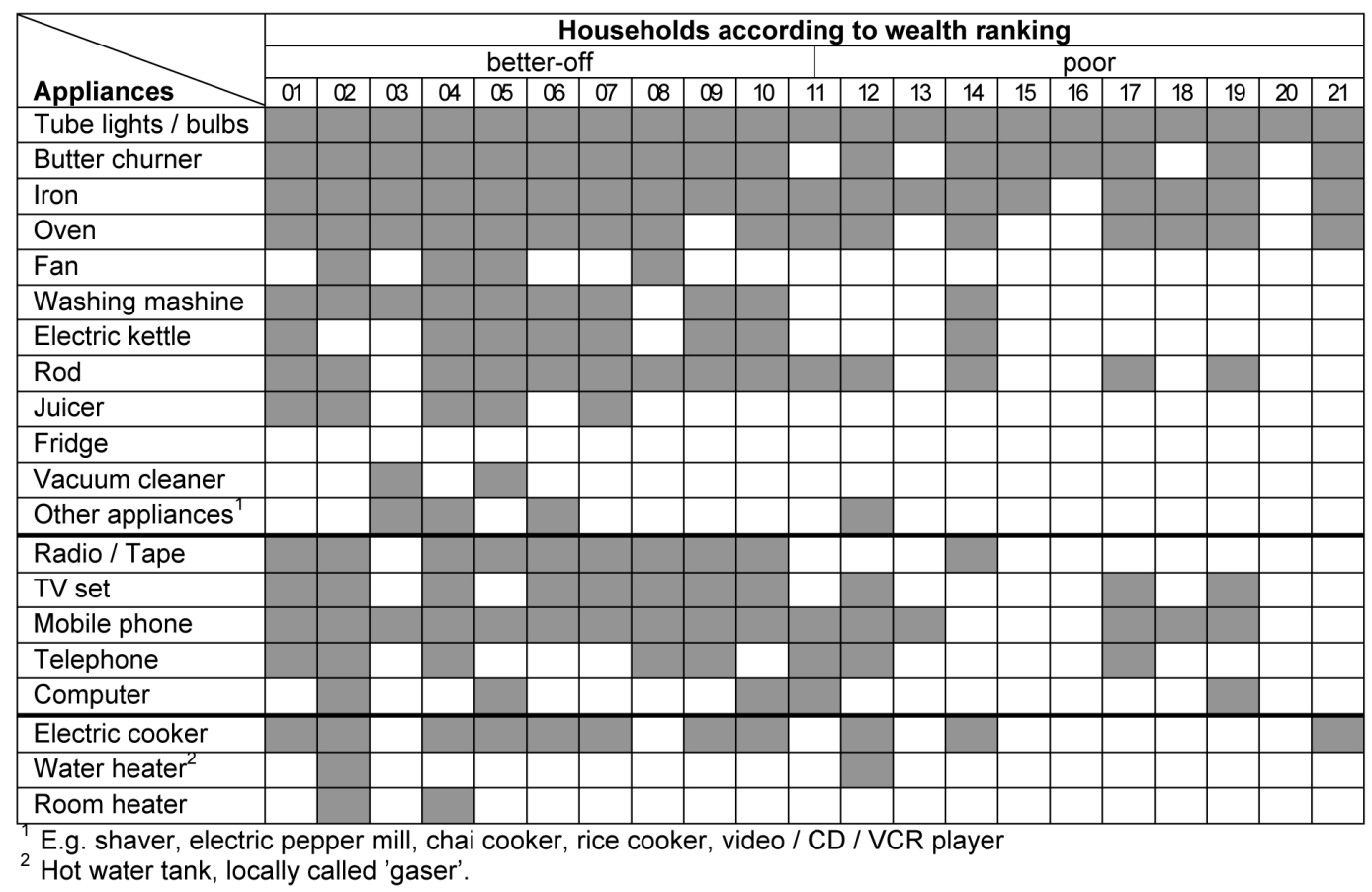

Figure 12 c: Ownership of appliances by wealth level (Sumayar)

Source: Own field data 2008

Apart from these three basic household appliances, washing machines, heating rods, electric kettles, and, above all, communication and information technologies (radios, TV sets, mobile phones, and computers) represent the most common devices in all three villages. In comparing the ownership of these items between the case studies, it can be noted that they are most widely spread in the households in Sumayar. The highest electricity capacity available there facilitates their more frequent use. Furthermore, especially when it comes to more expensive appliances such as washing machines, mobile phones, computers, or TV sets, it must be acknowledged that the better-off households own much more of these in all three villages. Their use influence daily routines and community life in several ways: Washing machines are another appliance that reduces regular workloads, as clothes are otherwise washed by hand. The introduction of television and modern communication technologies has various effects on the social life: TV sets make access to information much easier and enables people - including the illiterate - to learn about developments in other parts of Pakistan and the world by watching news programs. At the same time they open up the world of TV entertainment and can create certain images about living styles. According to AKRSP (2002b), TV sets (and radios) especially benefit women, whose mobility is restricted for cultural reasons and, hence, their exposure to the outside world remains limited. These forms of media are important sources of acquiring knowledge in a variety of fields, and, furthermore, allow them to obtain a few hours in their busy schedules for entertainment (AKRSP 2002b: 11). Last but not least, mobile phones considerably improve the opportunities of communication with relatives and friends living and working outside of the village or abroad. Because of increasing labour migration, this becomes more and more important and is highly appreciated by the households. But even inside villages, mobile phones seem to change 
dynamics of communication: Text messages (SMS) allow, for example, intensive communication among young people of different sexes that would otherwise be much more restricted.

Due to the differences regarding ownership of more expensive household appliances and communication and information technologies, however, it must be acknowledged that the positive effects of using them benefit primarily members of better-off households. Interviewees also pointed to these discrepancies (Box 5). Many poor people can simply not afford to purchase more expensive electronic appliances, and merely having access to electricity doesn't change this.

\section{Box 5: Disparate opportunities of using electricity}

(1) I have only one bulb, no appliances. But if the people have money they have many benefits of electricity.

Hajira, 55 years, widow from a poor household 22.04.2008, Ahmedabad

(2) If nothing changes in my home doesn't mean nothing changes in the village. There are many changes!

Mohammad, 61 years, water guard from a poor household 02.06.2008, Sumayar

(3) If someone has a government job he can use a lot of the electricity, if one doesn't have a job, he cannot.

Ali J an, 56 years, farmer from a poor household 13. 05. 2008, Bargo Bala

Furthermore, while most interviewees highlighted the positive impacts of the electrification projects on daily routines and community life, some also expressed concerns about risks and downfalls. While many stated, for instance, that the increased opportunities for meeting at night strengthened the community as such, others, on the contrary, noticed a growing disintegration and individualisation, as well as distracting effects on young students through the increasing use of TV sets at home (Box 6). The sociological and psychological processes initiated by electrification cannot be analysed in detail in this paper, as that would require specific, in-depth research, and a perspective on the individual. However, it can be noted that, in this context, negative effects may arise, which is further affirmed in an impact assessment of an earlier hydel project of AKRSP: "Access to electricity and electronic goods have created a culture of material competition (...). This breeds jealousy and resentment among less affluent ones, which can be highly disruptive for social life" (AKRSP 2000: 6). 
(1) Earlier people discussed in groups at night, now they prefer to watch TV at their homes.

J afar, 29 years, driver 01.06.2008, Sumayar

(2) Some kids have a TV or internet at home. On the one hand they improve their language skills in Urdu and English. But on the other hand, often their senses are not at the studies but at the TV.

Mohammad Shafa, 40 years, teacher 30.05.2008, Sumayar

It can be summarized that the access to electricity significantly influences daily routines and community life. The introduction of electrical lighting has positive effects for all households of all villages and wealth levels, and the same applies for the use of basic household appliances that reduce daily workloads. Furthermore, new opportunities of using energy in the fields of information, entertainment, and communication are opened up, however predominantly for better-off households. Two important results expected to derive from the described changes are enhancements of the educational as well as the health situation. They shall be discussed briefly in the following two sections.

\subsection{Educational effects of electrical lighting and information technologies}

In all three case study villages, the introduction of electrical lighting improved the learning situation for school children at their homes, as described. MAIER (2007: 26) also already found that "the bright light provided through electricity creates an improved environment to study in, and the number of hours children are spending on homework has increased significantly with electrical lighting". This was confirmed by interviewees in all three villages and, as all use electric lighting, is a benefit accessible for households of all wealth levels.

The second major educational impact expected from the projects relates to the access to modern technologies such as TV sets and computers. Some ambivalent consequences of the access to television have already been mentioned in the previous section. However, there are, without a doubt, some positive impacts of access to mass media in the realm of education, which shall be discussed here. Besides the enhanced access to information about developments in other parts of the world, especially young adults can make use of one of the distant-learning opportunities that are offered by different educational institutions in Pakistan ${ }^{33}$. These broadcast their lectures and courses on television while exams can be taken at certain dates in administrative centres, e.g. in Gilgit Town. This is particularly helpful for women, who often cannot attend colleges and universities in other parts of the country due to their restricted mobility, as UMMAR and SHER KHAN (2006: 13) have also reported for the neighbouring area of Chitral. The use of such distant learning

${ }^{33}$ These include the Alama Iqbal Open University and the Open University. 
opportunities was reported in the households of all three case studies: While in Bargo Bala $14 \%$ of the households owning a TV set stated that at least one household member was watching educational programs, this figure is as high as $50 \%$ and $70 \%$ for Sumayar and Ahmedabad respectively. Furthermore, computer skills become increasingly important, especially for the growing number of people seeking jobs in the service sector. Those growing up in a household owning a computer get the chance to become familiar with the computer technology at home.

However, these positive impacts are not equally accessible for all, as the ownership of TV sets, and especially of computers, is confined to better-off households (cf. Figure 12 a-c). Schools aim at making computer classes available to their students, but at the time of this research only the school of Ahmedabad was able to afford functioning personal computers and was offering regular courses. A positive example of a social project, making computers accessible for boys and girls from better-off as well as poor households, is the Computer Centre of Sumayar. It is able to operate on a very frequent basis (five hours daily, six days a week) due solely to the reliable and sufficient electricity supply in Sumayar, and aims to counteract wealth-related disparities regarding the access to computers (Box 7).

\section{Box 7: The Computer Centre of Sumayar}

The Computer Centre was just established in April 2008 as a non-profit institution. It owns five computers. In four to five sessions per day young boys and girls attend lessons in basic computer functions and typewriting from two teachers. Each session lasts one hour and they take place six days per week. The students have to pay 300 Rs. per month but so far no fees have been collected and it is the centre's objective to make the courses available for anybody who wants to take them. The majority of the students are girls.

Tahir, 41 years, teacher and owner of the Computer Centre 29.05.2008, Sumayar

At this point, a methodological problem, encountered while trying to determine the effects on education, shall be mentioned: For the described processes it is difficult to measure the extent of correlations, e.g. precisely assess the impact of an improved learning environment, as adequate respective indicators have not been developed in the literature about Sustainable Development assessment and rural electrification (section 2.1 and 2.2). This may be due to the fact that it is questionable if, for example, data such as school grades or graduation figures can be directly and causally linked to electrification efforts and, for example, the access to TV sets and computers. Moreover, as the data for this study reveal, statements of interviewees about how many hours their children spend learning at home seem to be very rough estimations, and also tell little about the quality of the studying time. Thus, again, in-depth research focusing on individual biographies would be more appropriate for impact assessments in this context. Therefore, for the present paper, the facts that many respondents pointed to the benefits of electric lighting for their children's learning situation (with no opposing statements), and that the access to 
modern technologies at least opens household members up the chance for education, must suffice as evidences.

To conclude, the research results for the field of education show that the basic benefits of the hydel projects, i.e. the improvement of the studying environment with electrical lighting, are relevant for all. Further positive educational impacts, as a consequence of accessing modern communication and information technology, are foremost confined to better-off households. To ensure a well-balanced allocation of such benefits, social projects with the objective to include all, such as the Computer Centre of Sumayar, can be very conducive.

\subsection{Impacts on indoor health conditions and medical services}

Impacts expected from the hydel projects in the health sector include the reduction of problems caused by indoor air pollution and unhygienic conditions, as well as improved health care services through the expanded use of electric and electronic equipment, e.g. refrigerators. To what extent are these impacts observable in the case studies?

Unfortunately, as mentioned in section 5.2, no (pre-electrification) data on health in the sample villages was available. Hence, conclusions about health impacts have to rely upon single interviewees' statements. Box 8 shows those most significant for health-related processes. With the bright light provided by electricity, hygienic conditions are improved, as thorough cleaning of the otherwise relatively dark interiors is made easier, and the preparation and eating of food becomes more sanitary as well. Infections of the digestive system represent one of the most common health problems in the region (Table 7 and 8, see also IUCN and GoP 2003a: 200), so the positive effect of improved hygienic conditions on the overall number of health problems may be considerable. Another effect of improved lighting conditions and cleanliness is pointed out by UMMAR and SHER KHAN (2006), who have noticed a considerable reduction in cases of scorpion bites in newly electrified villages in the neighbouring area of Chitral. Similarly, one interviewee from Bargo Bala stated that the use of fans has reduced mosquito bites, and, subsequently, the frequency of malaria infections (cf. Box 8).

\section{Box 8: Electricity and health}

(1) Now we can see everything we eat at night!

Sultan, 50 years, construction worker 25.04.2008, Ahmedabad

(2) The use of fans has reduced mosquito bites of children and the number of malaria infections.

$$
\text { Gulzada, } 45 \text { years, housewife, mother of six children }
$$

11.05.2008, Bargo Bala

(3) We were facing darkness before electricity came, now we're in light! The kerosene lanterns blackened our houses and affected our health.

Mohammad, 61 years, water guard 02.06.2008, Sumayar 
Another change induced by the electrification and relevant for the health sector is the reduced use of kerosene in all case study villages, as a consequence of its substitution with electricity (see section 7.2). This improves indoor air quality, as can be easily observed by comparing the colour of the walls in old and new buildings, or in those still lighted with kerosene and those with lighting by electricity or LPG: The latter are clean, while the former are blackened by the smoke of the kerosene lamps. The improved indoor air quality must be attributed to ovens with enhanced fume outlets, too, but the reduction of kerosene use has also had positive effects, and the number of diseases associated with indoor air pollution (eye and respiratory infections, lung diseases such as asthma, etc.) is declining. Nevertheless, it has to be kept in mind that due the still prevailing indoor biomass combustion, respiratory diseases remain one of the most serious health problems in the region, especially during winter months, and are a frequent cause of mortality (Table 7 and 8, IUCN and GoP 2003a: 201).

Table 7: Most common infectious diseases reported in Sumayar's health centre for selected months

\begin{tabular}{|l|r|r|r|}
\hline & July 2006 & December 2006 & January 2007 \\
\hline Respiratory infections & 122 & 300 & 280 \\
\hline Diarrhea & 404 & 24 & 25 \\
\hline Dysentery & 153 & 16 & 16 \\
\hline Scabies & 48 & 24 & 28 \\
\hline
\end{tabular}

Source: Files of the health centre, accessed on 01.06.2008

Table 8: Percentage of respiratory infections out of total health problems reported in Bargo Bala's and Ahmedabad's health centres

\begin{tabular}{|l|c|c|c|c|}
\hline \multirow{2}{*}{} & \multicolumn{2}{|c|}{ Bargo Bala } & \multicolumn{2}{c|}{ Ahmedabad } \\
\cline { 2 - 5 } & August 2007 & December 2007 & April 2008 & December 2007 \\
\hline Respiratory infections & $16 \%$ & $38 \%$ & $18 \%$ & $55 \%$ \\
\hline $\begin{array}{l}\text { Other (diarrhea, dysentery, } \\
\text { fevers, etc.) }\end{array}$ & $84 \%$ & $62 \%$ & $82 \%$ & $45 \%$ \\
\hline
\end{tabular}

Sources: Files of the health centres, accessed on 07.05.2008 (B.B.) and 26.04.2008 (A.) $n=50$ for Bargo Bala, $n=40$ for Ahmedabad

The positive health effects depicted above relate to the use of electricity for lighting and thus refer to households of all wealth levels. A further impact on the household level that should not be left out is the opportunity to heat bath water with electricity, which is helpful for protecting especially those with weaker immune systems (e.g. older people, small children) from colds. This is done occasionally with rods in several households in all case study villages. Hot water tanks, however, are only owned by very few better-off households in Sumayar (cf. Figure $12 \mathrm{c}$, and footnote 28). 
Regarding the improvement of health care through the use of electrical equipment, it has to be concluded that this was very limited by the lack of financial means. Only in Sumayar, the hydel project was followed by the installation of a refrigerator in the village's public health station, in which vaccines and other medicines are kept. Its acquisition, as well as the employment of an additional trained staff member to administrate and distribute vaccinations, was financed by the regional public health administration. The health centres in Bargo Bala and Ahmedabad, however, have no specifically medical benefits from the projects, in terms of extended service, except for the electrical lighting.

The results in the health sector can be summarized as follows: Similar to the realm of education, there are basic positive effects on the health situation that are related to the introduction of electrical light, which are beneficial for members of better-off as well as poor households. They are caused by improved hygiene, as well as by reduced indoor air pollution. Further effects, such as expanded opportunities for medical care, depend on additional preconditions, e.g. financial support for health centres to purchase equipment and employ staff to work with it.

\subsection{Electricity and the complex causalities determining workloads of women}

Rural electrification projects are frequently depicted as especially beneficial for women, as the collecting of firewood is often their duty, and by substituting electricity for wood they can be relieved of this strenuous work. However, in the present research, only a very limited substitution of electricity for fuel wood was observed (see section 7.2). Hence, the focus of the impact assessment of the hydel projects on workloads was not on the (presumably very small) effects on workloads for procuring wood, but rather on the consequences of the newly-created opportunities of consuming electricity for household appliances.

As analysed above, labour and time saving appliances such as butter churners, irons, and ovens are used in all the surveyed household of all three case studies, and thus workloads of household members are reduced in general. The corresponding activities are, as most other household tasks, too, the responsibility of women (only butter churning is sometimes also done by male household members). They are performed multiple times per week, which makes the women significant beneficiaries of these time and labour saving devices. Furthermore, many female interviewees noted that the improved quality of lighting made the carrying out of all indoor household tasks more comfortable.

\section{Box 9: Impact of electricity on women's workloads}

(1) Yes, the electricity has made everything easier, now we can prepare lessons in the after-noon.

Perveen, 40 years, teacher 26.04.2008, Ahmedabad

(2) With lanterns it was difficult to clean at night.

Amina, 35 years, housewife 29.05.2008, Sumayar 
However, some female interviewees' responses (Box 9) point to concerns about detrimental effects of the provision of electricity on women and their workloads, concerns that were also raised in a former impact study conducted for comparable hydel projects (AKRSP 2002a: 27). They are based on the following assumption: As a consequence of electrical lighting, women are better able to carry out tasks such as cleaning the house or home-based income-generating activities like handicraft production, during evening hours. This increases their free time during the day but instead of having more periods to rest, new tasks (in and outside the house) are assigned to them, which ultimately increases their total daily workload.

\section{Box 10: The daily routine of Nazia}

Nazia is 45 years old and the wife of the head of a household of Sumayar that consists of 13 members. The eldest of her sons lives with his wife and their first child in the house. Another son, staying only periodically in the house, is employed in the army, one works on their farm, while Nazia's six further children go to school.

Despite the large size of her household Nazia regularly gets some time to rest, while even using three hours every day to do handicraft. With the sale of the handicraft products, she can earn a small income. The tasks of looking after the animals and working in the vegetable fields are her responsibility, but she carries them out together with her daughter-in-law. Some chores like the washing of dishes and regular clean-ups, which are quite time-consuming in a household of 13 , are entirely delegated to her daughter-in-law. Nazia's two elder daughters, who are 13 and 14 years old, also help in the household.

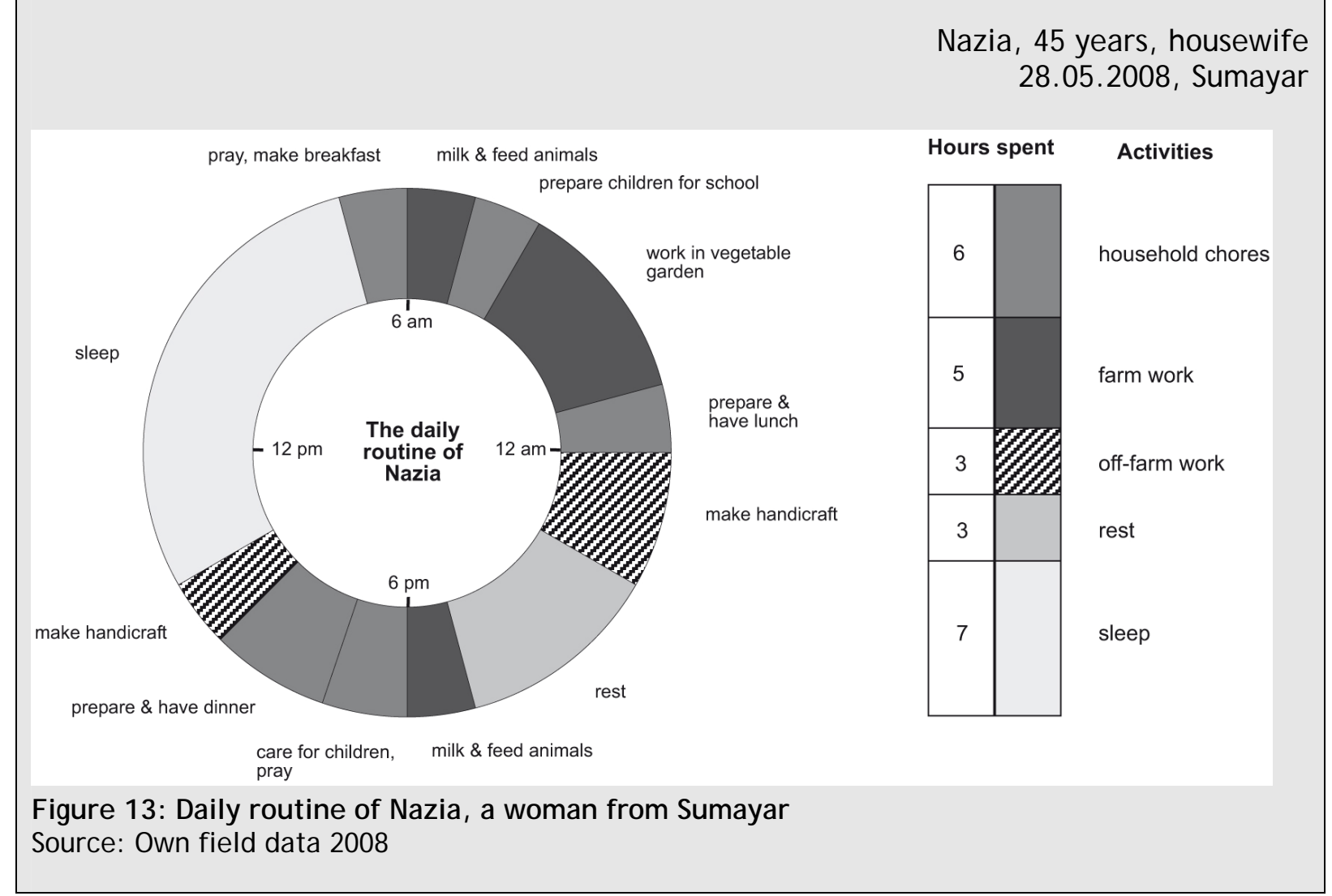


To analyse if this concern is relevant for the case studies women were interviewed about their daily routines in all three villages. The respective workloads were then compared by assigning the different activities to the categories of household chores, farm work, offfarm work, leisure time or rest, and sleeping periods, as suggested by HERBERS (2000: 118f. $)^{34}$. The results showed that women do use evening hours for household work, tasks related to their off-farm employment, or handicraft production. However, the total extent of their daily workloads does not depend on whether they do so or not, but, in fact, similar findings as those described by Herbers (2000: 112ff.) were made: She points out how the work allocation and labour division in households is influenced rather by how the respective household is composed, and which role the woman plays in it ${ }^{35}$. Box 10 and 11 present two typical and exemplary daily routines of women that indicate that these findings are relevant for the impacts of the hydel projects on workloads, too. While both women use evening hours to work, their respective total workloads differ significantly. Nazia (Box 10) gets three hours of rest daily as opposed to Perveen (Box 11) who has hardly any leisure or resting periods. From the analysis of their familiar backgrounds it can be deduced that their workloads are rather influenced by the questions of

- how many other female member help with household tasks,

- how many household members are to be taken care of in total,

- which role they have in the household (e.g. Perveen as a daughter-in-law), and

- if any off-farm employment is pursued.

Thus, general conclusions about a total increase of workloads, as a causally determined consequence of the possibility of working during the evenings and at night, do not seem reasonable. If women carry out household activities during evening hours or not, and if the total workload is affected negatively or positively, is rather a result of other dynamics.

Different studies with a specific focus on the changing roles of women have analysed respective processes. HERBERS (1997), for example, analyses the relation between female employment and intra-household organization of labour, and states that in this context "extended families have an advantage over small or nuclear families" (HERBERS 1997: 427) as every female off-farm employment causes a reduction of available household labour force, a gap that must be somehow bridged. While in extended families other women can take over the working woman's tasks, in smaller households such as Perveen's (Box 11) they have to be performed after the off-farm work or on weekends.

In addition, as mentioned in section 3.4, it has been observed that workloads of women often increase as a consequence of labour migration of men and the taking-over of tasks traditionally only done by male household members. Against this background it becomes relevant that the analysis of the demographic data of the case study villages reveals significant gender-related differences. In Ahmedabad, the ratio of male as well as female off-farm employment is significantly higher than in Bargo Bala and Sumayar, and a much

\footnotetext{
${ }^{34}$ It must be assumed that the women's actual workload is higher as a large amount of hidden work cannot be captured through interviews.

35 Furthermore, the workloads differ significantly between those women staying and working in the main villages and those staying in summer settlements. Mostly only one woman is sent to the summer settlements and has to carry out all the activities traditionally assigned to women on her own, hence these women have a higher workload than those staying in the main villages.
} 
greater proportion of male adults have employment outside of the village (cf. Table 4). It is therefore not surprising that the most examples of women with exceedingly high workloads, such as the one presented in Box 11, were found here.

\section{Box 11: The daily routine of Perveen}

The household Perveen lives in is composed of 7 members: Her two brothers-in-law, the wife of one of them, and their three daughters. Her own husband lives and works in Karachi and she only sees him two or three times per year. Her father-in-law - the head of the household - lives in Gilgit Town and visits them from time to time in their house in Ahmedabad.

Perveen is 40 years old and works as a teacher in the school of the village. Her average daily routine is dominated by her work for the school and reproductive works such as caring for the children and keeping the household. Furthermore, Perveen has to carry out some productive tasks: She is responsible for the vegetable fields near the house and looks after the animals. Household works that she doesn't get done during the week havehas to wait until the weekends: On Sundays she washes clothes and cleans the house thoroughly. With all this, almost no time for leisure and rest remains. Only late in the evening she sometimes watches television, but even then she often simultaneously helps the children with their homework.

Due to Perveen's role as the daughter-in-law, all these tasks are seen as clearly her and her sister-in-law's responsibility. Before the latter married into the family Perveen's daily workload was even higher. As long as the daughters are too young - two of them go to primary school while the third one is only three years old - there are no other women who support the two daughter-in-laws, or to whom they could delegate certain tasks. Asked what would help her most Perveen replied: "The men should help the women, men and women should work together. Nowadays women are also working outside of the farm but when they come home their men order them to do this, do that..."

Perveen, 40 years, teacher 26.04.2008, Ahmedabad

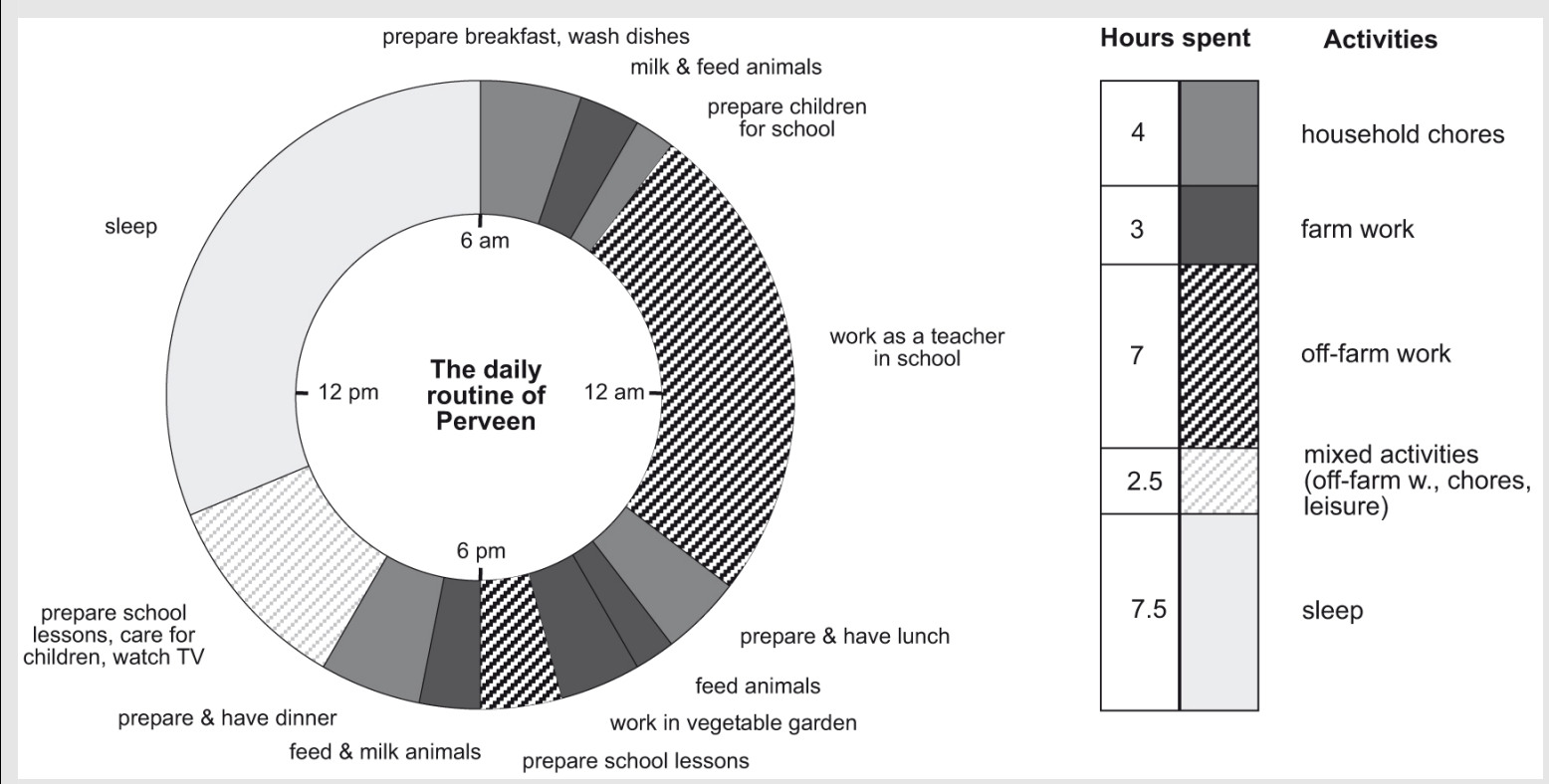

Figure 14: Daily routine of Perveen, a woman from Ahmedabad Source: Own field data 2008 
Another study on gender-related processes in the region is presented by HALVORSON (2003) who, in her analysis of children's vulnerability, investigates intra-household relationships. She points out their complex dynamics and concludes that not only the different roles of women and the household sizes and compositions, but also the quality of the relationship between mother- and daughter-in-law are decisive factors for women's workloads and the time spent for child-care. She calls for a conceptualization of vulnerability "that takes account of gendered and generational processes that create or break the livelihood and child health linkages between individuals, their children, and households" (HALVORSON 2003: 131). Looking at the results of the examination of impacts of the hydel projects on women's workloads, such a holistic perspective can also help to understand the depicted complex processes, that go far beyond the question if evening hours are spent for extra work, and that cannot be fully analysed in this paper. To conclude this section, it can finally be stated that the use of household appliances observed in all households of the case studies does in fact ease the daily life of women that, however, might become more strenuous due to other developments. 


\section{Economic dimension}

The impact assessment for the social dimension has shown that there are basic improvements for all households, but significant wealth-related differences regarding further-reaching benefits of the hydel projects. Furthermore, the relevance of concomitant supportive measures for a balanced distribution of benefits became clear. In order to analyse if these findings apply similarly to impacts in the economic dimension, the two aspects of employment and income generation will be analysed in the following chapter.

\subsection{Off-farm employment and qualification opportunities in the hydel projects}

The most evident economic impact of the hydel projects are the employment opportunities created by the power stations themselves. While during the construction of the power stations only temporary jobs are created, which are not available anymore after its completion, all hydel projects subsequently need staff for their operation, maintenance, and management in the long term. This positive employment impact was observed in all three case study villages. The two examples of Bargo Bala and Ahmedabad shall be presented in the following to illustrate and substantiate this. Furthermore, by comparing the employment structure in these two case studies, some interesting differences between the community-managed hydel in Ahmedabad and the state-run project in Bargo Bala are elaborated ${ }^{36}$.

In Ahmedabad, there are three employees who work full-time and are paid a regular salary by the Village Organisation (VO) that manages the hydel project. These are the three operators working in shifts in the powerhouse. All three have received specific training in how to operate the technology, one of them from AKRSP engineers and the other two from NAW\&PD staff. The further maintenance and management tasks of the project, such as administrating the finances and maintaining the local power grid, are fulfilled by members of Ahmedabad's VO on a honorary basis. Two meter readers collect the consumption data from all households once a month, a billing committee prepares the bills and is responsible for collecting the fees, while a maintenance committee regularly controls the grid and fuses, and gets active whenever any repairs become necessary. The two committees consist of five and seven persons respectively, and each selects a presiding Chairman. The only training offered in this context has been an accounting and book keeping course for a few VO members who are part of the committees. Even though the employment structure of the hydel project is thus largely not professionalized in the sense of paid staff, the management is fulfilling its functions well, which is illustrated by two facts. First, the hydel has been running very stably for many years (see section 6.2). And secondly, Ahmedabad's VO has successfully initiated the implementation of another, larger hydel project $(350 \mathrm{~kW})$ with the support of AKRSP in the village, for which the construction phase was nearly completed at the time this data was gathered. The experiences and skills obtained by managing the first hydel have been very important prerequisites for the self-

\footnotetext{
${ }^{36}$ The analysis of employment in the state-run project in Sumayar is omitted at this point, as it is very comparable to Bargo Bala and does not yield further insights.
} 
initiation, site selection, and construction of the new project by Ahmedabad's VO, which will also operate, maintain, and manage it in addition to the first one.

The hydel project in Bargo Bala is run by the NAW\&PD and employs 35 men who receive a regular salary for the operation and maintenance of the power station and the grid. They are comprised of 15 operators, 8 meter readers who are also giving out the bills and collect the fees, and 12 linemen who are responsible for the maintenance of the power distribution network. These employees do not receive any official training from the NAW\&PD's side. Moreover, they learn how to perform their respective tasks from their colleagues or predecessors, by experience, or when qualified engineers from Gilgit Town come for special repairs. The administration of the finances (salaries, maintenance costs, etc.), apart from the revenue collection, is done centrally in the NAW\&PD headquarters in Gilgit Town.

The two case studies show how the hydro power projects provide new opportunities for off-farm-employment in the villages. And it is not only jobs that are created, but specific skills and qualifications that are introduced. Some of the created jobs, such as those of the operators and linemen, require technical qualifications, which - once obtained either through respective trainings or by learning from other employees - are passed on. The new hydel project in Ahmedabad exemplifies how the technical as well as the management skills may be utilised in new development activities in a village. These processes can be seen as positive impacts. As there are no recruitment criteria hindering members of poor households to work in the projects, and the employees interviewed were from better-off as well as poor backgrounds, it can be concluded that these benefits are, in principle, accessible for households of all wealth levels. The fact that all employees of the hydel projects in all three case studies are men, however, reflects the still sizeable disparities regarding the employment figures of men and women in the region.

While the much higher number of employees for the state-run project in Bargo Bala can be, on one hand, seen as a positive aspect regarding the creation of new jobs, it must also be critically analysed in terms of management efficiency. In Ahmedabad, only three persons are paid staff, and all other tasks, including the complete financial management, are carried out by 14 honorary employees, whereas in Bargo Bala, 35 persons are employed, with a large part of the financial administration being done elsewhere. Even taking into account the higher number of total connections of Bargo Bala's hydel station (598), in comparison with the one in Ahmedabad (125), these differences remain conspicuous and might point to a comparatively higher level of management efficiency in the community-run project in Ahmedabad. This poses an interesting question for future research.

\subsection{Impacts on economic activities and income generation}

Apart from employment in the hydel projects, a much larger economic impact expected from them is the enhancement of existing, or the promotion of new, economic activities that enable households to generate extra monetary income. In the following section (9.2.1) the question of whether the projects lead to the promotion of so-called cottage 
industries (home-based production), and how this effect is achieved, will be briefly examined. Then, in section 9.2.2, impacts on the sectors of small businesses and industries in the case study villages and the question of who benefits from these developments, are analysed in more detail.

\subsubsection{Cottage industries and their working conditions}

In none of the case studies is the electricity directly used at home, e.g. by using electric machines, to produce any articles that are to be sold as a source of income. It can thus be concluded that no new cottage industries are initiated as a result of the electrification projects.

The only cottage industry existing in the three villages - which is, however, operated without electricity - is the production of handicraft, i.e. embroidery such as wall hangings, hats, pillowcases, small bags, etc. These products are usually manufactured by women, and beyond use in their own households, people traditionally give them as presents at festive events such as marriages. Some households also sell their products on the local market or via different marketing channels to tourists, and in this way the handicrafts can present a small source of extra income. Interestingly, for the neighbouring area of Chitral, UMMAR and SHER KHAN (2006) point to a correlation between electrification projects and the improvement of income-earning opportunities for women in cottage industries. According to them, the access to electricity has led to an increase both of the output and the quality of the production of shu, a traditional woollen fabric that is manufactured at home. They attribute this to the increased amount of time that is available for women when using time-saving appliances, and to the improved working conditions with electric lighting during the evenings (UMMAR and SHER KHAN 2006: 12).

For the case studies of this research, such a qualitative and quantitative increase actually influencing respective incomes could not be detected. However, women manufacturing handicraft did also report an improvement of their working conditions as a consequence of the access to electric lighting. This can be seen as a potential for positive effects on income-generation through home-based handicraft production. In this context it must be pointed out that external support, e.g. in the field of training or through collective marketing of products, may be very conducive, if not indispensable, for the success of such cottage industries. This is documented by the fact that only in the case studies of Ahmedabad and Sumayar did households report the sale of handicraft products as an extra source of income. And in both villages, these households were supported by specific development initiatives (Box 12). J ust as in the fields of education and health (see chapter 8), this stresses the importance of supportive development programmes in addition to the hydel projects in order to achieve development impacts in a broad range of sectors, including cottage industries. 


\section{Box 12: Initiatives supporting home-based handicraft production}

The Karakoram Area Development Organisation (KADO) is a non-profit NGO working in the area with the objective to create income and employment and a special focus on women and disadvantaged groups. Since 1996 about 3000 women have been trained in embroidery work in the context of KADO's Karakoram Handicraft Development Programme. Furthermore production and marketing support systems have been developed and trainings for supervisors, book keepers, quality controllers, marketing and design specialists have been conducted. This has led to the establishment of five companies that are now operating independently from KADO. They purchase embroideries from the households and organize the further processing, finishing and marketing.

In twelve households of Ahmedabad women are cooperating with KADO and the independent marketing companies. They have completed the embroidery training or learned from others who took part and are now selling their products to the companies.

KADO has moreover trained five of the 17 women working in the newly established Vocational Centre of Sumayar. This community-run centre was implemented with initial support from a district counselor. It organizes the training of women in stitching and handicraft works and collectively markets the products. Apart from having better working conditions with electric light the centre plans to start working with an electric stitching machine which will further improve the quality of the products.

\section{Hajira, 47 years, handicraft manufacturer} 27.04.2008, Ahmedabad

Zulfikar Ali Khan, 30 years, KADO Social Sector Development Manager 26.05.2008, KADO office Aliabad

Fizar, 26 years, handicraft manufacturer 01.06.2008, Sumayar

\subsubsection{Expansion of small businesses and industries, their premises, and related income effects}

To analyse impacts in the sector of small industries and businesses, first the range of respective activities in the three case study villages is examined and compared. The most common economic establishments that use electric or electronic devices include sawmills, carpentries, and flourmills in the field of small industries, and shops using fridges and icecream-machines in the sector of small businesses ${ }^{37}$. Table 9 shows that the largest amount of such activity exists in Sumayar, where some further enterprises, such as a photocopy service and a gemstone processing centre, are also located. With Sumayar being the case study with the most extended electricity supply, one could conclude that there are more productive uses of electricity for income-generating small industries and businesses where more power is available. But does an enhanced electricity supply unconditionally lead to an economic expansion in this sector?

\footnotetext{
${ }^{37}$ The use of electricity for lighting in shops is excluded here. Similar to households, owners of small businesses and industries benefit from electric lighting by saving expenses for formerly used lighting resources, and by the improved quality of the illumination.
} 
In order to find out in more detail how the hydel projects influence the economic activities, and if they have constituted a necessary precondition for their initiation, a more in depth analysis will be given here for the enterprises in Sumayar. Examples from the other two case studies are only referred to when their inclusion allows additional significant insights. The general processes determining their developments are assumed to be comparable to those in Sumayar.

Table 9: Entreprises using electric or electronic devices

\begin{tabular}{|c|c|c|c|}
\hline & Bargo Bala & Ahmedabad & Sumayar \\
\hline Small industries & $\begin{array}{l}\text { - } 1 \text { sawmill } \\
\text { - } 1 \text { carpentry } \\
\text { - } 1 \text { flour mill }\end{array}$ & $\begin{array}{l}\text { - } 1 \text { sawmill incl. minor } \\
\text { carpentry works } \\
\text { - } 1 \text { flour mill }\end{array}$ & $\begin{array}{l}\text { - } 2 \text { sawmills } \\
\text { - } 1 \text { carpentry } \\
\text { - } 1 \text { flour mill } \\
\text { - } 1 \text { Gem Cutting and } \\
\text { Polishing Centre }\end{array}$ \\
\hline Small businesses & $\begin{array}{l}\text { - } 1 \text { Public Call Office } \\
\text { - } 4 \text { shops with fridges } \\
\text { - } 1 \text { shop (ice-cream } \\
\text { machine) }\end{array}$ & & $\begin{array}{l}\text { - } 1 \text { bank branch (computer) } \\
\text { - } 1 \text { copy shop (photocopier, } \\
\text { PC printer) } \\
\text { - } 1 \text { restaurant (TV set) } \\
\text { - } 1 \text { tailor shop } \\
\text { - } 3 \text { shops (ice-cream } \\
\text { machine, fridge) }\end{array}$ \\
\hline
\end{tabular}

Source: Own field data 2008

Of the five small industries of Sumayar only one - a sawmill - existed before the second hydel (with a larger capacity of $250 \mathrm{~kW}$ ) started operating in 2007 . Due to the very low available capacity and high unreliability of the electricity supply at that time, the sawmill owners only used a diesel generator as a source of energy. However, this resulted in much higher costs compared to when the machines are run with hydro-electricity (Box 13). Correspondingly, for the establishment of the other four small industries of Sumayar, the construction of the $250 \mathrm{Kw}$ hydel has been a decisive prerequisite. They only opened after the plant started operating, as without the cheaper source of electricity the owners would have not taken the risk of investing in new equipment and subsequently bearing the high running costs for diesel. Even though the sawmill, formerly operating exclusively on diesel, as well as all newly established small industries of Sumayar, still own diesel generators, with the extended electrification by the hydels they only use them as a backup energy source in times of failing supply. Thus, in addition to the improvement of economic preconditions for small industries the hydel project has an ecological impact in this context, too, i.e. a reduction of the respective GHG emissions through the reduced use of generators. 
The household of Hassan started the first sawmill of Sumayar in the early 1980s. His father had been trained as a carpenter in a workshop in Gilgit Town. He passed on his skills by training his son Hassan and the other employees of the sawmill.

They immediately started to use the electricity from the first hydel project of Sumayar to power their machines after it was opened in 1987. But due to the frequent power outages and its low capacity they were forced to use their diesel generator most of the time. During periods of maximum production they needed up to 250 litres of diesel per month resulting in expenses of more than 10,000 Rs. (at prices of 2008).

Since the 250kW-hydel was opened in 2007 Hassan's family can operate their machines eight hours daily on electricity from the local grid during the summer. Only in winter they still have to use the generator as a supplementary source of power. With an average electricity bill of 2500 Rs. per month during maximum production phases the hydel project has allowed them a very significant reduction of costs while they have even increased their production output. In 2008 they earn a mean net income of 50,000 Rs. per month with their enterprise, making Hassan's household the one with the highest income of the 21 surveyed in Sumayar.

Hassan, 33 years, sawmill owner 01.06.2008, Sumayar

For the small businesses of Sumayar the situation appears somewhat different: Five out of the seven enterprises already existed before they had access to the extended electricity supply. Nevertheless, the use of electric or electronic devices has significantly enhanced their quality of service, e.g. through the use of computers in the bank branch, or opened up additional income sources through the introduction of new goods and services, such as ice-cream, cold drinks, or photocopies and computer printouts (see Box 14 as one example). The use of diesel generators to power such devices is not cost-effective. Accordingly, the photocopy shop - whose whole service is dependent on electricity - is one of the small businesses that did not exist before the opening of the $250 \mathrm{~kW}$ power plant.

\section{Box 14: A small business in Sumayar: Ali's ice-cream shop and flour mill}

Ali is the owner of two neighbouring shops in Sumayar that he has just started in spring 2008. In addition to the sale of garments and some sweets he operates an ice-cream machine and a flourmill. He has bought the respective machines for about 60,000 and 40,000 Rs. As Ali is a retired army officer he was able to use the compensation payment of 400,000 Rs. given to him after his retirement for the investment. So far it is paying off well: he earns about 15,000 Rs per month with his enterprise.

Ali, 60 years, shop owner 30.05.2008, Sumayar

It can be concluded that the example of Sumayar shows how conducive an extended electricity supply is for promoting economic activity. Small industries, thus far using diesel generators, benefit by saving energy expenses, and the foundation of new enterprises is facilitated by the provision of a cheaper source of electricity. For small businesses, the electricity supply allows the introduction of new goods and services. Thus, existent businesses are expanded, and new ones are even being started. 
However, the representative examples given in Box 13 and 14 show that the creation of new enterprises is not solely dependent on a cheap supply of electricity. Other conditions must be fulfilled, too, i.e. specific resources must be available. For the foundation of new enterprises it is vital that the owners have the necessary skills and qualifications to operate the machines and the financial means for making the initial investments for the equipment. This leads to the question of who has access to these resources and who, as a result, reaps most of the benefits of these promoted economic activities.

The described economic activities in the small industries and business sector offer various benefits that refer to differentially large groups. Some effects are positive for multiple households of the village and even of neighbouring ones. For example, the sawmills allow local preparation of timber for construction purposes. Thus, all customers from Sumayar, as well as from neighbouring settlements, can save the time and money they would otherwise spend for transporting the raw material to and from sawmills located farther away, e.g. in Aliabad or Gilgit Town. The same applies to the carpentry, where window and door frames and various furnitures are produced. In these small industries additional value is locally added to the timber, additional steps of the value chain are carried out in the village.

Further processes with several beneficiaries relate to the flour mill and the copy shop: Electricity-driven mills make the process of grinding the grains - a service that is used by all households of the village and formerly provided by mills with mechanically powered water wheels - faster and more hygienic. The photocopy and printing services offered by the shop improve the conditions for teaching in the schools, as teachers can easily copy worksheets. It thus benefits school children, too.

\section{Table 10: Ownership of enterprises in}

\section{Sumayar}

Enterprises of Sumayar owned by...

better-off households poor households

\begin{tabular}{l|l}
-1 sawmill & -1 sawmill \\
-1 carpentry & \\
-1 flour mill & \\
-1 copy shop & \\
-1 restaurant & \\
-1 shop &
\end{tabular}

Source: Own field data 2008
In addition to these improvements for multiple, if not all, households, the extra income earned by the owners of the small industries and businesses represents the most substantial benefit of the economic activities promoted by the hydel project. Taking into account the previously mentioned preconditions necessary for establishing enterprises, it is not surprising that the vast majority of the owners of Sumayar's enterprises are members of better-off households. Five of the twelve economic establishments using electric or electronic devices are owned by households of the better-off category while only one belongs to a poor household (Table 10) ${ }^{38}$.

\footnotetext{
${ }^{38}$ The further six enterprises of Sumayar were either owned by collective or outside entities (i.e. the Gem Cutting and Polishing Centre and the bank) or the respective household could - for different reasons - not be included in the household survey.
} 
Even if poor households manage to acquire the qualifications necessary for operating a small enterprise, they can rarely afford the initial investments. In terms of extra monetary income, it is thus predominantly better-off households that benefit substantially from the economic processes triggered by the hydel projects. In addition - just as in the case of employment in the power stations themselves (section 9.1) - it is men who find off-farm jobs in these enterprises. Hence, the generation of extra income specifically for women is not promoted.

\section{Box 15: Making economic benefits available for the poor and disadvantaged}

(1) Sultan owns and operates the only sawmill of Ahmedabad. He established it in 1995 and used the electricity from the micro hydel from the outset. Sultan's household was rather poor at the time and could not have afforded to buy the expensive machinery. So for the foundation of the enterprise it was a decisive precondition that he received a loan of 70,000 Rs. from the Village Organisation (VO) of Ahmedabad that was created with the support of AKRSP in the early 1980s. Without this micro credit Sultan would have not been able to establish his enterprise which in 2008 - 13 years later - includes a flourmill and yields a monthly income of about $25,000 \mathrm{Rs}$ in the summer and $6,000 \mathrm{Rs}$ in the winter months.

Sultan, 43 years, sawmill owner 23. 04.2008, Ahmedabad

(2) The "AKRSP Gem Cutting and Polishing Centre Sumayar, Nager" was opened on $9^{\text {th }}$ August 2007. The project is funded by the north-american non-profit Rupani Foundation and implemented and managed by AKRSP. It seeks to achieve its primary goal of poverty alleviation by enabling the people of Sumayar to increase their earnings from the sale of the gemstones found on the village's land. Up to the present the households that take part in the mining and trading business sell the gemstones as raw material or very roughly cut. By professionally processing them with cutting machines, trimsaws and gem polishing labs, between $100 \%$ and $400 \%$ of value can be added. The provision of enough electricity to run these machines has been a decisive prerequisite for the establishment of the centre as the running costs for diesel would otherwise be very high. Now the $5 \mathrm{~kW}$-generator is only needed as a backup energy.

The target group of the project are young women and men from households of all wealth levels: Anybody aged between 18 and 26 years can apply to participate in the training courses where they learn to handle the machines and perform the different production steps. Currently the project is in its initial stage but when the production phase is started the products shall be collectively marketed and all the trained persons shall share in the profits. Of the 37 persons participating 21 are women. For them the project presents the opportunity to earn an income in the gemstone business, which is otherwise exclusively dominated by men.

Mohammed, 31 years, trainer at the Gem centre 27.05.2008, Sumayar

In order to counteract these disparities, and to make economic benefits through incomegeneration available for poor and other disadvantaged groups such as women, supplementary measures can be very conducive as the two examples given in Box 15 
illustrate: Systems of savings and micro credits such as those introduced with the establishment of Village Organisations (VOs) by AKRSP, can enable the poor to overcome the barrier of high initial investment costs for starting an enterprise that capitalises on the electricity supply. And initiatives such as the "AKRSP Gem Cutting and Polishing Centre Sumayar, Nager" that specifically includes women in their target group, can assure that these take part in the economic benefits of an enhanced electricity supply, too. With its focus on providing training, it makes the qualifications needed for the productive use of the electricity available for members of all households ${ }^{39}$. Thus, the impact assessment of the hydel projects in the economic dimension shows results comparable to those of the social dimension as they highlight the relevance of the wealth levels of households and the importance of additional project measures to counterbalance the respective disparities.

\footnotetext{
${ }^{39}$ The project further contributes to the reduction of financial bottlenecks through the (external) funding of the machines, as well as to the multiplication of the locally added product-value through the enhanced processing of the gemstones.
} 


\section{Synthesis and Conclusion}

The results of the empirical research presented in the last four chapters must be viewed and finally analysed, in the context of the theoretical, analytical, and practical embedding that was outlined before. To conclude, the results of the study are summarized in the following section (10.1), before then educing final recommendations and conclusions (10.2).

\subsection{Summary of results}

The provision of electricity by means of renewable energy is expected both to contribute to the mitigation of climate change and to have positive development effects in regions that are under-supplied with electric power, or not electrified at all. The Clean Development Mechanism (CDM) - a policy instrument of the global climate regime of the Kyoto protocol - takes this into account and supports renewable energy projects in developing countries. The CDM pursues two objectives: To reduce GHG emissions and to foster Sustainable Development. An area of concern for critics of the instrument, however, is that CDM projects often do not contribute to Sustainable Development and fail to reduce socio-economic disparities by neglecting to address the poor. Against this background, three CDM-financed micro and mini hydel projects in Gilgit-Baltistan, Pakistan, were examined with regard to their contribution to Sustainable Development. Ecological, social, and economic processes relating to the use of energy, and the impact of the hydel projects on them, were analysed. To include the question of equity, a special focus was given to possible differences between relatively better-off and poorer households.

The processes and impacts examined can only be fully understood in the regional context of the hydel projects. The area is characterised by a high mountain environment. A welladapted system of mixed mountain agriculture, in which water and biomass resources play decisive roles, forms the economic basis of the people's livelihoods. Socially and economically, the area is subject to profound transition processes, and non-agrarian employment and income opportunities are gaining more and more importance. The empirical results of this study show that in this context the hydel projects have altogether positive Sustainable Development impacts. However, a broad range of effects can be observed of which some - especially in the social and economic dimension - are relevant for all people while others only apply to certain groups.

In the ecological dimension, moreover, a multiplicity of factors determining the question of energy resource consumption patterns, and thus co-influencing the hydel projects' respective impacts, was revealed. Electricity from the hydro power stations is substituted for lighting fuels, and respective monetary savings benefit all households. Furthermore, firewood remains the primary resource for the most energy-intensive purposes (cooking and heating) due to its integration in the agricultural system. The use of wood from onfarm sources is not valued in monetary terms and balanced against commercial resources. The goal to substitute electricity for firewood is only achieved under certain circumstances, i.e. if the electricity supply is sufficient and stable and if costs and/or workloads for the procurement of non-farm wood are high. The latter can be supported by 
banning biomass collection from natural forests. Furthermore, electricity use for cooking and heating is only supplementary to the predominant fuel wood use. Therefore, it only has very minor effects on the overall quantities of fuel wood consumption, on the reduction of respective GHG emissions, and on the conservation of forests of the region. Moreover, the substitution depends on the wealth level as well as on the availability of labour in a household. As the latter is linked to labour migration processes, the question of household resource mixes is even partially decoupled from the local spatial context.

Regarding effects on the local environment, such as environmental damages or detrimental effects on prevalent water utilisation and distribution practices, no significant negative impacts of the hydel schemes occur. This is due to their relatively small size (capacities up to $250 \mathrm{~kW}$ ). With an increased capacity of the power stations, the risk of local environmental damages increases, too. This points to the need of a very careful inspection and selection of construction sites and an adjusted civil engineering, above all, if largersized projects are chosen to be implemented.

The most substantial project impacts in the social dimension were diagnosed as a result of the improved illumination possibilities. They increase individuals' freedom of daily routines and evening activities, enhance home studying environments, and improve indoor health conditions. Group activities benefit as well from the increased convenience and the saving of lighting costs. As all households use electrical lighting, these benefits apply to all wealth levels. Further benefits resulting from the use of high-value appliances and information and communication technologies are confined to better-off households. In order to make them more accessible to all wealth groups, additional specific measures, such as public computer centres, are necessary. Similarly, extra (financial) support is needed in order to expand health care opportunities. The use of electrical lighting and household appliances has further positive effects on the daily routines of women, whose workloads are, however, also substantially and often negatively influenced by other developments in the socio-economic and socio-cultural realm.

Impacts assessed in the economic dimension show some characteristics comparable to the social sphere: They are differentiated according to household wealth levels, and additional supportive measures become necessary in order to assure social equity. Benefits principally accessible for all include the expansion of off-farm employment and qualification opportunities in the hydel projects. Furthermore, though no home-based production directly using electricity takes place, the working conditions for cottage industries are improved by electrical lighting. Supportive programmes are, however, also very important for the economic success of these cottage industries.

The hydel projects facilitate the expansion of existing, or the foundation of new, small businesses and industries. As these substitute hydro electricity for power from diesel generators, this leads to a reduction of their GHG emissions. The economic expansions have basic positive effects for all households of the respective village. They include time and cost savings as a result of local availability of certain products and improvements related to the access to special services. The benefit of earning extra monetary income is, however, limited to the households owning the enterprises, which are mostly better-off 
ones. This is due to the fact that the productive uses of electricity do not only depend on its mere provision, but on the availability of specific human and financial resources, too. In addition to this socio-economic disparity regarding the ownership of enterprises, all employment as well as income effects merely apply to men. Thus, in the economic dimension, supportive measures accompanying the electrification projects, such as microfinance programmes, or training and employment initiatives for men and women, are decisive to make benefits accessible for poor and disadvantaged groups, too.

In view of these results it must be concluded that the previously discussed scepticism towards the CDM and rural electrification projects is partially justified, as there is a broad range of impacts, including some of the negative aspects criticized. However, in all three dimensions of Sustainable Development there are also basic positive impacts relevant for all socio-economic groups. Furthermore, the deficits of the projects' impacts can be mitigated by means of complementary measures.

\subsection{Recommendations for enhanced Sustainable Development impacts of rural electrification projects and conclusions for the global climate policy}

The results of the impact assessment make it possible to educe some recommendations on how rural electrification projects, such as the micro and mini hydels in northern Pakistan, can be further optimized in their endeavour to achieve Sustainable Development. In general, the projects should be ideally embedded in holistic, programmatic rural development approaches. Only by including multiple components can the broad range of processes in the different dimensions of development that the projects influence be taken into account. Such holistic approaches can specifically address the differences regarding impacts on groups of varying wealth levels. Poorer households and other disadvantaged groups can be supported to take part in the expansion of economic activities and employment opportunities stimulated by the electrification projects, with measures such as microfinance programmes or training programmes. Initiatives in the social sector, e.g. computer centres, can make respective benefits accessible to those that are otherwise excluded from them.

Furthermore, if interventions seek to reduce overall GHG emission reductions, to ease the pressure on natural resources, and to reduce household expenses for energy resources at the same time they need to take into account the multiple factors influencing energy resource consumption patterns. How is the resource use related to the agricultural system and its integrated regular tasks? Which cost factors exist for the procurement of resources and can they by influenced by regulations such as restrictions on biomass collection? And which other factors such as migration processes and the availability of labour come into play? For the area of Gilgit-Baltistan measures adjusted to these ecological aspects should include the support for electrification, as well as for forestry and natural resource governance. Hydel projects can reduce energy resource expenses and decrease GHG emission reductions to a certain extent. As long as fuel wood is produced and thus available free of monetary costs on private farmland, the large-scale reduction of GHG emissions by aiming at the substitution of electricity for it is an unpromising endeavour. Instead, farm forestry measures could in fact increase the households' supply with this 
biomass resource and reduce the pressure to purchase or collect fuel wood from the natural forests of the region. In order to mitigate the exploitation of the latter, the development and implementation of forest use regulations are decisive and will support resource substitutions, too. Furthermore, detrimental effects of the hydro power projects on the local environment must be avoided by carefully adjusting the design and placement of the stations to the local conditions.

Looking especially at these latter recommendations for an enhancement of the hydel projects' ecological impacts, it becomes obvious that they can only be elaborated on the basis of a deep regional expertise and detailed analyses of the local conditions. Only then it is possible to do justice to the complexity and broadness of impacts of the projects and accompanying measures. This illustrates the difficulty that a global climate policy instrument such as the CDM is confronted with: It aims to establish a link between the global and the local level that meets the requirements of the former and at the same time guarantees that project measures are adjusted to local conditions and actually reach the people. It is not only the conception and implementation of these projects that have to meet this sophisticated demand, but the monitoring and evaluation standards, too. In order to facilitate an assessment that can be adjusted to the context, and that is sensitive for local specifications, public participation and stakeholder consultation mechanisms are very conducive. Thus far, the regulations for the CDM project cycle stipulate very few participatory elements (UNFCCC 2005: 15). This leads to a final conclusion regarding the integration of the objective of Sustainable Development in the CDM. If the latter is taken seriously and respective deficits regarding the impacts of many CDM projects are to be addressed, the requirements for the assessment of Sustainable Development impacts should be adjusted and increased. One option would be the international standardization of assessment procedures, including more participatory elements. The labelling model of the Gold Standard (cf. The Gold StAndard Foundation 2006) could present a constructive model in this context. It includes - in addition to its very stringent assessment criteria regarding environmental and Sustainable Development impacts -meaningful stakeholder consultation requirements, such as an active invitation for comments from all local stakeholders, adequate documentation of the project design by non-technical descriptions, and the publishing of the documents in appropriate local languages. The difficulty of establishing linkages between the global level of climate policy and the local project level should by no means be regarded as an insurmountable obstacle, but as a challenge that demands creative and well thought out solutions. 


\section{References}

AKRSP (2000): An Evaluation of Kuragh Micro Hydel. Gilgit.

AKRSP (2002a): Harnessing the Elements. Successes in Mountain Infrastructure and Engineering. Islamabad.

AKRSP (2002b): Impact of AKRSP Infrastructure Projects on Women. Gilgit.

AKRSP (2002c): Impact of Parabec Micro-Hydel Project on Women Gilgit.

AKRSP (2006): Project Proposal for Ahmedabad Mini Hydel Project Hunza Gilgit. Gilgit.

AKRSP (2007a): An Assessment of socio-economic trends in the Northern Areas and Chitral, Pakistan (1991-2005). Gilgit.

AKRSP (2007b): Biennial report 2005-2006. Gilgit.

AKRSP (2007c): CDM Project Design Document (PDD), Community-Based Renewable Energy Development in the Northern Areas and Chitral, Pakistan. (http:// www.cdmpakistan.gov.pk/ cdm_doc/ community\%20based\%20renewable\%20energy\%20develo pment\%20in\%20northern\%20areas\%20of\%20pakistan. pdf, 20.06.2008).

AKRSP (2007d): Initial Environmental Examination (IEE) Report. Mini and Micro Hydel Development Project, Northern Areas and Chitral, Pakistan. Islamabad.

Azhar-Hewitt, F. (1999): Women of the high pastures and the global economy: Reflections on the impacts of modernization in the Hushe Valley of the Karakorum, Northern Pakistan. In: Mountain Research and Development 19(2). pp. 141-151.

Begg, K., S. Parkinson, D. van der Horst, R. Wilkinson, D. Theuri, S. Gitonga, M. Mathenge, H. AmissahArthur, S. Atugba, S. Ackon, S. Ageby, H. Meena, S. Mwakifwamba and S. Mwakasonde (2003): Encouraging CDM energy projects to aid poverty alleviation. Final report of project R8037 under the DFID KAR programme. (http:// www. iesd.dmu. ac.uk/ contract_research/ publications/ kbl. pdf, 03.03.2008).

BMU (2006): Die projektbasierten Mechanismen CDM \& JI. Einführung und praktische Beispiele. Berlin.

CLEMENS, J. (2001): Ländliche Energieversorgung in Astor: Aspekte des nachhaltigen Ressourcenmanagements im nordpakistanischen Hochgebirge. Bonner Geographische Abhandlungen 106. Sankt Augustin.

DAwn (30.08.2009): Autonomy package for NAs approved. (http://www. dawn.com/ wps/ wcm/ connect/ dawn-content-library/ dawn/ news/ pakistan/ 18-northern-areas-to-berenamed-as-gilgit+baltistan-am-09, 20.10.2009).

Ehlers, E. and H. Kreutzmann (Eds.) (2000): High Mountain pastoralism in Northern Pakistan. Erdkundliches Wissen 132. Stuttgart.

FOREX (2009): Euro (EUR) in Pakistan Rupee (PKR). FOREX.pk - Rates - Charts - Calculater - News. (http:// www. forex. pk/ currency. php?send=Y, 23.10.1980).

GoP Population Census Organisation (2000): 1998 District Census Report of Gilgit. Islamabad.

Greenpeace International and European Renewable Energy Council (Eds.) (2007): Globale Energie[r]evolution. Ein Weg zu einer nachhaltigen Energie-Zukunft für die Welt. Amsterdam, Brüssel.

GROBER, U. (1999): Der Erfinder der Nachhaltigkeit. In: Die Zeit 48 / 1999, 25.11.1999. 
GTZ (2008a): Energieversorgung in ländlichen Gebieten. (http://www.gtz.de/ themen/ umweltinfrastruktur/ energie/ 1778. htm\#top, 20.03.2008).

HALVORSON, S. J . (2003): A Geography of Children's Vulnerability: Gender, Household Resources, and Water-Related Disease Hazard in Northern Pakistan. In: The Professional Geographer 55(2). pp. 120133.

Herbers, H. (1997): The Changing Position of Women in Northern Pakistan: From Agricultural Producers to Off-Farm Employees. In: I. Stellrecht and M. Winiger (Eds.): Perspectives on History and Change in the Karakorum, Hindukush, and Himalaya. Culture Area Karakorum Scientific Studies 3. Köln. pp. 417-430.

HERBERS, H. (2000): Undernutrition and Heavy Workload in Northern Pakistan. Consequences for Production and Reproduction. In: A. Dittman (Ed.): Mountain Societies in Transition. Contributions to the cultural geography of the Karakorum. Culture Area Karakorum Scientific Studies 6. Köln. pp. 103-130.

HERBERS, H. (2006): Landreform und Existenzsicherung in Tadschikistan: Die Handlungsmacht der Akteure im Kontext der postsowjetischen Transformation. Erlanger Geographische Arbeiten Sonderband 33. Erlangen.

ICIMOD (2001): Energy Issues in the Hindu Kush Himalayas. Mini/Micro Hydropower for the Mountains. 06.02.2008). focus/ energy/ energy_mmhp.htm,

IUCN and GoP (2003a): Northern Areas State of Environment \& Development. Karachi.

IUCN and GoP (2003b): Northern Areas Strategy for Sustainable Development. Karachi.

KHAN, S. W. and M. F. J OYIA (2003): NASSD Background Paper: Energy. IUCN Pakistan, Northern Areas Programme. Gilgit.

KoJ IMA, M. (2006): Pakistan Household Use of Commercial Energy. Report published for the the Energy Sector Management Assistance Program (ESMAP) of the World Bank. (http:// siteresources. worldbank. org/ EXTBNPP/ Resources/ ESMA32006PAKISTANFinalForWeb. pdf, 31.08.2009).

KreutZmann, H. (1993): Challenge and response in the Karakoram: Socioeconomic transformation in Hunza, Northern Areas, Pakistan. In: Mountain Research and Development 13(1). pp. 19-39.

KREUTZMAnN, H. (1995): Globalization, spatial integration, and Sustainabe Development in Northern Pakistan. In: Mountain Research and Development 15(3). pp. 213-227.

KreUtZmann, H. (2000a): Water Management in Mountain Oases of the Karakoram. In: H. Kreutzmann (Ed.): Sharing Water - Irrigation and Water Management in the Hindukush-Karakoram-Himalaya. Oxford. pp. 90-116.

Kreutzmann, H. (2000b): Water Towers of Humankind: Approaches and Perspectives for Research on Hydraulic Resources in the Mountains of South and Central Asia. In: H. Kreutzmann (Ed.): Sharing Water - Irrigation and Water Management in the Hindukush-Karakoram-Himalaya. Oxford. pp. 13-31.

KreUtZmann, H. (2006): High Mountain Agriculture and its Transformation in a Changing Socioeconomic Environment. In: H. Kreutzmann (Ed.): Karakoram in Transition. Culture, Development, and Ecology in the Hunza Valley. Oxford, New York, Karachi. pp. 329-358.

MAIER, C. (2007): Decentralised Rural Electrification by Means of Collective Action. The Sustainability of Community-Managed Micro Hydels in Chitral, Pakistan. Occasional Papers Geographie 33. Berlin.

MALIK, A. and M. PIRACHA (2006): Economic transition in Hunza and Nagar Valleys. In: H. Kreutzmann (Ed.): Karakoram in Transition. Culture, Development, and Ecology in the Hunza Valley. Oxford, New York, Karachi. pp. 360-369. 
Michaelowa, A. and K. Michaelowa (2005): Climate or development: Is ODA diverted from its original purpose? HWWI Research Paper No. 2. Hamburg.

OLSEN, K. H. (2005): The Clean Development Mechanism's Contribution to Sustainable Development. (http:// www.cd4cdm.org/ Publications/CDM\& SustainDevelop_literature.pdf).

OLSEN, K. H. and J. FENHANn (2008): Sustainable development benefits of clean development mechanism projects. A new methodology for sustainability assessment based on text analysis of the project design documents submitted for validation. In: Energy Policy 36(8). pp. 2819-2830.

RICHTER, M. and U. FRINGS (2005): Renewable energy in rural areas. Reduced poverty and improved living conditions thanks to RE? In: agriculture \& rural development 2005(2). pp. 61-64.

SCHICKHOFF, U. (2002). Die Degradierung der Gebirgswälder Nordpakistans: Faktoren, Prozesse und Wirkungszusammenhänge in einem regionalen Mensch-Umwelt-System. Stuttgart.

ScHICKHOFF, U. (2006): The Forests of Hunza Valley: Scarce Resources Under Threat. In: H. Kreutzmann (Ed.): Karakoram in Transition. Culture, Development, and Ecology in the Hunza Valley. Oxford, New York, Karachi. pp. 123-144.

SCHMIDT, M. (2004): Boden- und Wasserrecht in Shigar, Baltistan: Autochthone Institutionen der Ressourcennutzung im Zentralen Karakorum. Bonner Geographische Abhandlungen 112. Sankt Augustin.

SCHNEIDER, L. (2007): Is the CDM fulfilling its environmental and sustainable development objectives? An evaluation of the CDM and options for improvement. Report prepared for WWF on behalf of the Öko-Institut e.V. (http:/ / www. oekoinstitut. de/ oekodoc/ 622/ 2007-162-en. pdf, 20. 03. 2008).

SCHWEIZER, P. and K. PreISER (1997): Energy resources for remote highland areas. In: B. Messerli and J. D. Ives (Eds.): Mountains of the World. A Global Priority. London, New York. pp. 157-170.

SINCLAIR, A. J. (2003): Assessing the Impacts of Micro-Hydro Development in the Kullu District, Himachal Pradesh, India. In: Mountain Research and Development 23(1). pp. 11-13.

SIROHI, S. (2007): CDM: Is it a 'win-win' strategy for rural poverty alleviation in India? In: Climatic Change 84(1). pp. 91-110.

SteURER, R. (2001): Paradigmen der Nachhaltigkeit. In: ZfU (Zeitschrift für Umweltpolitik und Umweltrecht) 2001(4). pp. 537-566.

SUTTER, C. (2003): Sustainability Check-up for CDM Projects. How to assess the sustainability of international projects under the Kyoto Protocol. Berlin.

SUTTER, C. and J . C. PARREno (2007): Does the current Clean Development Mechanism (CDM) deliver its sustainable development claim? An analysis of officially registered CDM projects. In: Climatic Change 84(1). pp. 75-90.

The Gold Standard Foundation (2006): The Gold Standard. Manual for project developers. (http:// www.cdmgoldstandard.org/ uploads/ file/ Developer Manual_GS-CER. pdf, 03.03.2008).

Ummar, F. and A. SHer KHAN (2006): Electrification Benefits Women in Chitral, Pakistan. ENERGIA News 9(2). (http:// www.energia.org/resources/newsletter/ pdf/en-122006_ummar.pdf, 03.04.2008).

UN Division fOR Sustainable DeVelopment (2008): Home. (http:/ / www. un. org/ esa/ sustdev/ index.html, 10.12.2008).

UNDP (2007): Human Development Report 2007/2008. Fighting climate change: Human solidarity in a divided world. New York. 
UNFCCC (2005): Report of the Conference of the Parties serving as the meeting of the Parties to the Kyoto Protocol on its first session, held at Montreal from 28 November to 10 December 2005, FCCC/ KP/ CMP/ 2005/ 8/ Add.1. (http:// cdm. unfccc. int/ Reference/ COPMOP/ 08a01. pdf\#page=6, 16.10.2009).

UNSD (2009): Composition of macro geographical (continental) regions, geographical sub-regions, and selected economic and other groupings. United Nations Statistics Division. (http:// unstats. un. org/ unsd/ methods/ m49/ m49regin. htm\#tnc, 30.09.2009).

WORLD BANK (1996): Rural energy and development. Improving energy supplies for 2 billion people. Washington, D.C.

WORLD BANK (2007): Project Information Document (PID): Pakistan Community-Based Renewable Energy Development in Northern Areas and Chitral. (http://wwwwds. worldbank. org/ external/ default/ WDSContentServer/ WDSP/

IB/ 2007/ 02/07/000310607_20070207112615/Original/385810AKRSPOPID0draft0J anuary02007.doc, 20.03.2008).

WWF (2007): Emission Impossible: access to J I/CDM credits in phase II of the EU Emissions Trading Scheme. (http:// assets.panda.org/ downloads/ emission_impossible_final_.pdf, 10.12.2008). 
Annex A: Reference list of cited interviews

\begin{tabular}{|l|l|l|}
\hline Name & $\begin{array}{l}\text { Date and place } \\
\text { of the interview }\end{array}$ & $\begin{array}{l}\text { Profession or function of the } \\
\text { interviewee }\end{array}$ \\
\hline INAYAT ULLAH BAIG & $\begin{array}{l}20.4 .2008, \\
\text { Ahmedabad }\end{array}$ & $\begin{array}{l}\text { Manager of the Village Organisation of } \\
\text { Ahmedabad }\end{array}$ \\
\hline MOHAMMED ALI & $\begin{array}{l}18.05 .2008, \\
\text { Gilgit Town }\end{array}$ & $\begin{array}{l}\text { Executive Engineer for the Gilgit } \\
\text { subdivision, NAW\&PD }\end{array}$ \\
\hline MOHAMMED HUSSEIN & $\begin{array}{l}27.05 .2008, \\
\text { Sumayar }\end{array}$ & Chairman of the Union Council Sumayar \\
\hline MOHAMMED SHAFA & $\begin{array}{l}02.06 .2008, \\
\text { Sumayar }\end{array}$ & $\begin{array}{l}\text { Gemstone trader with several years' } \\
\text { experience in the business }\end{array}$ \\
\hline MUHAMMAD IBRAHIM & $\begin{array}{l}24.05 .2008, \\
\text { Gilgit Town }\end{array}$ & $\begin{array}{l}\text { Former AKRSP project forester and } \\
\text { current coordinator for AKRSP's Policy } \\
\text { Dialogue and Partnership Section for the } \\
\text { Gilgit region }\end{array}$ \\
\hline
\end{tabular}


No. 36 KREUTZMANN, H. \& S. SCHÜTTE (2009): Three Years After. Evaluation of the GRC/ICRC Livestock Programme in the Earthquake-affected Areas of Pakistan-administered Kashmir

No. 35 KREUTZMANN, H., M. SCHMIDT \&A. BENZ (Eds.) (2008): The Shigar Microcosm: Socio-economic Investigations in a Karakoram Oasis, Northem Areas of Pakistan

No. 34 BLANK, M. (2007): Rückkehr zur subsistenzorientierten Viehhaltung als Existenzsicherungsstrategie. Hochweidewirtschaft in Südkirgistan

No. 33 MAIER, C. (2007): Decentralised Rural Electrification by Means of Collective Action. The Sustainability of Community Managed Micro Hydels in Chitral, Pakistan

No. 32 SCHMIDT, M. (2006): Transformation der Livelihood Strategies im ländlichen Kirgistan. Verlorene Sicherheiten und neue Herausforderungen

No. 31 STUMPTNER, A., A. UNKRIG \& M. ZENS (2005): Globale Herausforderungen, lokale Akteure. Berliner Grundschulen im Spiegel neuer gesellschaftlicher Fragmentierungstendenzen

No. 30 BORCHERS, K. et al (2004): Globalisierung in Südindien. Keralas Bauern zwischen Weltmarkt und Subsistenz. Ein Beitrag zur qualitativ-sozialgeographischen Entwicklungsforschung

No. 29 GAD, G. (2005): „Vom Plan zum Markt“. R eformen bei der mobilen Tierhaltung auf dem Tibetischen Hochplateau in der V. R. China

No. 28 FRAYER, J \& J . MIRETE (2005): Landreformen in China. Eine Erfolgsgeschichte der Modemisierung?

No. 27 FUHR, L. \& R. SPRENGER (2004): Indische IT-Fachkräfte zwischen Bangalore und Berlin. Aktive Gestalter oder passive Mitläufer im Globalisierungsprozess.

No. 26 RYLL, M. \& A. SCHUBERT (2004): StreetArt und die Wechselwirkungen von Mensch und Raum in FriedrichshainKreuzberg

No. 25 MUELLER, B. (2004): Dörfer im Transformationsprozess Kirgistans. Tasma und Toru Aigyr im Biosphärenreservat Issyk-Kul

No. 24 SCHOLZ, F. (2004): Globalisierung. Geographische Forschungsbeiträge

No. 23 NEUDERT, E. (2004): »Housing poverty« und weibliche Armut in Städten der »Dritten Welt« am Beispiel eines Railwayslums in Bombay

No. 22 SCHENKEL, K. (2004): Kulturelle Selbstwahrnehmung jugendlicher Berliner Türkinnen

No. 21 SCHOLZ-ZIEGELBAUER, H. (Hrsg.) (2004): Geographische Skizzen

No. 20 SCHÜTT, B. (ed.) (2004): Watershed management in the Abaya - Chamo basin, South Ethiopia

No. 19 FEUCHTE, B. (2003): Der Ansatz der „Transnationalen sozialen Räume“ zur Erklärung von Migrationprozessen

No. 18 DROWSKI, R. \& M. MEYER (2003): Förderung von Forschungs- und Entwicklungseinrichtungen in Berlin unter Berücksichtigung der Anforderungen der Globalisierung

No. 17 KROIS, J ., T. TARASCHEWSKI \& E. TROSCHKE (2003): Standardisierung und Internationalisierung des Waren- und Dienstleistungsangebots als Folge von G lobalisierungsprozessen am Beispiel Berlins

No. 16 ODIJ K, S. van, S. OEHM \& J . SCHÜTZE (2002): Berlin - Bahnhof Zoologischer Garten. Gibt es im Zuge von G lobalisierung eine Verdrängung von Armutsbevölkerung aus (ehemals) öffentlichem Raum?

No. 15 WEGNER, A. (2002): Entwicklungshilfe durch Informationstechnologie. Ägyptens Kleinunternehmer proben E-Commerce im Cyberbazaar

No. 14 GAD, G. (2002): Public Private Partnership (PPP) in der Entwicklungszusammenarbeit

No. 13 HILLMANN, F. (2002): Positionierung und Bedeutung ethnischer Arbeitsmärkte

No. 12 SCHOLZ, F. et al. (2001): Lebenswirklichkeit in einem „globalisierten Ort“. Das Beispiel Dhaka, Hauptstadt von Bangladesh. Eine sozialgeographische Skizze

No. 11 GAD, G. (2001): Die Bedeutung von Untemehmensethik im Entscheidungs- und Handlungsprozeß transnationaler Unternehmer in Entwicklungsländern

No. 10 HEINRICH, I. \& S. LOOS (2000): Mutterwerden als Weg in die Armut. Eine sozialgeographische Studie 